University of Nebraska - Lincoln

DigitalCommons@University of Nebraska - Lincoln

\title{
Raman/Rayleigh scattering and CO-LIF measurements in laminar and turbulent jet flames of dimethyl ether
}

Frederik Fuest

Center of Smart Interfaces, TU Darmstadt, Petersenstr, Darmstadt, Germany

Robert S. Barlow

Sandia National Laboratories, Livermore CA

Jyh-Yuan Chen

University of California, Berkeley, CA

Andreas Dreizler

Center of Smart Interfaces, TU Darmstadt, Petersenstr, Darmstadt, Germany

Follow this and additional works at: https://digitalcommons.unl.edu/usdoepub

Part of the Bioresource and Agricultural Engineering Commons

Fuest, Frederik; Barlow, Robert S.; Chen, Jyh-Yuan; and Dreizler, Andreas, "Raman/Rayleigh scattering and CO-LIF measurements in laminar and turbulent jet flames of dimethyl ether" (2012). US Department of Energy Publications. 112.

https://digitalcommons.unl.edu/usdoepub/112

This Article is brought to you for free and open access by the U.S. Department of Energy at DigitalCommons@University of Nebraska - Lincoln. It has been accepted for inclusion in US Department of Energy Publications by an authorized administrator of DigitalCommons@University of Nebraska - Lincoln. 


\title{
Raman/Rayleigh scattering and CO-LIF measurements in laminar and turbulent jet flames of dimethyl ether
}

\author{
Frederik Fuest $^{\mathrm{a}, *}$, Robert S. Barlow ${ }^{\mathrm{b}}$, Jyh-Yuan Chen ${ }^{\mathrm{c}}$, Andreas Dreizler ${ }^{\mathrm{a}}$ \\ ${ }^{a}$ FG Reactive Flows and Diagnostics, Center of Smart Interfaces, TU Darmstadt, Petersenstr. 32, 64287 Darmstadt, Germany \\ ${ }^{\mathrm{b}}$ Sandia National Laboratories, 7011 East Avenue, Livermore, CA, USA \\ ' Department of Mechanical Engineering, University of California, Berkeley, CA 94720, USA
}

\section{A R T I C L E I N F O}

\section{Article history:}

Available online $\mathrm{xxxx}$

\section{Keywords:}

Dimethyl ether

Raman/Rayleigh scattering

Raman spectroscopy

Combustion diagnostics

Hydrocarbon intermediates

Rayleigh cross-sections

\begin{abstract}
A B S T R A C T
To reduce the impact of combustion of fossil fuels on air quality and climate change, dimethyl ether (DME) is a promising alternative diesel fuel candidate. Technical combustion processes, including formation of pollutants, are influenced by turbulence-chemistry interaction. Therefore, accurate prediction by computational combustion models of combustion systems burning DME must account for multiple scalars and scalar gradients. The testing of such models requires detailed experiments. Here a study is presented on the feasibility of simultaneous species and temperature measurements in turbulent dimethyl ether flames, using line-imaged Raman/Rayleigh scattering of the major species $\mathrm{H}_{2}, \mathrm{O}_{2}, \mathrm{~N}_{2}$, $\mathrm{CO}, \mathrm{CO}_{2}, \mathrm{H}_{2} \mathrm{O}, \mathrm{C}_{2} \mathrm{H}_{6} \mathrm{O}$ and laser induced fluorescence of $\mathrm{CO}$. The measurement system and data evaluation methods developed to investigate methane-air flames are extended to address dimethyl ether flames. The Raman signal intensity and spectral shape of the Raman scattering from dimethyl ether over a range of temperatures are presented, based on measurements in electrically heated flows and laminar jet flames. These data are used to develop an iterative method for data evaluation that allows determination of indispensable crosstalk correction terms for the concentration measurements of $\mathrm{O}_{2}$ and $\mathrm{CO}_{2}$. Issues of fluorescence interferences, mainly from $C_{2}$ radicals on the fuel-rich side of the reaction zone, and their corrections are discussed. Laminar flame calculations are used to investigate the role of the intermediate species $\left(\mathrm{CH}_{4}, \mathrm{CH}_{2} \mathrm{O}, \mathrm{C}_{2} \mathrm{H}_{4}, \mathrm{C}_{2} \mathrm{H}_{2}, \mathrm{C}_{2} \mathrm{H}_{6}, \mathrm{CH}_{3}\right)$ in the reaction zone. In particular, their effect on the mixture fraction calculation and its relationship to the experimentally determined mixture fraction is examined. The impact of the intermediate species on deviations in concentration and temperature profiles due to species-specific Raman- and Rayleigh scattering cross-sections is demonstrated. Finally, species concentrations and temperature profiles from measurements in a turbulent piloted jet flame of dimethyl ether are shown.
\end{abstract}

() 2011 The Combustion Institute. Published by Elsevier Inc. All rights reserved.

\section{Introduction}

Turbulent combustion processes are of high practical relevance. A variety of complex physical-chemical interactions control pollutant formation, ignition, and flame stability, calling for a more detailed understanding. Significant progress has been made in collaborative research within the TNF Workshops [1], addressing these phenomena by providing well-documented bench mark flames that also significantly pushed advances in numerical simulations. These collaborative efforts began by looking into diluted hydrogen-fueled jet flames $[2,3]$ and were subsequently extended to hydrogen/methane/nitrogen jet flames [4]. As the next step in complexity, piloted partially-premixed methane/air flames were studied [4-9]. In addition to velocity measurements, instantaneous

\footnotetext{
* Corresponding author. Fax: +496151166555.

E-mail address: fuest@csi.tu-darmstadt.de (F. Fuest).
}

measurements of the thermochemical state were performed. This requires the simultaneous measurement of multiple scalars. Point-wise and more recently line-imaged instantaneous Raman/ Rayleigh scattering was developed and forms an important basis for understanding turbulence-chemistry interactions in turbulent flames. This paper reports on extending these investigations to flames with more complex fuels than methane.

The emission of carbon dioxide $\left(\mathrm{CO}_{2}\right)$ as a greenhouse gas enforces an increased use of renewable fuels. Among a variety of choices dimethyl ether $\left(\mathrm{C}_{2} \mathrm{H}_{6} \mathrm{O}\right)$ exhibits a number of interesting properties. Chemically dimethyl ether (DME) is the simplest ether. In atmospheric-pressure flames neither preheating of the fuel is necessary nor does condensation occur in the fuel feeding pipes due to sufficient vapor pressure at room temperature. DME is an excellent alternative for Diesel fuel, with low NOx emission levels, low particulate emissions, and a high cetane number for good auto-ignition performance. In terms of Raman/Rayleigh scattering 
DME stands out due to relatively low $C_{2}$ and soot precursor formation that causes significant fluorescence interferences on different Raman bands.

Previous studies using Raman scattering in gaseous hydrocarbon/air flames with fuels chemically more complex than methane are rare. In an early study by Stårner et al. [10] simultaneous Raman/Rayleigh/LIF measurements were made in piloted turbulent jet diffusion flames of diluted propane. It was shown that Raman measurements were feasible only when propane was diluted substantially by air or nitrogen, preventing overwhelming soot precursor interferences. Pilot-stabilized non-premixed methanol flames were investigated by Masri et al. [11] for stable conditions as well as close to blowoff. Propane flames, partly in mixture with dodecane or Diesel, were investigated by Dreyer et al. [12]. The speciality of this work was a Raman measurement in the vicinity of liquid fuel droplets. One important conclusion was that for their experimental conditions $355 \mathrm{~nm}$ excitation proved to be a better candidate wavelength than previously thought. Meier and Keck [13] and Rabenstein and Leipertz [14] investigated premixed sooting and non-sooting $\mathrm{C}_{2} \mathrm{H}_{4} /$ air and $\mathrm{CH}_{4}$ /air flames, respectively. In Meier and Keck's comparative study the signal-to-background ratio of Raman measurements was investigated for pulsed laser radiation at 532, 489, 355, and $266 \mathrm{~nm}$. Excitation wavelength of $532 \mathrm{~nm}$ proved to be most suitable, and limitations of concentration measurements by laser Raman measurements were demonstrated. In contrast, for soot-volume concentrations nearly two orders of magnitude higher, Egermann et al. [15] reported excitation wavelengths of $266 \mathrm{~nm}$ to be beneficial compared to $355 \mathrm{~nm}$ in ethylene diffusion flames because of reduced spectral overlap between Raman bands and LIF interferences. Nooren et al. [16] reported on Raman/Rayleigh/LIF measurements in Dutch natural gas jet diffusion flames. High levels of fluorescence interferences were subtracted from the Raman signals by empirical correlations using, amongst others, an interference channel monitored at $615 \mathrm{~nm}$. This approach was exploited by Dibble et al. [17] and it is followed similarly in the present study. Brockhinke et al. [18] studied LIF of $C_{2}$ following a UV-excitation at $248 \mathrm{~nm}$. They identified fluorescence in different spectral ranges and discussed possible interferences with Raman bands especially around $350 \mathrm{~nm}$. Removal of LIF interferences by separating and subtracting the signals in two polarization directions was proposed as a possible approach to measuring mole fractions by Raman scattering in fuel rich laminar premixed propylene/oxygen flames. Egermann et al. [15] similarly proposed the possibility of Raman measurements with excitation at $266 \mathrm{~nm}$ in sooting ethylene diffusion flames using horizontal and vertical polarization directions. None of these studies, however, addressed in sufficient detail the role of intermediate hydrocarbons or strategies to account for the resulting effects on Raman/Rayleigh scattering.

The extension of quantitative line-imaged Raman/Rayleigh scattering to turbulent flames of hydrocarbon species more complex than methane is an important research priority. The present work was initiated as an exploratory study to investigate the temperature-dependent Raman scattering properties of several simple hydrocarbon fuels (ethane, ethylene, propane, and DME) and to assess the prospects of obtaining turbulent flame measurements of the quality appropriate for combustion model validation. The focus was on DME because of the practical relevance noted above and also because, as an oxygenated fuel, DME has the lowest propensity to form soot or soot precursors, which generate strong fluorescence interference in Raman experiments.

Raman scattering spectra were measured in heated flows and in laminar jet flames. Early analysis made it clear that interpretation of Raman/Rayleigh signals from flames of DME (or any of the other tested fuels) was significantly more challenging than for methane flames. The main reason is that the hydrocarbon intermediates formed in these flames constitute significantly higher mole fractions than in corresponding methane flames and their Raman and Rayleigh scattering properties are, in some cases, significantly different than those of the parent fuel.

In partially premixed methane flames it has been demonstrated by Barlow et al. [19] that differences between the mass fraction of $\mathrm{CH}_{4}$ and the total mass fraction of all hydrocarbons are relatively small. The Raman scattering signal corresponding to $\mathrm{C}-\mathrm{H}$ bond stretch in the hydrocarbon intermediates overlaps the spectrum of $\mathrm{CH}_{4}$. Consequently, with appropriate calibration of the temperature dependent response of the ' $\mathrm{CH}_{4}$ channel', the processed results yield a good approximation of the total hydrocarbon mass fraction and good agreement with laminar flame calculations on profiles of major species, temperature and mixture fraction.

The above fortuitous condition does not hold for DME flames, where laminar calculations show that the total mole fraction of hydrocarbon intermediates can exceed $5 \%$ in the fuel-rich region of a partially premixed DME/air flame. Intermediate hydrocarbon species, such as methane $\left(\mathrm{CH}_{4}\right)$, ethane $\left(\mathrm{C}_{2} \mathrm{H}_{6}\right)$, or ethylene $\left(\mathrm{C}_{2} \mathrm{H}_{4}\right)$, exhibit rovibrational Raman bands that spectrally overlap the DME Raman bands and cannot easily be separated, especially when on-chip binning is used in the spectral direction as a noise reduction strategy demonstrated by Miles [20] and for the current experimental setup by Fuest et al. [21]. These intermediate species contribute to measured Raman signal intensities on the same detection channel as used for DME such that the Raman response of this channel depends strongly on the local hydrocarbon composition as well as temperature. Due to huge differences in particular Rayleigh cross-sections of important intermediate hydrocarbons the effective Rayleigh cross-section also depends on the local hydrocarbon composition. Furthermore, rovibrational Raman transitions of DME and hydrocarbon intermediates spectrally overlap with other species, including rovibrational lines of $\mathrm{CO}_{2}$, molecular oxygen $\left(\mathrm{O}_{2}\right)$, carbon monoxide $(\mathrm{CO})$, and molecular nitrogen $\left(\mathrm{N}_{2}\right)$, and also the spectral region used to monitor fluorescence interference. These crosstalk contributions need to be characterized indepth when quantifying species mole fractions. In short, Raman/ Rayleigh measurements cannot be interpreted in a quantitatively useful way without accounting for the concentrations and scattering properties of the main hydrocarbon intermediates.

The present paper presents a method for post-processing of line-imaged Raman/Rayleigh scattering measurements in DME/ air flames. The method relies on species information derived from laminar flame calculations, as well as detailed information on the scattering properties of relevant molecules. The paper is structured as follows: Section 2 discusses the experimental setup, briefly introduces the extended matrix inversion method [21], specifies the laminar and turbulent DME/air flames, and outlines laminar flame calculations. In Section 3 the role of intermediates in DME/ air flames is addressed. It is shown that particularly hydrocarbon intermediates cannot be neglected. The impact of the intermediate species upon Raman responses, crosstalks, effective Rayleigh crosssections and mixture fraction is examined. For the first time models to account for intermediate species impact on Raman and Rayleigh responses are proposed and detailed instructions are given to systematically obtain the Raman response characteristics of the fuel and crosstalk channels which rely upon a priori information from laminar flame calculations. At appropriate stages, sensitivity studies are used to show the influence of simplifying assumptions. Following the conceptual explanations, Section 4 presents Raman response and crosstalk curves specifically used in this study. Broadband and $C_{2}$ interferences are discussed in detail followed by results and discussions of laminar DME/air flames. The applicability of instantaneous line-imaged Raman/Rayleigh/LIF measurements in piloted turbulent premixed and partially-premixed DME/air flames is demonstrated. Finally the most important 
findings are summarized. A comprehensive Appendix presents details that are addressed particularly to readers using combined Raman/Rayleigh- or just Rayleigh- measurements to study any complex hydrocarbon flames.

\section{Experimental and numerical approach}

\subsection{Experimental setup and data post-processing}

Line-imaged multi-scalar measurements were conducted at the Combustion Research Facility of the Sandia National Laboratories. The experimental setup has been described previously by Karpetis and Barlow $[22,23]$ such that here only a brief description is provided. Raman and Rayleigh scattering was excited by a cluster of four sequentially fired frequency-doubled Nd:YAG lasers (Continuum) operating at $532 \mathrm{~nm}$. Three successive optical delay lines stretched the pulse to lower the probability of optical breakdown. The combined laser energy at the probe volume location was up to $1.8 \mathrm{~J} /$ pulse with a beam width of $300 \mu \mathrm{m}\left(1 / \mathrm{e}^{2}\right)$. The one-dimensional probe volume length spanned $6 \mathrm{~mm}$. Using a custom designed achromatic lens (Linos Photonics, $f_{1}=300 \mathrm{~mm}, f / 2$, and f/4) and spectral separation by a long pass beam splitter, Rayleigh and Raman scattering was measured by two CCD cameras. Rayleigh images were recorded using a $2 \times 2$ hardware binning and a pixel resolution of $\sim 20 \mu \mathrm{m}$. In front of the Rayleigh camera a $10 \mathrm{~nm}$ (FWHM) $532 \mathrm{~nm}$ band pass filter was positioned. Before entering the Rayleigh camera, CO fluorescence was split off using a dichroic beam splitter reflecting $484 \mathrm{~nm}$ but transmitting $532 \mathrm{~nm}$.

Raman scattering passed a high-transmission thin-film polarizer reducing the crosstalk of depolarized broadband and $\mathrm{C}_{2}$-fluorescence interferences by up to $50 \%$. All measurements were repeated with the polarizer turned by $90^{\circ}$ to monitor the background and minor contributions from depolarized Raman scattering. Polarization properties of Raman bands and background were used to gain insights into the spectroscopic nature of the observed signals. The custom transmission spectrometer dispersing Raman scattering provided high optical throughput [23]. Gating at $3.9 \mu \mathrm{s}$ (FWHM) was achieved by a fast rotating shutter at the entrance to the spectrometer. Raman data were acquired in two modes, one using on-chip (hardware) binning and the other using full spectral resolution (roughly $0.12 \mathrm{~nm} / \mathrm{pixel}$ ) and subsequent software binning. In both cases, on-chip binning by 10 pixels was used in the spatial direction for a projected resolution of $102 \mu \mathrm{m}$ across the $6 \mathrm{~mm}$ probe length, resulting in 60 strips of spectral information. In wavelength direction spectral ranges for both hardware and software binning were selected to define seven Raman detection channels to monitor seven major species as described in [21]. In addition, two spectrally binned regions were similarly defined for monitoring of fluorescence interference and back- ground luminosity around Raman shifts of $930 \mathrm{~cm}^{-1}$ and $4300 \mathrm{~cm}^{-1}$, respectively.

Data post-processing was based on the hybrid matrix inversion method described in [21]. In this method the binned signals from the Raman channels, fluorescence channel, and background channel comprise a signal vector $S$. Number densities of individual chemical species, $N$, are calculated from the signal vector $S$ using the matrix equation,

$S=P(T) N$.

The matrix elements $p_{i j}(T)$ depend on temperature and specific experimental conditions. The diagonal elements represent the Raman detection system response for each species. For the nonhydrocarbon species $\left(\mathrm{CO}_{2}, \mathrm{O}_{2}, \mathrm{CO}, \mathrm{N}_{2}, \mathrm{H}_{2} \mathrm{O}\right.$, and $\left.\mathrm{H}_{2}\right)$ the temperature dependence of these diagonal elements is determined from integration of spectral libraries over intervals corresponding to the binned Raman channels. The spectral libraries are based on quantum chemical calculations [21].

For hydrocarbon species this approach is not feasible because of lacking reliable quantum chemical spectra simulations, particularly for calculating reliable temperature dependencies of integrated Raman signals. Moreover, in DME/air flames, a variety of hydrocarbons contribute to the same channel and a special treatment is required as detailed in Section 3. In the following, diagonal matrix elements are termed as Raman responses. Off-diagonal elements represent crosstalk between different species due to spectral superposition of Raman signals. Additional off-diagonal elements represent correlations between signals on the fluorescence channel (or background channel) and fluorescence interference (or background luminosity) landing on the various species channels. Again, for Raman scattering crosstalk between nonhydrocarbon species, the temperature dependence of matrix elements is determined by integrating theoretically based spectral libraries. Temperature dependent Raman responses and crosstalk curves for the stable hydrocarbons of interest were determined from measurements in electrically heated gas mixtures and various laminar flames. In Section 4.1 Raman response and crosstalk curves are discussed and Appendix C provides supplementary crosstalk curves used in this work.

Simultaneously to the line-imaged Raman/Rayleigh measurements, $\mathrm{CO}$ was detected by two-photon laser-induced fluorescence (LIF). For low CO number densities LIF has advantages over Raman scattering, yielding higher precision and accuracy, especially in flames with strong fluorescence interference. The CO-LIF setup was described by Karpetis and Barlow [6] and Barlow et al. [23].

Uncertainties in these multi-scalar measurements are similar to previous measurements [23], but slightly increased due to use of the polarization filter. Representative values for precision and accuracy in temperature and non-hydrocarbon species measurements are detailed in Table 1 . In this paper, measurements in

Table 1

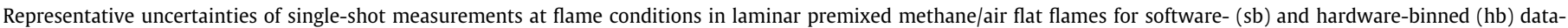

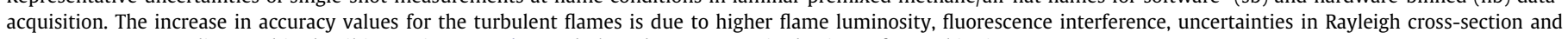
Raman responses as discussed in detail in Sections 3 and 4. Turbulent data was acquired using software-binning.

\begin{tabular}{|c|c|c|c|c|}
\hline Scalar & $\begin{array}{l}\text { Precision } \sigma(\%) \\
\mathrm{hb} / \mathrm{sb}\end{array}$ & $\begin{array}{l}\text { Accuracy (\%) } \\
\text { laminar flames }\end{array}$ & $\begin{array}{l}\text { Laminar flame } \\
\text { condition }\end{array}$ & $\begin{array}{l}\text { Accuracy (\%) } \\
\text { turbulent flames }\end{array}$ \\
\hline$T$ & $0.9 / 3$ & 2 & $\phi=0.97, T=2171 \mathrm{~K}$ & 3-8 (max. of $8 \% @ 1400 \mathrm{~K}$, fuel-rich) \\
\hline $\mathrm{N}_{2}$ & $0.8 / 4$ & 2 & $\phi=0.97, T=2171 \mathrm{~K}$ & 3 \\
\hline $\mathrm{CO}_{2}$ & $3 / 9$ & 4 & $\phi=0.97, T=2171 \mathrm{~K}$ & 6 \\
\hline $\mathrm{H}_{2} \mathrm{O}$ & $2.3 / 6.5$ & 3 & $\phi=0.97, T=2171 \mathrm{~K}$ & 6 \\
\hline $\mathrm{O}_{2}\left(X_{\mathrm{O}_{2}}=0.01\right)$ & $35 / 150$ & 2 & $\phi=0.97, T=2171 \mathrm{~K}$ & 50 (strong LIF interference in T2) \\
\hline$\phi$ or $F$ & $2.3 / 11$ & 5 & $\phi=0.97, T=2171 \mathrm{~K}$ & 10 \\
\hline $\mathrm{CO}$ & $7.5 / 30$ & 10 & $\phi=1.28, T=2029 \mathrm{~K}$ & 20 \\
\hline CO-LIF & $6.5 / 9$ & 10 & $\phi=1.28, T=2029 \mathrm{~K}$ & 15 \\
\hline $\mathrm{H}_{2}$ & $7.5 / 40$ & 10 & $\phi=1.28, T=2029 \mathrm{~K}$ & 15 \\
\hline
\end{tabular}


Table 2

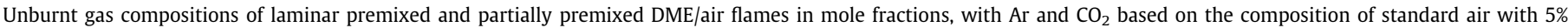
relative humidity. In the experiment the co-flowing air contained $35 \%$ relative humidity ( 0.007 mole fractions). The gas temperature was $290 \mathrm{~K}$.

\begin{tabular}{|c|c|c|c|c|c|c|c|c|c|}
\hline & DME & $\mathrm{N}_{2}$ & $\mathrm{O}_{2}$ & $\mathrm{Ar}$ & $\mathrm{H}_{2} \mathrm{O}$ & $\mathrm{CO}_{2}$ & $u(\mathrm{~m} / \mathrm{s})$ & $R e$ & $\phi$ \\
\hline L1 & 0.114 & 0.6911 & 0.1854 & 0.0083 & 0.0009 & 0.0003 & 2.7 & $\sim 1730$ & 1.85 \\
\hline L2 & 0.281 & 0.5608 & 0.1504 & 0.0067 & 0.0007 & 0.0003 & 2.3 & $\sim 1880$ & 5.6 \\
\hline
\end{tabular}

Table 3

Unburnt gas compositions of turbulent DME/air flames in mole fractions.

\begin{tabular}{|c|c|c|c|c|c|c|c|c|c|}
\hline & DME & $\mathrm{N}_{2}$ & $\mathrm{O}_{2}$ & $\mathrm{Ar}$ & $\mathrm{H}_{2} \mathrm{O}$ & $\mathrm{CO}_{2}$ & $u(\mathrm{~m} / \mathrm{s})$ & $R e$ & $\phi$ \\
\hline $\mathrm{T} 1$ & 0.114 & 0.6911 & 0.1854 & 0.0083 & 0.0009 & 0.0003 & 41.0 & $\sim 23,500$ & 1.85 \\
\hline $\mathrm{T} 2$ & 0.197 & 0.6264 & 0.1680 & 0.0075 & 0.0008 & 0.0003 & 41.0 & $\sim 26,500$ & 3.5 \\
\hline
\end{tabular}

turbulent flames are evaluated using spectrally resolved Ramandata in combination with software-binning, resulting in higher cumulated readout-noise from the CCD. Note that using software-binning shifts the overall precision-limit of the system at flame temperatures from being shot-noise limited to readoutnoise limited.

\subsection{Flame configurations}

In this study laminar and turbulent rich premixed and rich partially premixed DME/air jet flames were investigated. DME is advantageous compared to other fuels, such as $\mathrm{C}_{2} \mathrm{H}_{4}, \mathrm{C}_{2} \mathrm{H}_{6}$, or $\mathrm{C}_{3} \mathrm{H}_{8}$ because of less fluorescence interference levels. The stoichiometric point for DME in air is 6.5 vol.\%. For the laminar jet flames a nozzle diameter of $8 \mathrm{~mm}$ was used. Bulk flow velocities of premixed and partially premixed jets were 2.7 and $2.3 \mathrm{~m} / \mathrm{s}$, respectively. Corresponding Reynolds numbers are below 2000. Stoichiometric values of the mixture fraction are $F_{\mathrm{st}}=0.59$ and 0.26 for L1 and L2, respectively. The jet was shielded from the surrounding environment by a low-velocity $(0.3 \mathrm{~m} / \mathrm{s})$ laminar coflow of air. All electronic flow controllers (MKS or Tescom) were calibrated against laminar flow elements. Line-imaged multi-scalar measurements were conducted $20 \mathrm{~mm}$ downstream of the nozzle exit in radial direction. Two different mixture compositions were used that are termed $\mathrm{L} 1$ and $\mathrm{L} 2$. The gas compositions of these two flames are provided in Table 2 . Flame L1 burned with a central premixed cone (tip height $\sim 80 \mathrm{~mm}$ ) surrounded by a stratified post-oxidation region (Bunsen type flame), where a methane-counterpart was investigated by Chou et al. [24]. Flame L2, having a richer jet mixture, did not exhibit an inner premixed reaction zone and, therefore, provides a flame structure more typical of non-premixed flames, with a single reaction zone near the stoichiometric condition.

Multi-scalar measurements were applied to piloted, turbulent DME/air jet flames to investigate the feasibility of applying the present approach to flames of relevance to turbulent combustion model validation. For this purpose the well-known burner configuration of the Sandia-Sydney piloted flame series A-F was used [5,4,6-9]. Two DME/air flames were investigated, as detailed in Table 3 . The gas composition of the lean premixed pilot was $\mathrm{CH}_{4} / \mathrm{H}_{2} /$ air: $0.055 / 0.055 / 0.89$. This pilot composition was used for simplicity in this first study, knowing that it will be appropriate in future work to match the enthalpy and atom balance of pilot to that of the main fuel at the same equivalence ratio. Stoichiometric values of the mixture fraction are $F_{\mathrm{st}}=0.59$ and 0.36 for $\mathrm{T} 1$ and $\mathrm{T} 2$, respectively. The total bulk velocity of the main jet was fixed at $41 \mathrm{~ms}^{-1}$, but the DME/air ratio was varied. Reynolds numbers are 23.500 and 26.500 for T1 and T2, respectively, recalling characteristics of piloted $\mathrm{CH}_{4}$ /air flame D. As will be shown, T2 has a scalar flame structure analogous to the piloted partially premixed $\mathrm{CH}_{4}$ /air

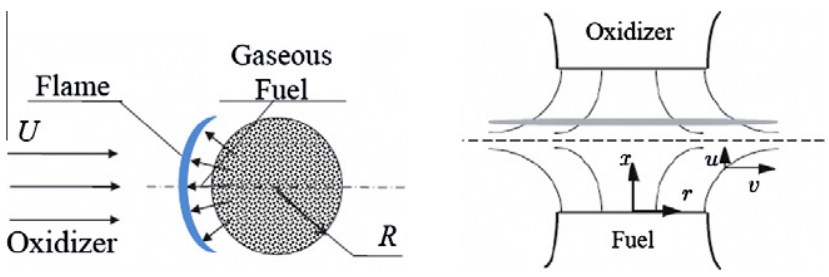

Fig. 1. Sketch of Tsuji burner (left) and opposed flow burner (right).

jet flames, with most of the heat release occurring in a diffusion controlled reaction zone at the stoichiometric condition. In contrast, flame $\mathrm{T} 1$ is a turbulent Bunsen flame, with much of the heat release occurring in a rich premixed reaction zone.

\subsection{Numerical procedure}

The analysis of DME/air flames was supported using 1D computations. Laminar flames are simulated using both the Tsuji and opposed jet geometries (Fig. 1). In the Tsuji geometry, the flame is stabilized in the forward stagnation region of a porous cylinder immersed in a uniform oxidizer flow. The imposed strain on the flame is calculated as

$a=2 U / R$,

where $U$ is the approaching velocity of the oxidizer and $R$ is the radius of the cylinder. With a stagnation flow formulation, the Tsuji flames were computed using the OPPFLOW code developed by Miller et al. [25].

In the opposed jet configuration fuel and oxidizer issue from two opposed nozzles and imping against each other. The flame is stabilized between the two jets near the stagnation plane. The global strain rate of the flame is calculated as proposed by Seshadri and Williams [26]

$a=\frac{U_{\mathrm{o}}}{H}\left(1+\frac{U_{\mathrm{f}}}{U_{\mathrm{o}}} \sqrt{\frac{\rho_{\mathrm{f}}}{\rho_{\mathrm{o}}}}\right)$.

Where $U_{\mathrm{o}}$ is the velocity and $\rho_{\mathrm{o}}$ the density of the oxidizer stream and $U_{\mathrm{f}}, \rho_{\mathrm{F}}$ of the fuel stream, respectively. $H$ is the distance between nozzles. The computer code OPPDIF developed by Lutz et al. [27] was used. In case of rich partially-premixed jets, two flame zones form consisting of a rich premixed flame and a diffusion flame. Both flame zones partly overlap resulting in a flame structure more complex than pure premixed or diffusion flames.

Two reaction mechanisms from Zhao et al. [28] (55 species) and Kaiser et al. [29] (78 species) were compared. Planar premixed flame speeds were computed using the PREMIX code by Kee et al. [30] as one method of evaluating differences between the mechanisms. Laminar flame speeds resulting from the two reaction 


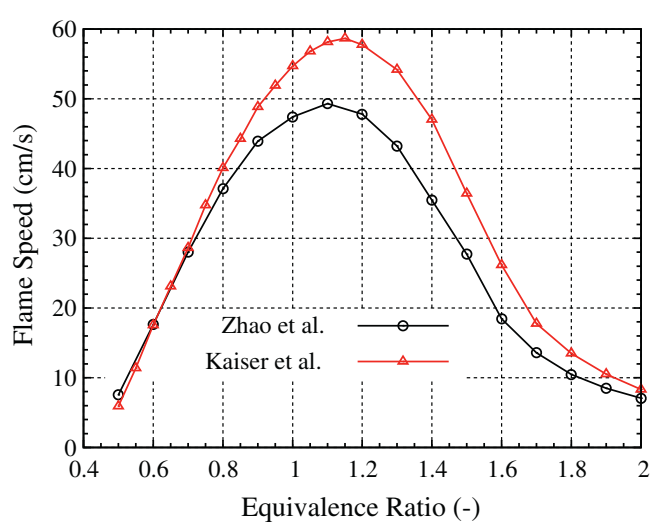

Fig. 2. Laminar flame speed of DME/air vs. equivalence ratio comparing both mechanisms. Lines between calculated equivalence ratios are interpolated and only included to guide eyes.

mechanisms are compared in Fig. 2. The Kaiser mechanism overpredicts laminar flame speeds, whereas good agreement between results obtained from the Zhao mechanism and experimental data is found by Zhao et al. [28]. Based on this comparison, the Zhao mechanism was used primarily in this work. However, the differences in species prediction between the two mechanisms are briefly considered in Section 3.1. Tsuji flames were simulated over a range of strain rates from $a=100 \mathrm{~s}^{-1}$ to near-extinction for each of the four DME/air mixtures (L1, L2, T1, and T2), using both multicomponent transport and equal diffusivities (mass diffusivity equals thermal diffusivity), with the latter results expected to be more representative of turbulent flames where differential diffusion effects become less obvious. Opposed jet calculations with multi-component transport were done just for L1 and T1 at strain rates of $a=50$ and $100 \mathrm{~s}^{-1}$. Results are used in the analysis that follows.

\section{Analysis based on laminar flame calculation}

In hydrocarbon flames, Raman and Rayleigh scattering originates from educts, products (major species) and intermediates. In $\mathrm{CH}_{4}$ /air flames these intermediates so far have not been treated systematically because of comparatively low concentrations and relatively minor influence on effective scattering cross-sections. As stated in the introduction, Raman/Rayleigh measurements from flames of DME and other more complex fuels cannot be processed using the same simple methods from $\mathrm{CH}_{4}$ flames; initial attempts in the present study revealed significant inconsistencies.

In this section, results of the laminar DME/air flame calculations are used together with data on integrated Raman signal intensities and Rayleigh scattering cross-sections to analyze the influence of hydrocarbon intermediates on Raman and Rayleigh scattering measurements. Details of scattering properties needed for this analysis are provided in Appendices A and B. Following the identification of all relevant intermediates, the special circumstances resulting from the matrix inversion (MI) method commonly used for evaluation of Raman/Rayleigh scattering are addressed. In the present experimental setup, the spectral region for Raman shifts located between 2775 and $3263 \mathrm{~cm}^{-1}$ (hydrocarbon channel) is used to detect the Raman scattering signal from DME and some of the intermediate hydrocarbon species. Details of the superposed spectral signature of the hydrocarbon mix are lost due to pixel binning. Consequently, a priori information on composition and temperature must be used. In the approach presented, different models for the Raman response within the hydrocarbon channel, the effective Rayleigh cross-section, and the calculation of the mixture fraction are introduced.
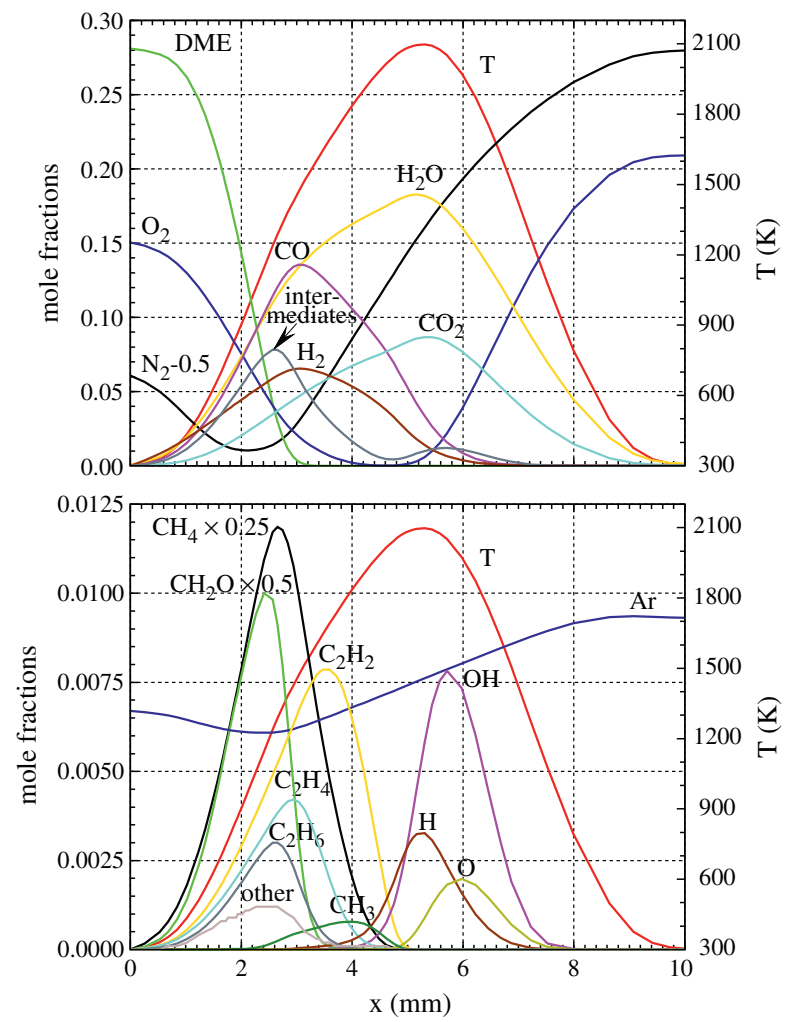

Fig. 3. Species and temperature profiles from laminar flamelet calculation. Tsuji geometry, Zhao et al. mechanism, $a=50 \mathrm{~s}^{-1}$, L2, multi-component transport. In (top) the sum of the species from (bottom) except Ar is shown as 'intermediates'. These seventeen species always represent more than 0.998 mol fractions of all 55 species from the mechanism.

\subsection{Identification of species relevant to Raman/Rayleigh scattering in DME flames}

Based on laminar flame calculations described in Section 2.3 major and intermediate species are now identified that significantly contribute to Raman and Rayleigh scattering in DME/air flames. This analysis, however, is focused only on fuel/air mixture compositions introduced in Tables 2 and 3. General observations are reported using just case L2 followed by a discussion of the impact of mixture composition variations, reaction mechanisms from Zhao et al. and Kaiser et al., strain rate variation, and flow geometry (opposed jet and Tsuji). To select relevant species contributing significantly to Raman and Rayleigh scattering a minimum mole fraction of 0.001 was used as threshold. Thereby the seven common major species $\left(\mathrm{CO}_{2}, \mathrm{O}_{2}, \mathrm{CO}, \mathrm{N}_{2}, \mathrm{DME}, \mathrm{H}_{2} \mathrm{O}, \mathrm{H}_{2}\right)$, and additionally ten minor species $\left(\mathrm{CH}_{4}, \mathrm{CH}_{2} \mathrm{O}, \mathrm{Ar}, \mathrm{OH}, \mathrm{C}_{2} \mathrm{H}_{2}, \mathrm{H}\right.$, $\mathrm{C}_{2} \mathrm{H}_{4}, \mathrm{O}, \mathrm{C}_{2} \mathrm{H}_{6}, \mathrm{CH}_{3}$ ) were identified for further analysis.

For case $\mathrm{L} 2$ (28.1\% DME in air) the spatial profiles for mole fractions and temperature are presented in Fig. 3. In the top of Fig. 3 the common seven major species are shown in comparison to the total mole fraction of nine intermediates (excluding Ar from the ten minor species above). Intermediate species contribute up to a mole fraction of 0.078 at maximum. This peak is located at the fuel-rich side of the flame, with a corresponding temperature of $1239 \mathrm{~K}$ at $x=2.57 \mathrm{~mm}$. The bottom of Fig. 3 shows the ten species individually and all remaining low-concentration species are summed up in 'other'. The following observations can be made from these profiles: First, $\mathrm{CH}_{4}$ and $\mathrm{CH}_{2} \mathrm{O}$ are the most abundant intermediates with maximum mole fractions of 0.048 and 0.02 , respectively. At $x=2.66 \mathrm{~mm}(1287 \mathrm{~K})$, the corresponding DME mole fraction has approached already 0.03 , corresponding to less 
than half of the intermediates. Second, four intermediate hydrocarbons $\left(\mathrm{CH}_{4}, \mathrm{C}_{2} \mathrm{H}_{2}, \mathrm{C}_{2} \mathrm{H}_{4}, \mathrm{C}_{2} \mathrm{H}_{6}, \mathrm{CH}_{3}\right)$ add up to a mole fraction of 0.07 . Just these four intermediates contribute to the hydrocarbon Raman channel in the present measurements, but all of them contribute to the effective Rayleigh cross-section as shown in Sections 3.2 and 3.3. Third, all other species excluded from the seventeen species mentioned above never exceed a total mole fraction of 0.002 . In spite of typical experimental sensitivities, especially for single laser shot Raman scattering, such low concentrations are well justified to be neglected.

To evaluate the sensitivity of these findings, a parametric variation of laminar flame calculations was conducted. Using a mixture composition of 19.7\% DME in air, the reaction intermediates sum up to a mole fraction of 0.052 , compared to 0.07 in the $28.1 \%$ DME in air flame, both $a=100 \mathrm{~s}^{-1}$, multi-component transport. Switching to equal diffusivity transport, the maximum intermediates mole fraction decreases to 0.05 . Increasing the strain rate to just below the extinction limit (multi-component: $a=1750 \mathrm{~s}^{-1}$ and equal diffusivity: $a=2500 \mathrm{~s}^{-1}$ ) the intermediates mole fraction reduces to 0.035 and 0.028 , respectively. The same trends are observed when replacing the Zhao et al. mechanism by the Kaiser et al. mechanism. However, using the Kaiser et al. mechanism, the mole fractions summed up from the same intermediate species in total is reduced by approximately $10 \%$. It is apparent from these calculations that the total mole fraction of hydrocarbon intermediates decreases with decreasing DME fraction in the fuel/air mixture, decreases with increasing strain rate, and decreases when equal diffusivities are applied rather than multi-component transport. However, the intermediates mole fraction remains important in all cases and must be considered because scattering cross-sections, molar masses, and atomic constitutions differ significantly from the parent fuel. Neglecting hydrocarbon intermediates in the evaluation procedure would result in systematic errors in assumed scattering properties, as is detailed in the following sections.

\subsection{Analysis of Raman scattering response}

Temperature dependent distributions of DME and relevant intermediate hydrocarbon species from laminar flame calculations are now used to quantify their impact on the Raman response of the hydrocarbon channel. A strong Raman crosstalk on $\mathrm{CO}_{2}$ and $\mathrm{O}_{2}$ is addressed in Section 4 and the Appendix B. In the following treatment sensitivities of Raman response to strain, transport, mixture composition, and geometry are investigated. For this sensitivity study, integrated Raman signal intensities from DME and intermediate hydrocarbons are assumed not to vary with temperature. Referring to Table B.6 in the Appendix, this simplification is well justified up to $820 \mathrm{~K}$ as measured in the heated gas flows. However, this restriction is not applied for the final data evaluation of the flames. Response curves in Section 4 differ accordingly and linear extrapolations of measured temperature dependences to higher temperatures are included (compare Fig. 12). Note also that the effects of optical bowing in the spectrometer as indicated in Fig. B.24 and resulting strip-dependence of the Raman response are included in the final data analysis. This is not discussed here for simplicity of presenting the conceptual approach.

The analysis that follows is for the center of the bowed image. The hydrocarbon channel ranging on this center strip from $2798 \mathrm{~cm}^{-1}$ to $3263 \mathrm{~cm}^{-1}$ covers a major part of the spontaneous Raman scattering originating from DME, $\mathrm{CH}_{4}, \mathrm{C}_{2} \mathrm{H}_{4}, \mathrm{C}_{2} \mathrm{H}_{6}$, and $\mathrm{CH}_{3}$. Concurrently, remaining hydrocarbons like $\mathrm{CH}_{2} \mathrm{O}$ and $\mathrm{C}_{2} \mathrm{H}_{2}$ are not contributing to this spectral range because of their different Raman shifts (compare spectra and text presented in Appendix B). As the integrated Raman scattering signal is linear with number density, the temperature dependence of the collective response

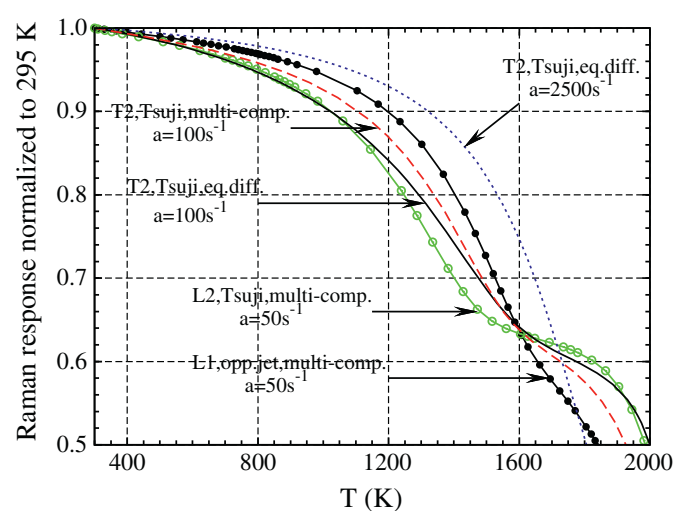

Fig. 4. Sensitivity of the Raman response on the hydrocarbon channel to strain transport model, and geometry using Eq. (4) and constant signal intensity ratios from Table B.6 (right column, $820 \mathrm{~K}$ ).

on the hydrocarbon channel $I_{\mathrm{Ram}, \mathrm{HC}}$ is described by a linear combination of the five relative hydrocarbon mole fractions $X_{i}(T) / \sum_{j=1}^{5} X_{j}(T)$ weighted by their corresponding relative intensities $I_{\text {Ram, }, i} / I_{\text {Ram,DME }}$

$I_{\text {Ram }, \mathrm{HC}}(T)=\frac{\sum_{i=1}^{5} X_{i}(T) \frac{I_{\text {Ram }, i}}{I_{\text {Ram }, \text { MME }}}}{\sum_{j=1}^{5} X_{j}(T)}$.

This temperature dependence solely comes from the decomposition and oxidation reactions of hydrocarbons at rising temperatures. Density effects are excluded from Eq. (4). Raman responses based on Eq. (4) are shown in Fig. 4.

Obviously, the consumption of hydrocarbon species by chemical reactions depends on boundary conditions. Therefore the Raman response in Eq. (4) has been derived using $X_{i}(T)$ from laminar flame calculations, various strain rates, transport models, flow geometries, and mixture compositions. For the T2 mixture composition (19.7\% DME in air), the Raman response differs up to $20 \%$ at $1500 \mathrm{~K}$ when the strain rate increases from $a=100 \mathrm{~s}^{-1}$ to $a=2500 \mathrm{~s}^{-1}$. Switching the transport model from multicomponent to equal diffusivities yields small differences in the range of $1-3 \%$. Similar variations are observed for the mechanism by Kaiser et al. [29] (not shown in Fig. 4). Results of the L1 mixture composition (11.4\% DME in air) are shown for the opposed flow configuration. Although this flame burns with an inner premixed cone the Raman response is bounded by the results for the diffusion-flame-like cases. It is concluded from this analysis that the proposed model approach simplifies the physical-chemical processes, especially for turbulent flames with varying influence of molecular transport effects, strain, flow patterns, or even local extinction. However, Section 4 will show its practicability by presenting results which are based on different Raman responses, each corresponding to an appropriate laminar calculation.

Signal intensity ratios describing the crosstalk onto detection channels for the fluorescence interference channel, $\mathrm{CO}_{2}$, and $\mathrm{O}_{2}$ at lower Raman shifts are provided in Tables B.7,B.8,B.9 in the Appendix. At these lower Raman shifts differences in scattering intensities are much more pronounced among the individual hydrocarbon molecules because their rovibrational bands are separated. The crosstalks onto the $\mathrm{O}_{2}, \mathrm{CO}_{2}$, and fluorescence channels are discussed in detail in Section 4.

\subsection{Effective Rayleigh cross-section}

The laminar flame calculations from Section 3.2 are also used to understand the influence of the intermediate species on the Rayleigh temperature measurements. The Rayleigh signal intensity is 
proportional to the effective Rayleigh cross-section. The effective Rayleigh cross-section is determined from a linear combination of species-specific Rayleigh cross-sections $\sigma_{\mathrm{Ray}, i}$ weighted by the respective mole fractions $X_{i}$

$\sigma_{\text {Ray }, \text { eff }}=\sum_{i} X_{i} \sigma_{\text {Ray }, i}$.

In the data evaluation of simultaneous Raman/Rayleigh measurements, species mole fractions are determined from the Raman responses on the different channels. These mole fractions are used to calculate the Rayleigh cross-section of the mixture. Then the matrix Eq. (1) is solved iteratively since Raman responses depend on temperature. In contrast, Rayleigh cross-sections are independent or only weakly dependent on temperature. In practice, Rayleigh cross-sections measured at room temperature are used throughout the whole temperature range in flames. This assumption of constant cross-sections may cause a bias towards low temperatures by up to $2 \%$ as remarked by Sutton et al. [31]. However, according to the authors' experience for the present flames, this systematic deviation is below $1 \%$. Hence, temperature dependencies of Rayleigh crosssections are neglected in the following analysis. Rayleigh cross-sections for various species have been derived from the literature and experiments and are listed in the Appendix in Table A.5.

In this study Rayleigh cross-sections based on refraction indices from Gardiner et al. [32] for $532 \mathrm{~nm}$ excitation wavelength along with a static value from Bacskay et al. [33] for formaldehyde are used. All values are normalized to $\mathrm{N}_{2}$. The seventeen relevant species identified in Section 3.1 are now further assessed considered for their contributions to Rayleigh scattering. Contributions to the Rayleigh signal from all other lower-concentrated species are not significant and are neglected. Contributions from $\mathrm{Ar}, \mathrm{O}, \mathrm{H}$, and $\mathrm{OH}$ are neglected as well (see Appendix B.2). Therefore, thirteen species remain $\left(\mathrm{CO}_{2}, \mathrm{O}_{2}, \mathrm{CO}, \mathrm{N}_{2}, \mathrm{DME}, \mathrm{H}_{2} \mathrm{O}, \mathrm{H}_{2}, \mathrm{CH}_{4}, \mathrm{CH}_{2} \mathrm{O}\right.$, $\mathrm{C}_{2} \mathrm{H}_{2}, \mathrm{C}_{2} \mathrm{H}_{4}, \mathrm{C}_{2} \mathrm{H}_{6}, \mathrm{CH}_{3}$ ), and the effective Rayleigh cross-section for DME/air flames reads,

$\sigma_{\text {Ray,eff, ref }}=\frac{\sum_{i=1}^{13} X_{i}(T, a) \sigma_{\text {Ray }, i}}{\sum_{i=1}^{13} X_{i}(T, a)}$.

Mole fractions are denoted here as functions of both temperature $T$ and strain rate $a$, expressing their dependence upon the specific laminar flame calculation. This Rayleigh cross-section is denoted as 'reference' because all mole fractions $X_{i}$ of the contributing species are assumed to be known, whereas, in the experiment, this assumption is true only for the major species $\left(\mathrm{CO}_{2}, \mathrm{O}_{2}, \mathrm{CO}, \mathrm{N}_{2}\right.$, $\mathrm{H}_{2} \mathrm{O}, \mathrm{H}_{2}$ ). Since both $\mathrm{C}_{2} \mathrm{H}_{2}$ and $\mathrm{CH}_{2} \mathrm{O}$ do not contribute to the signal on the hydrocarbon channel, data from this channel represent contributions from five remaining hydrocarbons (DME, $\mathrm{CH}_{4}, \mathrm{C}_{2} \mathrm{H}_{4}, \mathrm{C}_{2} \mathrm{H}_{6}$, and $\mathrm{CH}_{3}$ ). Therefore, information accessible from the experiment reduces to only eleven species. Accordingly, the 'experimental' effective Rayleigh cross-section is composed only by eleven species and can be described as

$$
\begin{aligned}
\sigma_{\text {Ray,eff, exp }}= & \frac{\sum_{i=1}^{6} X_{i}(T, a) \sigma_{\text {Ray }, i}+\sum_{i=7}^{11} X_{i}(T, a) \sigma_{\text {Ray, HC }}}{\sum_{i=1}^{11} X_{i}(T, a)} \\
= & \frac{\sum_{i=1}^{6} X_{i}(T, a) \sigma_{\text {Ray }, i}+X_{\mathrm{HC}}(T, a) \sigma_{\text {Ray }, \mathrm{HC}}}{\sum_{i=1}^{6} X_{i}(T, a)+X_{\mathrm{HC}}(T, a)} .
\end{aligned}
$$

In Eq. (7b), contributions from the six major non-hydrocarbon species and the five hydrocarbon species (excluding $\mathrm{C}_{2} \mathrm{H}_{2}$ and $\mathrm{CH}_{2} \mathrm{O}$ ) are grouped into two terms, $\sum_{i=1}^{6} X_{i}(T, a) \sigma_{\mathrm{Ray}, i}$ and $X_{\mathrm{HC}}(T, a) \sigma_{\mathrm{Ray}, \mathrm{HC}}$. In the latter, instead of the species-specific Rayleigh cross-sections an effective, mole-weighted cross-section $\sigma_{\text {Ray,HC }}$ is used for the hydrocarbons. Because mole fractions of the five hydrocarbon species remain unknown from the experiment, a model has to be implemented providing a sound estimation of the hydrocarbon
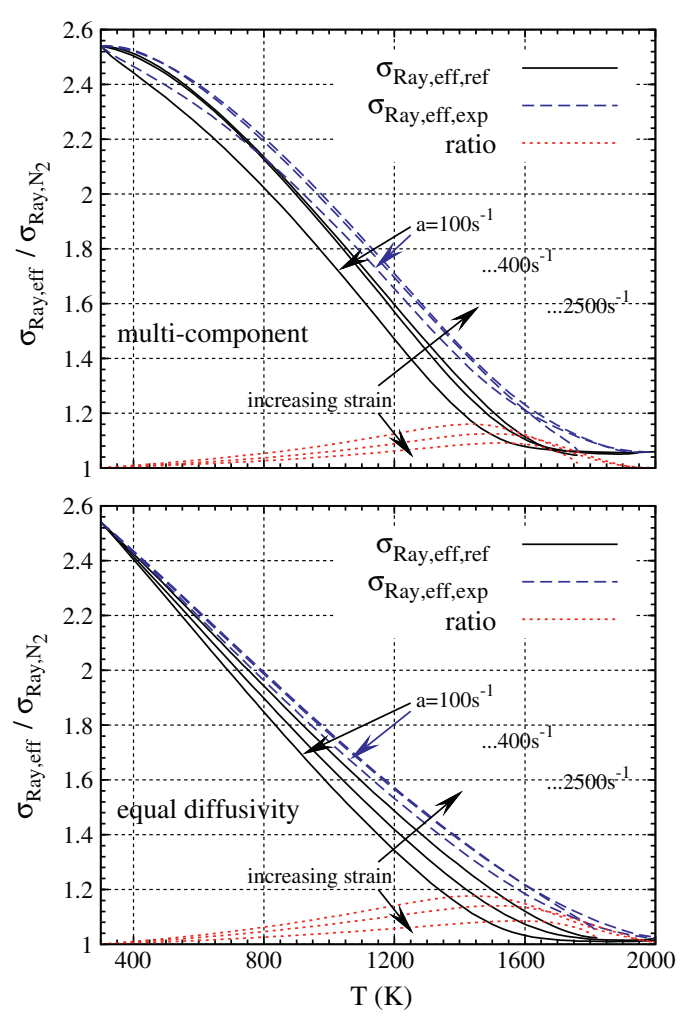

Fig. 5. Effective Rayleigh cross-section for $\mathrm{T} 2$ configuration (19.7\% DME) from laminar flame calculation in Tsuji geometry, mechanism from Zhao et al., using (top) multi-component and thermal diffusivity transport and (bottom) equal diffusivity. Solid lines show the cross-sections for different strain rates including the thirteen most relevant species deduced from Eq. (6). Dashed lines are derived following Eq. (7b), where $\sigma_{\text {Ray, } \mathrm{HC}}=\sigma_{\text {Ray,DME }}$ is assumed for the five hydrocarbons. Dotted lines show the ratio $\sigma_{\text {Ray, eff,exp }} / \sigma_{\text {Ray,eff,ref. }}$

contribution to the Rayleigh scattering signal, $\sum_{i=7}^{11} X_{i}(T, a)$ $\sigma_{\text {Ray }, \mathrm{HC}}=X_{\mathrm{HC}}(T, a) \sigma_{\mathrm{Ray}, \mathrm{HC}}$. Prior to introducing the model for this term, the temperature dependent deviation between Eqs. (6) and (7b) is considered with the Rayleigh cross-section of DME being used for all five in Eq. (7b), i.e. $\sigma_{\text {Ray, HC }}=\sigma_{\text {Ray,DME. }}$ This is effectively what is assumed in Raman/Rayleigh processing measurements from methane flames, where the Rayleigh cross-section for $\mathrm{CH}_{4}$ is applied to all molecules contributing to the fuel Raman channel, without causing significant error.

Figure 5 provides temperature dependent effective cross-sections normalized to nitrogen. Results for $\sigma_{\text {Ray,eff,ref }}$ and $\sigma_{\text {Ray,eff,exp }}$ (assuming $\sigma_{\mathrm{Ray}, \mathrm{HC}}=\sigma_{\mathrm{Ray}, \mathrm{DME}}$ ) are shown for both transport models and various strain rates. The deviations of $\sigma_{\text {Ray,eff,exp }}$ are quantified by the ratio $\sigma_{\text {Ray,eff,exp }} / \sigma_{\text {Ray, eff,ref. }}$ With rising temperature in DME flames the true value of $\sigma_{\text {Ray,HC }}$ becomes significantly smaller than $\sigma_{\text {Ray,DME }}$ due to the build-up of the intermediate hydrocarbons that exhibit smaller Rayleigh cross-sections. Significant differences between $\sigma_{\text {Ray,eff,exp }}$ and $\sigma_{\text {Ray,eff,ref }}$ are observed. These differences would translate directly to systematic error in temperature measured in fuel rich conditions. For the lowest strain rate $a=100 \mathrm{~s}^{-1}$ the maximum of $\sigma_{\text {Ray,eff, exp }} / \sigma_{\text {Ray,eff,ref }}$ around $1435 \mathrm{~K}$ is slightly larger for equal diffusivity (18\%) than for the multi-component transport model (16\%). Independent of the transport model the ratio decreases with increasing strain rates due to diminishing of variation in $\sigma_{\text {Ray,eff,exp }}$ for rising strain.

\subsection{Temperature and strain rate dependent Rayleigh cross-section model}

In order to avoid the unacceptably large systematic errors illustrated by Fig. 5, a model must be used to account for species 

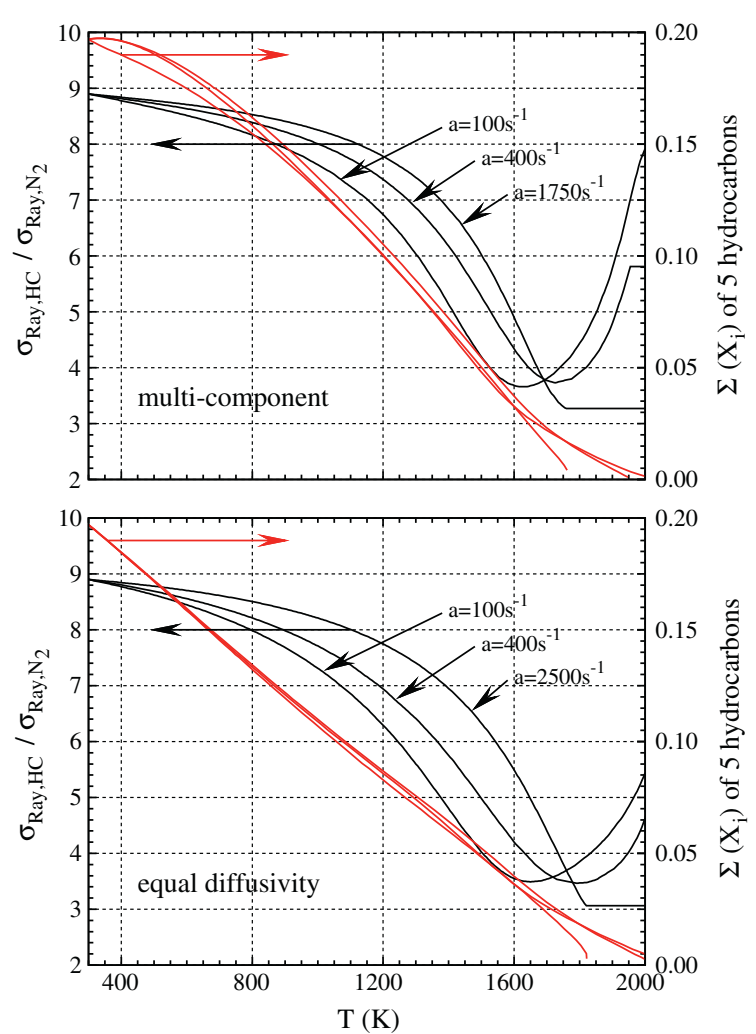

Fig. 6. Effective Rayleigh cross-section of the combined hydrocarbons $\mathrm{DME}, \mathrm{CH}_{4}$, $\mathrm{C}_{2} \mathrm{H}_{4}, \mathrm{C}_{2} \mathrm{H}_{6}$, and $\mathrm{CH}_{3}$, based on mole fractions from laminar calculations for the two transport models and the T2 boundary conditions (same calculations as in Fig. 5).

specific Rayleigh cross-sections of the important hydrocarbon intermediates that contribute signal to the Raman fuel channel. The following expression is used to represent the weighted Rayleigh cross-section for hydrocarbons as it depends on temperature and strain rate, based on laminar flame calculations.

$\sigma_{\text {Ray }, \mathrm{HC}}(T, a)=\frac{\sigma_{\text {Ray }, \mathrm{eff}, \text { ref }} \sum_{i=1}^{11} X_{i}(T, a)-\sum_{i=1}^{6} X_{i}(T, a) \sigma_{\text {Ray }, i}}{\sum_{i=7}^{11} X_{i}(T, a)}$

This equation is inserted to Eq. (7b), which is used within the iterative Raman/Rayleigh data evaluation. Based on the input of laminar flame calculations, by nature the model varies with strain, transport model etc. This dependence is shown in Fig. 6 for two different transport models at various strain rates. In addition the integrated mole fraction $\sum_{i=7}^{11} X_{i}(T, a)=X_{\mathrm{HC}}(T, a)$ is included to the figure. Whereas $\sigma_{\text {Ray,HC }}$ shows a sensitivity with regard to strain and transport model, $X_{\mathrm{HC}}$ is much less dependent on strain. However, slight differences especially at low temperatures are observed between the two transport models. Significant values of $X_{\mathrm{HC}}$ are present throughout the whole temperature range underlying the important role of intermediate hydrocarbons in Raman and Rayleigh scattering. Considering the sensitivity on the strain rate, deviations for $a=100 \mathrm{~s}^{-1}$ and $a=2500 \mathrm{~s}^{-1}$, respectively, are up to $+60 \%$ relative to the result for $a=100 \mathrm{~s}^{-1}$ at $1550 \mathrm{~K}$. Differences resulting from the two transport models at equal strain rate are smaller. At $1300 \mathrm{~K}$ differences add up to $8 \%$ but increase for temperatures above $1700 \mathrm{~K}$. Increased sensitivity of the model at these high temperatures is of minor influence because of the relatively low value of $X_{\mathrm{HC}}$. The impact of the sensitivity of $\sigma_{\mathrm{Ray}, \mathrm{HC}}$ upon $\sigma_{\text {Ray,eff, exp }}$ calculated from Eq. (7b) is now evaluated by using the following expression:

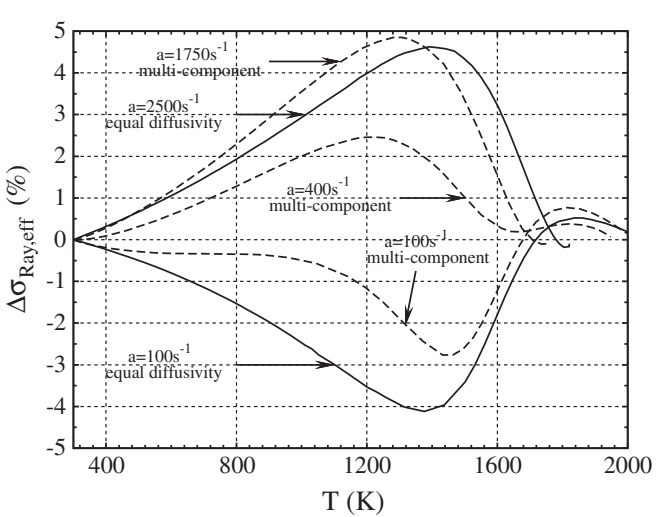

Fig. 7. Emerging differences between effective Rayleigh cross-sections using just one particular model ( $a=400 \mathrm{~s}^{-1}$, equal diffusivity) for distinct strain rates and transport.

$\Delta \sigma_{\text {Ray }, \text { eff }}=\frac{\sigma_{\text {Ray, eff,ref }}-\sigma_{\text {Ray,eff, exp }}\left(\sigma_{\text {Ray,HC,a=400 s-1 }}\right)}{\sigma_{\text {Ray,eff,ref }}} \cdot 100 \%$

Results shown in Fig. 7 are based on the effective cross-section of

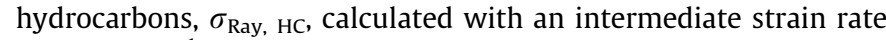
of $a=400 \mathrm{~s}^{-1}$ and equal diffusivity. For the reference effective

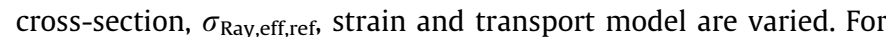
equal diffusivities deviations sum up to $\pm 4.5 \%$ at $1400 \mathrm{~K}$. For multi-component transport models $\Delta \sigma_{\text {Ray,eff }}$ is reduced to approximately $2.5 \%$ using the identical strain rate of $a=400 \mathrm{~s}^{-1}$. In case of turbulent flames with varying strain inaccuracies will depend on instantaneous flow properties and can be as high as $4.5 \%$. Note that all these considerations affect the effective Rayleigh scattering cross-section only. In the iterative Raman/Rayleigh data evaluation procedure these model-based inaccuracies do have a continuative impact because of the mutual interaction of temperature and mole fraction determination. Using one particular laminar flame calculation for both the Raman response and the Rayleigh cross-section model, inaccuracies may partly compensate or amplify. In the end, final inaccuracies of the entire evaluation scheme can be assessed best by benchmarking measurements against laminar flame calculations. Another issue is how the time-average in physical space and the conditional average on mixture fraction in turbulent flames are affected. This will be discussed in Section 4.3 on the experimental results of $\mathrm{T} 2$ (compare Fig. 22).

\subsection{Mixture fraction space, mass fractions, and atom ratios}

The presence of intermediate hydrocarbon species in the DME flames impacts the calculation of mixture fraction. Thus in this section the determination of mixture fraction is examined, using laminar flame calculations as well as information about experimentally accessible data. The impact of detection issues regarding the hydrocarbons described in Sections 3.1,3.2,3.3,3.4 is discussed in the context of molar masses and atom numbers. The mixture fraction is calculated following the method of Barlow and Frank [5], where oxygen is excluded from the expression of Bilger et al. [34]:

$F=\frac{2\left(Y_{\mathrm{C}}-Y_{\mathrm{C}, 2}\right) / w_{\mathrm{C}}+\left(Y_{\mathrm{H}}-Y_{\mathrm{H}, 2}\right) / 2 w_{\mathrm{H}}}{2\left(Y_{\mathrm{C}, 1}-Y_{\mathrm{C}, 2}\right) / w_{\mathrm{C}}+\left(Y_{\mathrm{H}, 1}-Y_{\mathrm{H}, 2}\right) / 2 w_{\mathrm{H}}}$.

Herein $Y_{\mathrm{C}}, Y_{\mathrm{H}}$ are local elemental mass fractions, $w_{\mathrm{C}}, w_{\mathrm{H}}$ are atomic masses, and subscripts 1 and 2 refer to the inflow conditions of the main jet and co-flowing air, respectively. This expression has some advantage in partially premixed flames, where oxygen mass fraction boundary conditions are similar in the two streams, making the full Bilger expression more sensitive to experimental noise. 
Elemental mass fractions are derived from the species mass fractions $Y_{\mathrm{C}_{x} \mathrm{H}_{y} \mathrm{O}_{z}}$

$$
\begin{aligned}
& Y_{\mathrm{C}}=w_{\mathrm{C}} \sum_{i} x_{i}\left(Y_{\mathrm{C}_{x} \mathrm{H}_{y} \mathrm{O}_{z}}\right)_{i} /\left(w_{\mathrm{C}_{x} \mathrm{H}_{y} \mathrm{O}_{z}}\right)_{i} \text {, } \\
& Y_{\mathrm{H}}=w_{\mathrm{H}} \sum_{i} y_{i}\left(Y_{\mathrm{C}_{x} \mathrm{H}_{y}} \mathrm{O}_{z}\right)_{i} /\left(w_{\mathrm{C}_{x} \mathrm{H}_{y} \mathrm{O}_{z}}\right)_{i} \text {, }
\end{aligned}
$$

where $x, y$ and $z$ refer to the corresponding number of $\mathrm{C}, \mathrm{H}, \mathrm{O}$ atoms and $w_{\mathrm{C}_{x} \mathrm{H}_{y} \mathrm{O}_{z}}$ to the respective molar mass of the species $i$. Raman measurements provide species concentrations $C_{\mathrm{C}_{x} \mathrm{H}_{y} \mathrm{O}_{z}}$. Species mass or mole fractions are derived via post-processing, using a molar mass weighted normalization or simple normalization, respectively:

$Y_{\mathrm{C}_{x} \mathrm{H}_{y} \mathrm{O}_{z}}=C_{\mathrm{C}_{x} \mathrm{H}_{y}} \mathrm{O}_{z} w_{\mathrm{C}_{x} \mathrm{H}_{y} \mathrm{O}_{z}} / \sum_{i}\left(C_{\mathrm{C}_{x} \mathrm{H}_{y}} \mathrm{O}_{z} w_{\mathrm{C}_{x} \mathrm{H}_{y} \mathrm{O}_{z}}\right)_{i}$,

$X_{\mathrm{C}_{x} \mathrm{H}_{y} \mathrm{O}_{z}}=C_{\mathrm{C}_{x} \mathrm{H}_{y} \mathrm{O}_{z}} / \sum_{i}\left(C_{\mathrm{C}_{x} \mathrm{H}_{y} \mathrm{O}_{z}}\right)_{i}$.

In practical Raman/Rayleigh measurements, hydrocarbon species are cumulated into the hydrocarbon channel. Thus, individual concentrations of fuel and intermediate hydrocarbons (HC) are summarized in

$C_{\mathrm{HC}}=\sum_{i}\left(C_{\mathrm{C}_{x} \mathrm{H}_{y} \mathrm{O}_{z}}\right)_{i}, \quad x \wedge y \neq 0$.

Accordingly information on $C_{\mathrm{C}_{x} \mathrm{H}_{y} \mathrm{O}_{z}} w_{\mathrm{C}_{x} \mathrm{H}_{y} \mathrm{O}_{z}}$ for intermediate hydrocarbons necessary for calculation of Eq. (13) is not available from the measurements. In the present approach the molar mass of DME is used for representing all hydrocarbons cumulated into the Raman channel:

$\left(w_{\mathrm{C}_{x} \mathrm{H}_{y} \mathrm{O}_{z}}\right)_{i}=w_{\text {DME }}, \quad x \wedge y \neq 0$.

This is a crude simplification. However, as will be shown, comparisons between experiments and calculations can still be made on a consistent basis, and an additional level of complexity is avoided in the implementation of the overall method of Raman/Rayleigh data analysis for DME flames. The assumption (16) causes significant deviations in calculated mass fractions and mixture fraction from normally defined values, so adapted mass and mixture fraction definitions are introduced and denoted by $Y^{*}$ and $F^{*}$, respectively. The cumulated mass fractions of hydrocarbons and non-hydrocarbons read

$Y_{\mathrm{HC}}^{*}=C_{\mathrm{HC}} w_{\mathrm{DME}} /\left\{C_{\mathrm{HC}} w_{\mathrm{DME}}+\sum_{i}\left(C_{i} w_{i}\right)_{\mathrm{nonHC}}\right\}$

and

$$
\left(Y_{i}^{*}\right)_{\mathrm{nonHC}}=\left(C_{i} w_{i}\right)_{\mathrm{nonHC}} /\left\{C_{\mathrm{HC}} w_{\mathrm{DME}}+\sum_{i}\left(C_{i} w_{i}\right)_{\mathrm{nonHC}}\right\} .
$$

Note, that normalization in Eqs. (17) and (18) affects mass fractions of all species. This is shown in Fig. 8. To derive corresponding elemental mass fractions, Eqs. (11) and (12) are split into two terms:

$Y_{\mathrm{C}}^{*}=Y_{\mathrm{C}_{\mathrm{nonHC}}}^{*}+Y_{\mathrm{CHC}_{\mathrm{HC}}}^{*}$

$Y_{\mathrm{H}}^{*}=Y_{\mathrm{H}_{\mathrm{nonHC}}}^{*}+Y_{\mathrm{H}_{\mathrm{HC}}}^{*}$.

For species emerging from the reaction mechanism by Zhao et al. the non-hydrocarbon part is provided by

$Y_{\mathrm{C}_{\mathrm{nonH}}}^{*}=Y_{\mathrm{C}_{\mathrm{CO}_{2}}}+Y_{\mathrm{C}}^{*}$

and

$Y_{\mathrm{H}_{\text {nonHC }}}^{*}=Y_{\mathrm{H}_{\mathrm{H}_{2}}}^{*}+Y_{\mathrm{H}_{\mathrm{H}_{2} \mathrm{O}}}^{*}+\left(Y_{\mathrm{H}_{\mathrm{OH}}}^{*}+Y_{\mathrm{H}_{\mathrm{H}}}^{*}+Y_{\mathrm{H}_{\mathrm{H}_{2}}}^{*}+Y_{\mathrm{H}_{\mathrm{H}_{2} \mathrm{O}_{2}}}^{*}\right)$.

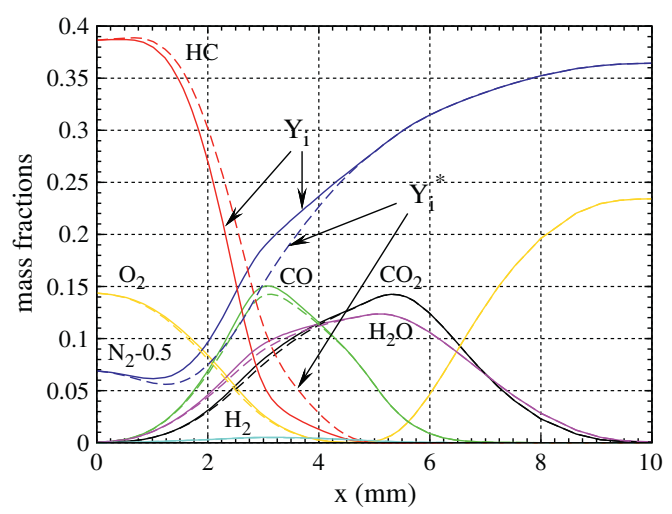

Fig. 8. Effect on species mass fractions due to the approximation (16) of using the molar mass of DME for all hydrocarbons. This molar mass and the resulting mass fraction is generally too high: $Y_{\mathrm{HC}}^{*} \geqslant Y_{\mathrm{HC}}$. Thus, all other species mass fractions are too small due to the normalization: $\left(Y_{i}\right)^{*}{ }_{\text {nonHc }} \leqslant\left(Y_{i}\right)_{\text {nonHc }}$. Based on a laminar calculation for L2 conditions, Tsuji geometry with $a=50 \mathrm{~s}^{-1}$, Zhao mechanism, and multi-component.

Minor species contributions to $Y_{\mathrm{H}_{\text {nontc }}}$ are summarized in parentheses. Their total contribution is small as will be shown in Section 3.6 below, and they are neglected. The hydrocarbon part reads

$Y_{\mathrm{C}_{\mathrm{HC}}}^{*}=2 Y_{\mathrm{HC}}^{*} w_{\mathrm{C}} / w_{\mathrm{DME}}$

and

$Y_{\mathrm{H}_{\mathrm{HC}}}^{*}=6 Y_{\mathrm{HC}}^{*} w_{\mathrm{H}} / w_{\mathrm{DME}}$.

Consistent with Eq. (16) numbers of $\mathrm{C}$ and $\mathrm{H}$ atoms are those for DME. Accordingly, corresponding atom ratios are also affected and denoted by $\mathrm{C}^{*} / \mathrm{H}^{*}, \mathrm{C}^{*} / \mathrm{O}^{*}$ and so forth. Species which contribute significantly in Eq. (17) to the cumulated mass fractions of hydrocarbons, $Y_{\mathrm{HC}}^{*}$, within Raman measurements in DME/air flames are discussed below. Finally, the adapted mixture fraction $F^{*}$ reads

$F^{*}=\frac{2\left(Y_{\mathrm{C}}^{*}-Y_{\mathrm{C}, 2}\right) / w_{\mathrm{C}}+\left(Y_{\mathrm{H}}^{*}-Y_{\mathrm{H}, 2}\right) / 2 w_{\mathrm{H}}}{2\left(Y_{\mathrm{C}, 1}-Y_{\mathrm{C}, 2}\right) / w_{\mathrm{C}}+\left(Y_{\mathrm{H}, 1}-Y_{\mathrm{H}, 2}\right) / 2 w_{\mathrm{H}}}$,

Clearly, the use of the adapted mass fractions $Y^{*}$ and the corresponding $F^{*}$ must be justified. First, this is the approach that is used in analyzing Raman/Rayleigh data from $\mathrm{CH}_{4}$ flames, where hydrocarbon intermediates have a much smaller influence on results. Second, species mass fractions and mixture fraction are quantities derived only in the post-processing; they are not used within the iterative evaluation of Raman/Rayleigh data. Third, because of lack of knowledge of individual intermediate hydrocarbon species concentrations, simplifying assumptions must be made. In order to keep the approach as simple as possible, the assumption (16) for the molar mass and the assumptions in Eqs. (23) and (24) for corresponding atom numbers are preferred to other conceivable approaches, such as taking the concentration-weighted molar masses from specific laminar flame calculations. Fourth, the differences $\Delta\left(F^{*}-F\right)$ seen below in Fig. 9 can be minimized by selecting an optimal number of intermediate hydrocarbon species within the entire evaluation procedure. This selection is presented in the next section. Finally, by applying the same method of post processing to both computational and experimental results, consistent quantitative comparisons can be carried out, as will be demonstrated in Section 4.3. Note that especially for comparison of species mass fractions this procedure is essential, as easily seen from the differences shown in Fig. 8. 


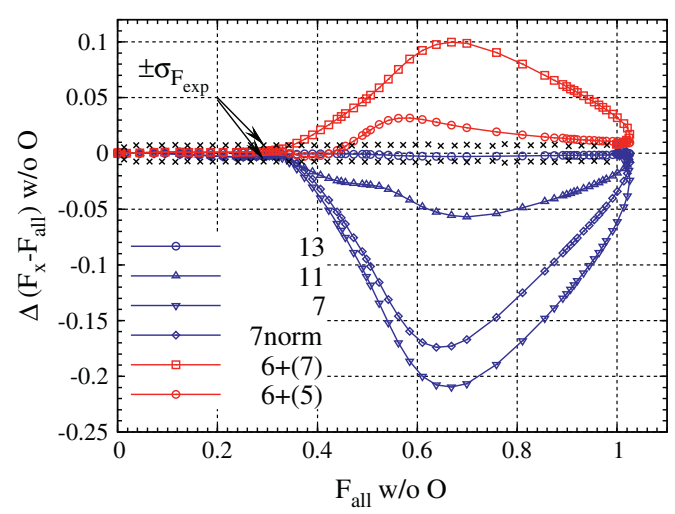

Fig. 9. Deviation of mixture fraction for cases $2 b, 2 d, 2 e, 2 f, 3 a$, and $3 b$ plotted vs. mixture fraction of the reference case. Crosses represent experimental precision of the mixture fraction in actual L2 experiments using on-chip binning.

\subsection{Impact of intermediates on mixture fraction determination}

Laminar flame results are now used to investigate the impact of different sets of hydrocarbon intermediates on the computed mixture fraction. Mixture fraction deviations are compared to a reference case, which is calculated from Eq. (10). Results are found similar for all laminar flame calculations used in this work and are presented for the Tsuji flame geometry using 28.1\% DME in air (L2 configuration), multi-component transport, and a strain rate of $a=50 \mathrm{~s}^{-1}$. The reference case is listed as case 1 in Table 4 . The case 'Bilger' in the second row refers to the original mixture fraction definition including oxygen [34] and all 55 chemical species in the Zhao mechanism. Cases $2 \mathrm{a}-\mathrm{f}$ refer to the mixture fraction definition from Eq. (10), excluding oxygen and progressively omitting the less significant hydrocarbon species. Elemental mass fractions are calculated from Eqs. (11) and (12) before insertion into Eq. (10). These cases 2 show the impact of particular species and from an experimental point of view they reflect a separate measurement of correct species mass fractions. A conclusion can be drawn regarding which species would be necessary to allow accurate mixture fraction measurements in DME/air flames.

1. Reference case using all 55 species mass fractions.

2. (a) 16 species mass fractions, $Y_{\mathrm{CO}_{2}}, Y_{\mathrm{O}_{2}}, Y_{\mathrm{CO}}, Y_{\mathrm{N}_{2}}, Y_{\mathrm{H}_{2} \mathrm{O}}, Y_{\mathrm{H}_{2}}$, $Y_{\text {DME }}, Y_{\mathrm{CH}_{4}}, Y_{\mathrm{CH}_{2} \mathrm{O}}, Y_{\mathrm{C}_{2} \mathrm{H}_{2}}, Y_{\mathrm{C}_{2} \mathrm{H}_{4}}, Y_{\mathrm{C}_{2} \mathrm{H}_{6}}, Y_{\mathrm{CH}_{3}}, Y_{\mathrm{OH}}, Y_{\mathrm{O}}, Y_{\mathrm{H}}$.

(b) 13 species, omitting $Y_{\mathrm{OH}}, Y_{\mathrm{O}}, Y_{\mathrm{H}}$ in 2a.

(c) 12 species, omitting $Y_{\mathrm{CH}_{3}}$ in $2 \mathrm{~b}$.

(d) 11 species, omitting $Y_{\mathrm{CH}_{2} \mathrm{O}}, Y_{\mathrm{C}_{2} \mathrm{H}_{2}}$ in $2 \mathrm{~b}$. (e) 7 species, omitting $Y_{\mathrm{CH}_{4}}, Y_{\mathrm{C}_{2} \mathrm{H}_{4}}, Y_{\mathrm{C}_{2} \mathrm{H}_{6}}, Y_{\mathrm{CH}_{3}}$ in $2 \mathrm{~d}$.

(f) 7 species, same as $2 \mathrm{e}$, but normalized to $\sum_{i=1}^{7} Y_{i}$.

Additionally, two cases $3 \mathrm{a}$ and $3 \mathrm{~b}$ are defined to mimic the actual experimental condition where fuel and intermediate hydrocarbons are cumulated in a single detection channel. Both cases require simplifying assumptions regarding the molar masses and atom numbers of intermediate hydrocarbons corresponding to the assumptions leading to the adapted mixture fraction $F^{*}$ given by Eq. (25). They are defined on the basis of mole fractions, which here is equivalent to the Raman-measured concentrations in Eqs. (17) and (18).

3. (a) 6+(7) species, $X_{\mathrm{CO}_{2}}, X_{\mathrm{O}_{2}}, \quad X_{\mathrm{CO}}, \quad X_{\mathrm{N}_{2}}, X_{\mathrm{H}_{2} \mathrm{O}}, X_{\mathrm{H}_{2}}$, $\left(X_{\mathrm{DME}}, X_{\mathrm{CH}_{4}}, X_{\mathrm{CH}_{2} \mathrm{O}}, X_{\mathrm{C}_{2} \mathrm{H}_{2}}, X_{\mathrm{C}_{2} \mathrm{H}_{4}}, X_{\mathrm{C}_{2} \mathrm{H}_{6}}, X_{\mathrm{CH}_{3}}\right)$.

(b) 6+(5) species, as above but omitting $X_{\mathrm{CH}_{2} \mathrm{O}}, X_{\mathrm{C}_{2} \mathrm{H}_{2}}$.

Case 3b, containing 6 non-HC species and 5 HC species, corresponds to the selection of species already introduced in Sections 3.2 and 3.3 above. Elemental mass fractions, Eqs. (19) and (20), were calculated from the species mass fractions, Eqs. (17) and (18), using mole fractions $X_{i}$ and employing the approximations (16), (23), and (24), which assign the molar mass and atom numbers of DME to all considered hydrocarbon intermediates. This simplification leads to differences between the corresponding cases $2 \mathrm{~b} \leftrightarrow 3 \mathrm{a}$ and $2 \mathrm{~d} \leftrightarrow 3 \mathrm{~b}$, despite of identical species considered.

Maximum differences of all cases relative to the reference case are summarized in Table 4 for selected measures as specified in the table caption. From cases 2 it turns out that the separate detection of twelve species of case $2 \mathrm{c}$ would suffice to allow mixture fraction and temperature measurements in the order of current measurement precisions. Further negligence of species leads to unacceptable distortions, i.e. for case $2 \mathrm{e}$ with just seven species of up to $\Delta F_{\max }=-0.2$ causing a $\Delta T_{\max }=-472 \mathrm{~K}$. Unacceptable distortions are also obtained for the cases $3 \mathrm{a}$ and $3 \mathrm{~b}$ due to the loss of information on particular hydrocarbons.

Figure 9 shows distortions of the mixture fraction with respect to the reference case for the entire mixture fraction space. Note that mixture fraction $F_{\text {all }}>1$ is accessed. This is a consequence of differential diffusion effects and is especially pronounced in the rich-premixed laminar configuration L1 (see Fig. 20). As expected, missing species in Eq. (10) cause the mixture fraction to go down. Deviations for 2e and 2f, using only 7 species, peak at -0.2 near $F_{\text {all }}=0.65$. The deviations are up to two orders of magnitude larger than in comparable flames of methane and extend over a wide range in fuel-rich conditions where significant intermediate hydrocarbons are present. Obviously, differences for all cases 2 decrease with increasing number of species considered. In case of 13 species (case $2 \mathrm{~b}$ ) the deviations are even below present experimental

Table 4

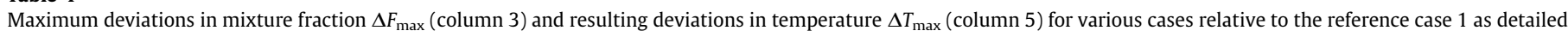

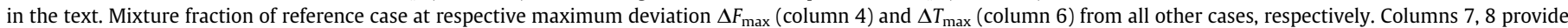
the minimum of sums of mass and columns 9, 10 minimum of mole fractions within the entire mixture fraction space.

\begin{tabular}{|c|c|c|c|c|c|c|c|c|c|}
\hline Case & No. species & $\Delta F_{\max }$ & $F_{\text {all }} @ \Delta F_{\max }$ & $\Delta T_{\max }(\mathrm{K})$ & $F_{\text {all }}, T @ \Delta T_{\max }$ & $\min \left(\sum_{i} Y_{i}\right) \mathrm{w} \mathrm{Ar}$ & $\min \left(\sum_{i} Y_{i}\right) \mathrm{w} / \mathrm{o} \mathrm{Ar}$ & $\min \left(\sum_{i} X_{i}\right) \mathrm{w} \mathrm{Ar}$ & $\min \left(\sum_{i} X_{i}\right) \mathrm{w} / \mathrm{o} \mathrm{Ar}$ \\
\hline 1, Bilger w/o 0 & All (55) & - & - & - & - & 1 & 0.987 & 1 & 0.991 \\
\hline Bilger & All $^{\mathrm{a}}$ & -0.0056 & 0.238 & 20 & $0.145,478$ & 1 & 0.987 & 1 & 0.991 \\
\hline $2 a$ & 16 & -0.0027 & 0.668 & -6 & $0.608,1382$ & 0.998 & 0.987 & 0.999 & 0.991 \\
\hline $2 b$ & 13 & -0.0032 & 0.251 & 11 & $0.289,1963$ & 0.994 & 0.983 & 0.988 & 0.980 \\
\hline $2 c$ & 12 & -0.0034 & 0.638 & 11 & $0.289,1963$ & 0.994 & 0.983 & 0.988 & 0.980 \\
\hline $2 d$ & 11 & -0.0569 & 0.699 & -130 & $0.998,516$ & 0.971 & 0.962 & 0.974 & 0.968 \\
\hline $2 e$ & 7 & -0.2097 & 0.668 & -472 & $0.492,1854$ & 0.935 & 0.926 & 0.920 & 0.914 \\
\hline $2 f$ & 7norm & -0.1741 & 0.638 & -394 & $0.611,1776$ & $1^{\mathrm{b}}$ & $1^{\mathrm{b}}$ & 0.920 & 0.914 \\
\hline $3 a$ & $6+(7)$ & 0.0997 & 0.668 & 170 & $1.037,531$ & $1^{\mathrm{c}}$ & $1^{\mathrm{c}}$ & 0.988 & 0.980 \\
\hline $3 b$ & $6+(5)$ & 0.0318 & 0.584 & 99 & $1.022,461$ & $1^{\mathrm{c}}$ & $1^{\mathrm{c}}$ & 0.974 & 0.968 \\
\hline
\end{tabular}

a Using the definition by Bilger et al. [34].

b Sum of mass fractions is that from 7, but renormalized.

c Mass fractions are calculated based on mole fractions, this implicates renormalization. 

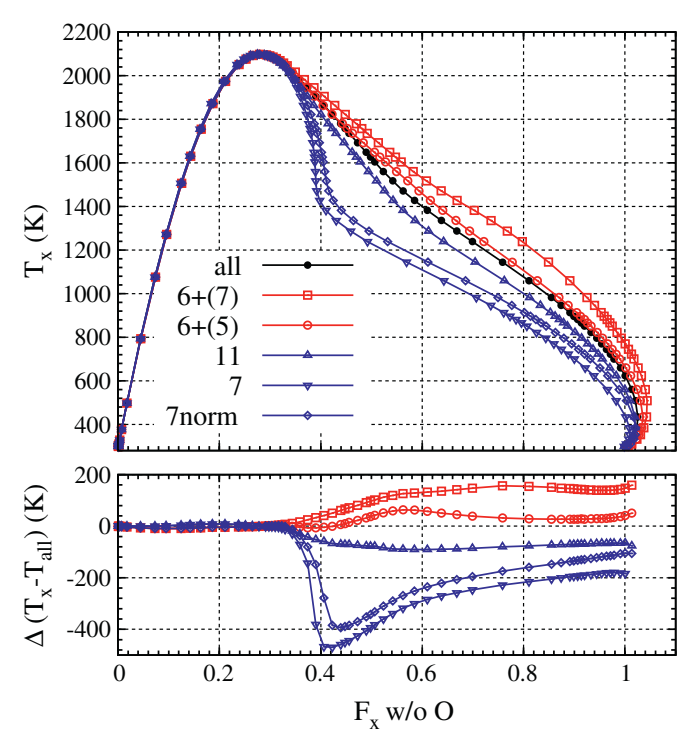

Fig. 10. Impact of differences in the mixture fraction calculation on scalars, exemplified here for temperature. Closed circles denote the reference case 1 using Eq. (10) and including all species. Blue curves shifted to the left relative to the reference case show the influence of neglecting species in Eq. (10). Red curves represent the adapted mixture fraction calculation defined by Eq. (25). (For interpretation of the references to colour in this figure legend, the reader is referred to the web version of this article.)

precision denoted by $\sigma_{\mathrm{F}, \exp }$ (crosses in Fig. 9). This is still satisfied for the case of 12 species (2c) but is not shown. Cases 3a and 3b, which represent the actual experimental situation, exhibit deviations from $F_{\text {all }}$ exceeding experimental uncertainties. In contrast to the cases 2 , cases $3 \mathrm{a}$ and $3 \mathrm{~b}$ show an overestimation of the mixture fraction and decreasing deviation with decreasing number of species considered. Closer agreement between $F_{\text {all }}$ and $F_{6+(5) \text { species }}^{*}$ is favourable and even provides a benefit of the exclusion of $\mathrm{C}_{2} \mathrm{H}_{2}$ and $\mathrm{CH}_{2} \mathrm{O}$ from the processing of the Raman response.

A distortion of the mixture fraction coordinate impacts correspondingly the scalar profiles in mixture fraction space. This is shown for temperature in Fig. 10. The temperature of the reference case 1 is plotted versus its mixture fraction $F_{\text {all }}$. Cases $2 \mathrm{~d}, 2 \mathrm{e}, 2 \mathrm{f}, 3 \mathrm{a}$, and $3 \mathrm{~b}$ are compared to the reference case. As mentioned already, apparent deviations $\Delta T$ are due to a distortion of the mixture fraction coordinate and can reach up to $500 \mathrm{~K}$ depending on case and mixture fraction. The case $3 \mathrm{~b}$ selected in previous sections shows the smallest deviation.

\subsection{Summary on sensitivity analysis of the mixture fraction calculation}

The starting point for the sensitivity analysis was that Raman signals of intermediate hydrocarbons and fuel spectrally overlap and are cumulated into a single detection channel in the context of the matrix inversion method. Consequently, the local composition of intermediate hydrocarbons cannot be determined directly from the experiments. Thus, using laminar flame calculations two different approaches were conceived to judge on the importance of particular hydrocarbon intermediates regarding the calculation of the mixture fraction. First, contributions of twelve species mass fractions are found to impact the mixture fraction significantly. Second, hydrocarbon mole fractions are summarized in $X_{\mathrm{HC}}$, reflecting the actual experimental conditions. Instead of species-specific molar masses and atom numbers those of DME were used for the following conversion from species mole fractions to mixture fraction. These assumptions distort the calculated mixture fraction. To account for the difference, the adapted mixture fraction $F^{*}$ was introduced. In consistence with conclusions from Sections 3.2 and 3.3, a case of $6+(5)$ species $\left(\mathrm{CO}_{2}, \mathrm{O}_{2}, \mathrm{CO}, \mathrm{N}_{2}\right.$, $\left.\mathrm{H}_{2} \mathrm{O}, \mathrm{H}_{2}\right)+\left(\right.$ DME, $\mathrm{CH}_{4}, \mathrm{C}_{2} \mathrm{H}_{4}, \mathrm{C}_{2} \mathrm{H}_{6}$, and $\left.\mathrm{CH}_{3}\right)$ was investigated and found to yield smaller deviations in mixture fraction $\Delta\left(F_{\text {all }}-F_{6+(5) \text { species }}^{*}\right)$ than the case including all significant hydrocarbons. However, remaining differences are still too high to be ignored. Therefore, all plots in mixture fraction space shown in Section 4 are based on $F^{*}=F_{6+(5) \text { species }}^{*}$ rather than $F_{\text {all }}$. This adapted mixture fraction is proposed as an appropriate basis for comparison of Raman/Rayleigh measurements with both laminar calculations and turbulent combustion modeling results. That is, mixture fraction should be calculated from the modeled species results using the adapted $F^{*}$ definition before comparison with experimental results in mixture fraction space.

\section{Results and discussion}

This part is composed of three sections. Section 4.1 provides the temperature dependent Raman response and crosstalk curves essential for the data evaluation. In Section 4.2 important corrections of broadband and $\mathrm{C}_{2}$-LIF interferences are discussed. Finally, Section 4.3 shows results of laminar and turbulent DME/air flames for the mixture compositions provided in Section 2.2.

\subsection{Hydrocarbon Raman response and crosstalk curves}

In conclusions from Section 3 the Raman scattering from DME/ air flames detected on the seven species-channels is treated as being composed of $6+(5)$ species. The signal of the hydrocarbon channel is composed of contributions from DME, $\mathrm{CH}_{4}, \mathrm{C}_{2} \mathrm{H}_{4}, \mathrm{C}_{2} \mathrm{H}_{6}$, and $\mathrm{CH}_{3}$. This is labeled DME $+4 \mathrm{HCs}$ in the following. In the matrix inversion method diagonal elements represent the temperature dependent Raman responses of the species $\mathrm{CO}_{2}, \mathrm{O}_{2}, \mathrm{CO}, \mathrm{N}_{2}, \mathrm{H}_{2} \mathrm{O}$, $\mathrm{H}_{2}$, and DME $+4 \mathrm{HCs}$. The Raman response from the DME $+4 \mathrm{HCs}$ channel is calculated using Eq. (4) with information taken from the laminar flame calculation and the relative Raman signal intensities from calibration measurements. Off-diagonal elements represent the crosstalk caused by spectral overlap. Crosstalk is denoted here by ' $\mathrm{X} \leftarrow \mathrm{Y}$ '. For example, $\mathrm{CO}_{2}$ crosstalk onto the $\mathrm{O}_{2}$ channel is denoted $\mathrm{O}_{2} \leftarrow \mathrm{CO}_{2}$.

Calculation of temperature-dependent rovibrational Raman spectra of hydrocarbon species such as DME, $\mathrm{CH}_{4}, \mathrm{C}_{2} \mathrm{H}_{4}$, or $\mathrm{C}_{2} \mathrm{H}_{6}$, from first principles is not available or not sufficiently accurate to replace calibration measurements. For this reason relative Raman signal intensities within the hydrocarbon channel are extracted from Raman measurements in electrically heated gas mixtures. The temperature accessed is limited to the range between $295 \mathrm{~K}$ and $820 \mathrm{~K}$. For temperatures exceeding $820 \mathrm{~K}$ relative Raman signal intensities are extrapolated linearly to $2500 \mathrm{~K}$. Four different mixtures of $9 \%$ hydrocarbon in nitrogen, DME/ $\mathrm{N}_{2}, \mathrm{CH}_{4} /$ $\mathrm{N}_{2}, \mathrm{C}_{2} \mathrm{H}_{4} / \mathrm{N}_{2}, \mathrm{C}_{2} \mathrm{H}_{6} / \mathrm{N}_{2}$, were investigated and Raman signal intensities were measured for the entire spectral range $\left(720-4600 \mathrm{~cm}^{-1}\right)$ that is monitored in the experiment. Contributions from individual hydrocarbon species onto the hydrocarbon channel and all other species channels (crosstalk) were thereby quantified.

To assess the possibility of thermal decomposition of DME in the heating process a computation of pyrolysis of the same DME/ $\mathrm{N}_{2}$ mixture was conducted using the plug flow reactor code by Lutz et al. [35]. Results for the three highest temperatures are shown in Fig. 11. For experimental-like residence times of mostly $0.15 \mathrm{~s}$ pyrolysis is just starting at $900 \mathrm{~K}$ (loss in $\left.X_{\mathrm{DME}}<0.001\right)$. To further ensure that no pyrolysis locally occured near the heating elements, the Raman channels of two products of the pyrolysis, $\mathrm{CO}$ and $\mathrm{H}_{2}$, were carefully monitored where no evidence of pyrolysis was found either. However, small parts of methane and formaldehyde 

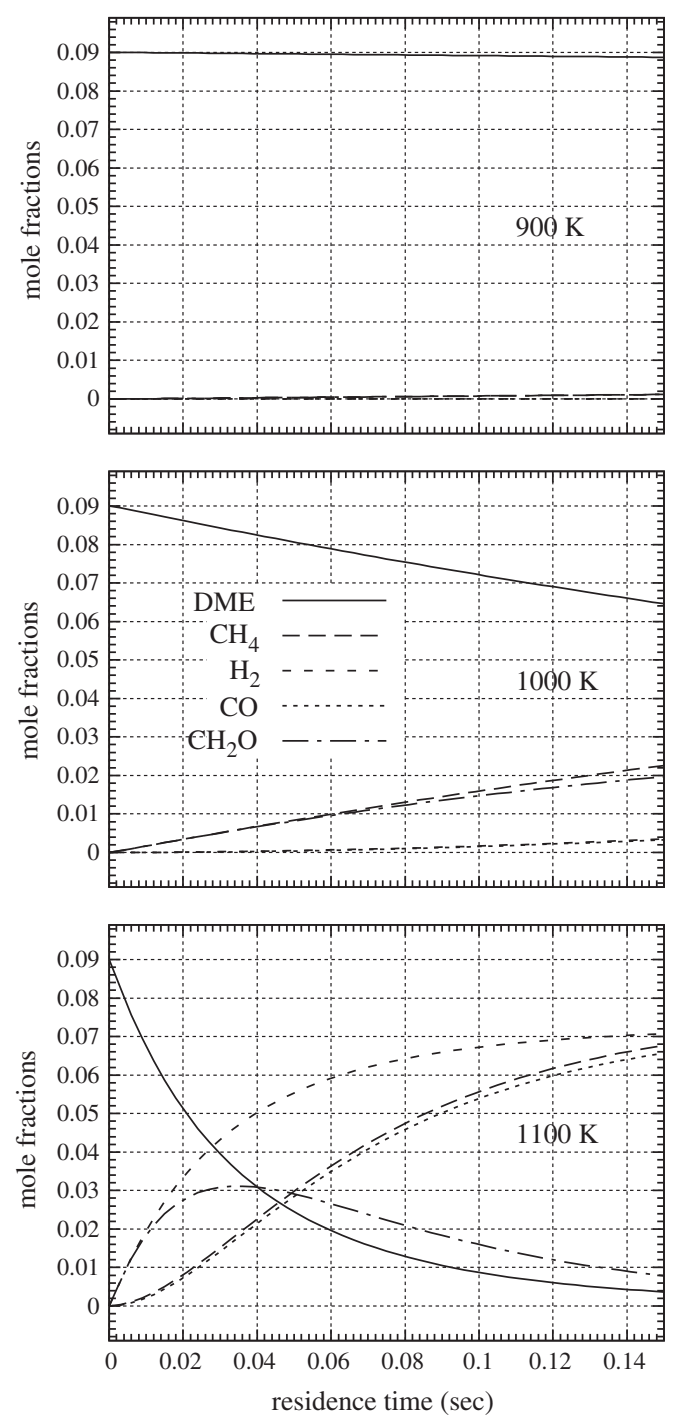

Fig. 11. Computation of thermal decomposition of DME in a flow plug reactor.

cannot be distinguished from DME in the Raman spectrum due to spectral overlap. Hence, a small uncertainty of approximately $2 \%$ in the measured Raman signal from DME at $820 \mathrm{~K}$ is left.

For all strips the relative Raman signal from $\mathrm{CH}_{3}$ is treated as one quarter of the $\mathrm{CH}_{4}$ response $\left(0.25 \times I_{\mathrm{Ram}_{\mathrm{CH}}}\right)$ following the findings in Hädrich et al. [36]. In contrast to the response curves shown in Fig. 4, linear extrapolation of Raman responses and an accounting for the effect of optical bowing [21], illustrated in Fig. B.24, are applied for each species before summing up the hydrocarbon contributions to the final response curves using Eq. (4). Apart from the bowing effect, the resulting difference between the curves in Fig. 4 (based on constant integrated Raman signal ratios) and those computed here using elaborated temperature dependencies for each species, is rather small $(<5 \%$, maximum at $1400 \mathrm{~K}$ ). This small difference is a good indication of the hydrocarbon response curve being dominated by the mixing process of species and not by unknown Raman signal intensities at higher temperatures. Especially for temperatures above $1400 \mathrm{~K}$, the relative importance of this response curve is attenuated due to upcoming LIF-interferences. The amount of hydrocarbons, which are finally measured, is then dominated by the accuracy of the LIF-interference correction.

Starting with the reference strip 37 (bowing center), Fig. 12 shows the Raman response curve for the hydrocarbon channel
$\mathrm{DME}+4 \mathrm{HCs}$ and the most important crosstalk curves, $\mathrm{CO}_{2} \leftarrow \mathrm{D}-$ $\mathrm{ME}+4 \mathrm{HCs}, \mathrm{O}_{2} \leftarrow \mathrm{DME}+4 \mathrm{HCs}$, and $\mathrm{F} 560 \leftarrow \mathrm{DME}+4 \mathrm{HCs}$, derived using on-chip binning. Smaller crosstalk contributions from $\mathrm{N}_{2} \leftarrow \mathrm{DME}+4 \mathrm{HCs}$ and $\mathrm{CO} \leftarrow \mathrm{DME}+4 \mathrm{HCs}$ were found at low temperatures and were corrected without temperature dependence. Other hydrocarbon-specific crosstalk curves are of less importance and taken from previous methane-air flame investigations (see Appendix $\mathrm{C}$ ). Note that for $\mathrm{CO}_{2} \leftarrow \mathrm{DME}+4 \mathrm{HCs}$ and $\mathrm{O}_{2} \leftarrow \mathrm{DME}+$ $4 \mathrm{HCs}$ two sets of curves are shown. The upper ones were adjusted for temperature exceeding $820 \mathrm{~K}$ and account for possible errors introduced by the extrapolation of the crosstalk-response to higher temperatures, additional broadband interferences, that are missed in the F560-channel (see next section), or differences between the species composition of the underlying 1D-calculation and those from the measured jet flame. These corrections are justified by better matching experimental results with laminar flame calculations as shown in Appendix D. The high importance of these crosstalks is demonstrated in Fig. 16. For example at the fuel-rich side of the flame the crosstalk from DME on $\mathrm{O}_{2}$ is as high as the signal from $\mathrm{O}_{2}$ itself.

The spectrometer dispersing the Raman bands has a short focal length, which leads to optical bowing of the image of the entrance slit and laser beam [21]. In consequence Raman bands shift relative to rectangular regions of hardware binning (see Fig. B.24) causing space-dependent variations in all response and crosstalk curves $p_{i j}(T)$ in Eq. (1). Whereas for diatomic species, $\mathrm{CO}_{2}$, and $\mathrm{H}_{2} \mathrm{O}$, these bowing effects can be accounted for by calculations [21], hydrocarbon species still must be treated empirically. First, the effect of optical bowing is separated from the response and crosstalk characteristics. This is expressed by

$\left[p_{i j}(T)\right]_{k}=\left[p_{i j}(T)\right]_{37}^{\text {hardware-binned }} \circ\left[\left(f_{\text {bowing }}\right)_{i j}(T)\right]_{k}^{\text {software-binned }}$,

where the index $k$ embraces all strip numbers from 1 to 60 . In order to take advantage of lower readout noise from hardware-binned data the temperature dependence of curve $p_{i j}$ is determined from measured Raman signal intensities from hardware-binned data at the bowing center on strip 37. The same measurements on strip 37 from spectrally resolved data are used to determine the stripdependent variations in the measured Raman signal intensities for the corresponding shift on strip $k$. The resulting correction functions $f_{\text {bowing }}$ were already implied in Fig. 12 and are shown explicitly in Fig. 13.

\subsection{Broadband and $C_{2}$ interferences}

A spectrally flat background was determined around $4300 \mathrm{~cm}^{-1}$ (b3) and was subtracted from all Raman channels. In addition, at rich mixture composition in hydrocarbon-air flames, a variety of intermediate species and diatomic $C_{2}$ are formed. These intermediate species are excited by $532-\mathrm{nm}$ radiation and give rise to fluorescence signals interfering with rovibrational Raman bands and rotational $\mathrm{H}_{2}$ Raman lines. These interferences are monitored by an additional channel located near $560 \mathrm{~nm}$ (F560 channel spanning from $\sim 730$ to $1100 \mathrm{~cm}^{-1}$ in the Raman spectrum). Temperature and bowing dependencies of the corresponding crosstalks were treated empirically.

First, to demonstrate the significance of the LIF interferences, Fig. 14 shows the temperature dependent signal cumulated in the F560 channel for both laminar and turbulent flames. These interferences impact the Raman responses over a wide temperature range above $1000 \mathrm{~K}$ with a peak between 1600 and $1700 \mathrm{~K}$ dependent on the mixture composition. Small scatter for the laminar cases are self-evident, but the large scatter in both turbulent cases with a wide spread of interfering signal intensities for temperatures above $1000 \mathrm{~K}$ indicates intense turbulence-chemistry 

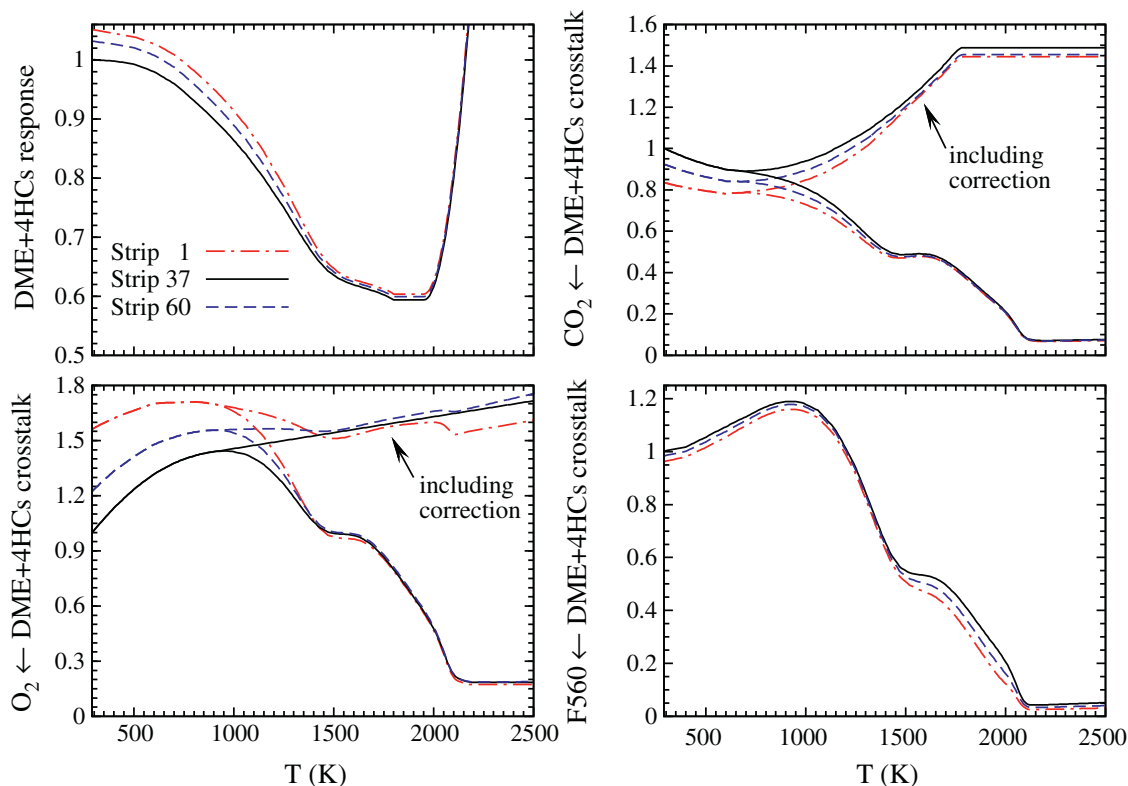

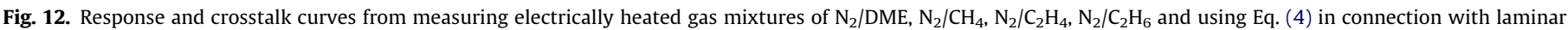

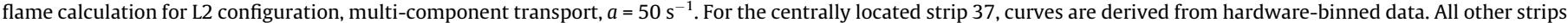
are corrected for bowing effects relative to strip 37 using spectrally resolved data.
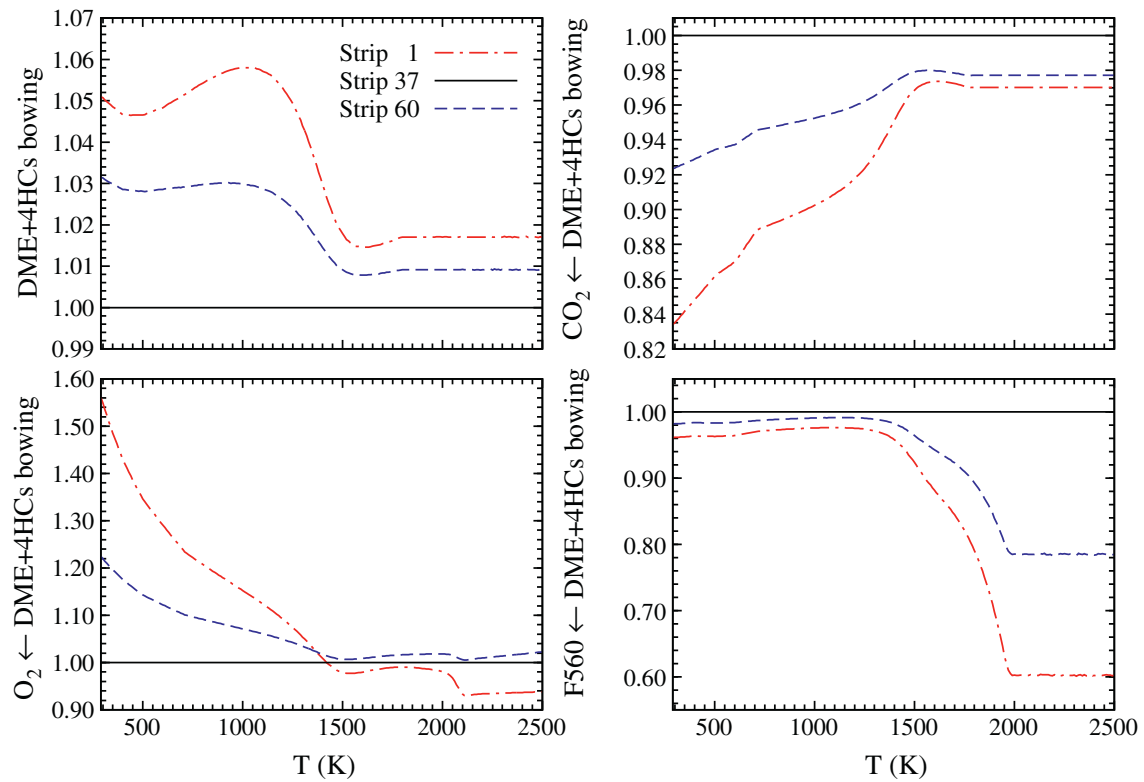

Fig. 13. Bowing correction vs. temperature of $\mathrm{DME}+4 \mathrm{HCs}$ response and its crosstalks relative to the center strip 37 .

interactions. For comparison, a laminar jet with a mixture of 25/ 75 vol.\% methane/air has a count level of 340 and a mixture of $44 / 54$ vol.\% methane/air a level of 1000 (not shown). This is slightly smaller than in corresponding DME/air mixtures, but still very close and one of the main reasons DME is considered a relatively Raman-friendly hydrocarbon fuel. However, the crosstalk of LIF interferences at temperatures exceeding $1000 \mathrm{~K}$ is significant and must be accounted for. The peak is located near $1650 \mathrm{~K}$. The highest signals are found in the turbulent T2 case of up to 900 , where on average the mixture composition of $28.1 \%$ DME in air (L2 configuration) generates the highest LIF interference signals of about 650 at the F560 channel. This signal corresponds to 31.000 photoelectrons $\mathrm{e}^{-}\left(\sigma_{\text {shot-noise }}=176 \mathrm{e}^{-}\right.$or $\left.0.6 \%\right)$. The crosstalk onto the $\mathrm{N}_{2}$ channel for these specific conditions contributes by approximately $3450 \mathrm{e}^{-}$, which corresponds to almost half of the total signal of $7000 \mathrm{e}^{-}$.

The dependence of F560 response on temperature and the associated important crosstalk curves are plotted in Fig. 15 for central strip 37 and the most exterior strips 1 and 60, respectively. The bowing effect at the F560 response crosstalk curve is accounted for by using a similar approach as described in Section 4.1. Temperature dependencies for particular channels were derived from comparison with laminar calculations in physical, temperature, and mixture fraction space. To provide reasonable agreement of the same measurements at inner and outer strips, linearly increasing $\left(\mathrm{O}_{2}, \mathrm{CO}\right)$ or decreasing $\left(\mathrm{N}_{2}\right)$ bowing corrections were introduced. Neither temperature- nor strip-dependence was found for $\mathrm{H}_{2}$ at all. 


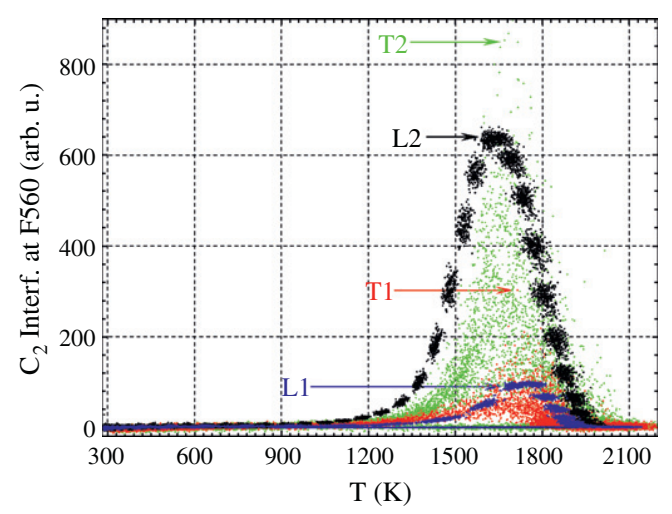

Fig. 14. LIF signal cumulated in the F560 channel from mostly diatomic $C_{2}$ following excitation at $532 \mathrm{~nm}$ in different laminar and turbulent DME/air flames.

Based on the temperature dependent Raman responses and crosstalk curves from Figs. 15 and 16 provide a survey of the relative crosstalk contributions (from 100-shot average at most interesting position in the L2 flame, centered at $r=4.5 \mathrm{~mm}$ ) for selected channels in physical space marks, with non-linearly mapped temperature and mixture fraction coordinates also displayed. Examining the L2 configuration at the maximum signal level in the F560 channel, the crosstalk contributions from various species compared to the Raman signal from the corresponding molecule are: (1) at the $\mathrm{N}_{2}$ channel $100 \%$, (2) $30 \%$ at the $\mathrm{CO}_{2}$ channel, (3) $300 \%$ at the CO channel, (4) $400 \%$ at the DME channel, (5) $35 \%$ at the $\mathrm{H}_{2} \mathrm{O}$ channel, and (6) $100 \%$ at the $\mathrm{H}_{2}$ channel. Around $1850 \mathrm{~K}$ almost no oxygen is left and the crosstalk dominates completely. Since the crosstalk impact of the LIF interferences decreases with decreasing fractions of DME in air (see Fig. 14), just small deviations from a linear dependence on the signal measured at
F560 is found between the L1 and L2 cases. Hence, a correspondingly smaller crosstalk is observed in the L1 case (11.4\% DME in air) at the thermo-chemical state with highest F560 impact. The CO channel is influenced by $50 \%$ LIF interferences or the DME + 4HCs channel by up to $40 \%$.

\subsection{Results of laminar and turbulent DME/air flame measurements}

The entire procedure discussed so far is now shown in its application by evaluating spatially resolved 1D Raman/Rayleigh data collected from the two laminar (L1, L2) and two turbulent DME/ air flames (T2, T1) at mixture compositions given in Tables 2 and 3. Overall good agreement and remaining deviations between measurements and laminar calculations are discussed below. Figure 17 shows results for the case $\mathrm{L} 2$ in physical space. The radial profile spans $13.5 \mathrm{~mm}$ and is composed of three line-imaged Raman/Rayleigh/CO-LIF measurement positions $r=0,4.5,7.5 \mathrm{~mm}$ resulting in 1.5 and $3 \mathrm{~mm}$ spatial overlap between adjacent probe volume locations. Generally, 100 shots were recorded at each position, at the most interesting position $r=4.5 \mathrm{~mm}$ two sets of 100 shots were taken. For comparison in physical space the laminar calculation at strain rate $a=50 \mathrm{~s}^{-1}$ (multi-component transport) yields best agreement in the width of the measured temperature profiles.

Overall the agreement between laminar flame calculations and experimental data using the post-processing discussed above is very good. This holds true as well for the hydrocarbons at the DME + 4HCs channel. The measured peak temperature is lower than the computed peak by $60 \mathrm{~K}$. About $45 \mathrm{~K}$ are caused by negligence of radiation in the simulations, another $10 \mathrm{~K}$ by not accounting for $35 \%$ relative humidity ( 0.007 mole fractions) in the co-flowing air-stream apparent in the experiments, and a mismatch of $10 \mathrm{~K}$ at the inflow boundaries (290 K measured but $300 \mathrm{~K}$ in the calculation), which is equivalent to $\sim 5 \mathrm{~K}$ in $T_{\text {max }}$. Deviations
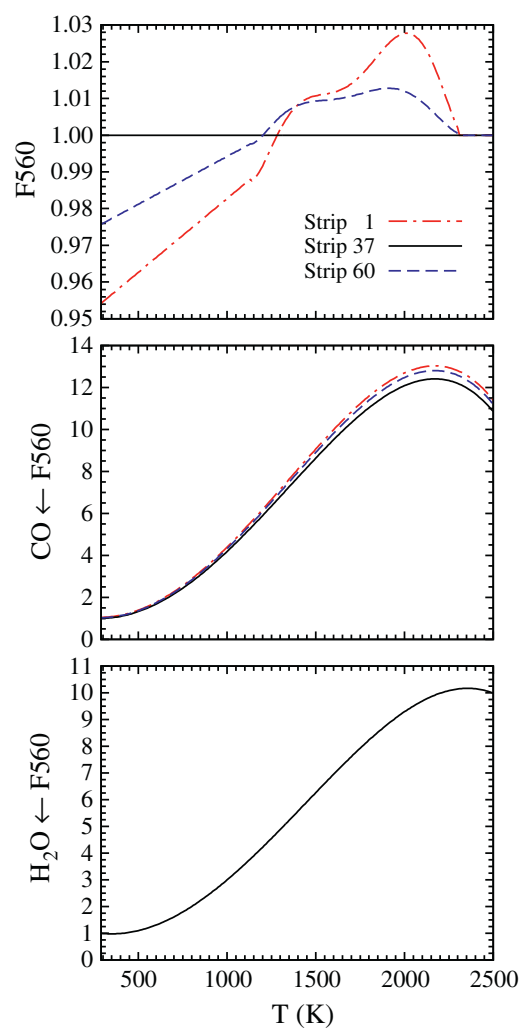
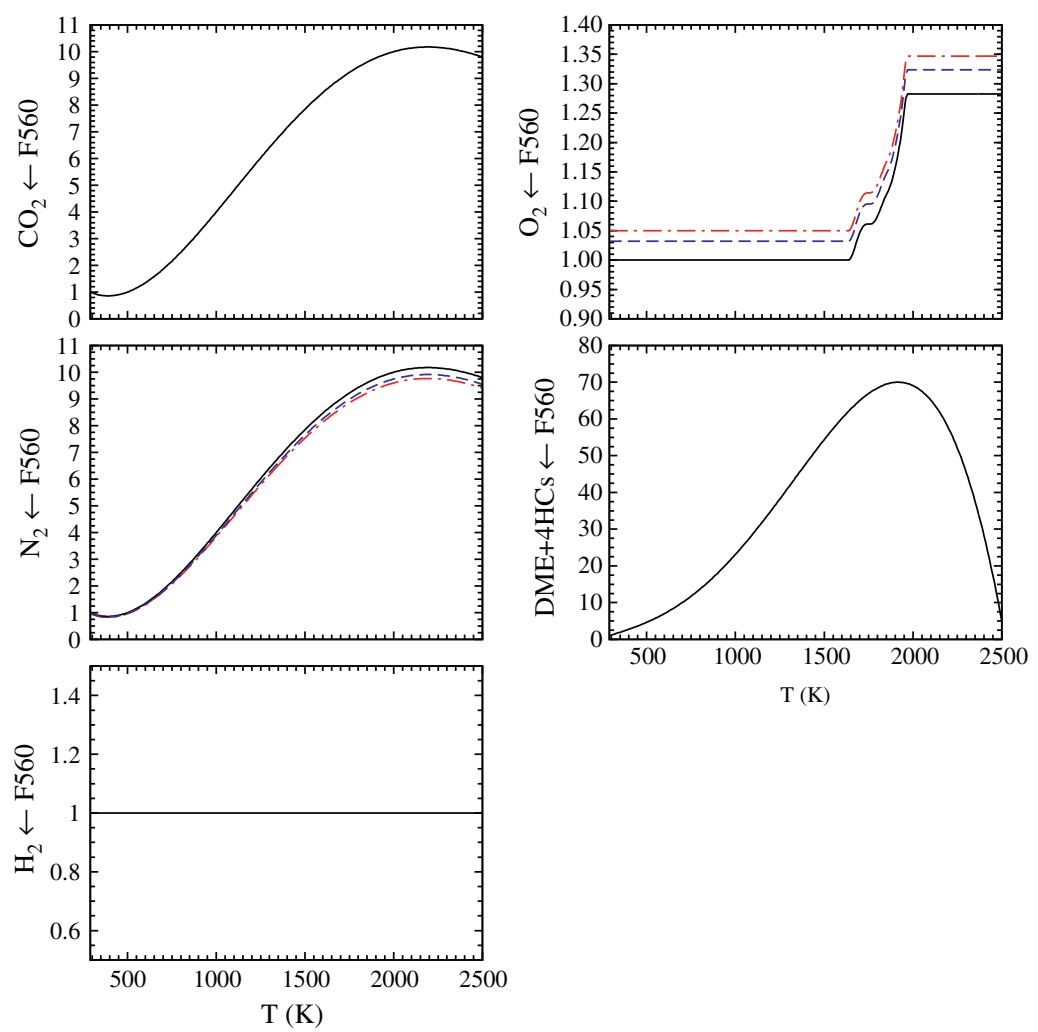

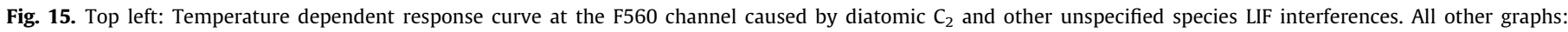
Corresponding crosstalk curves accounting for the impact of LIF interference on the respective Raman channel. 

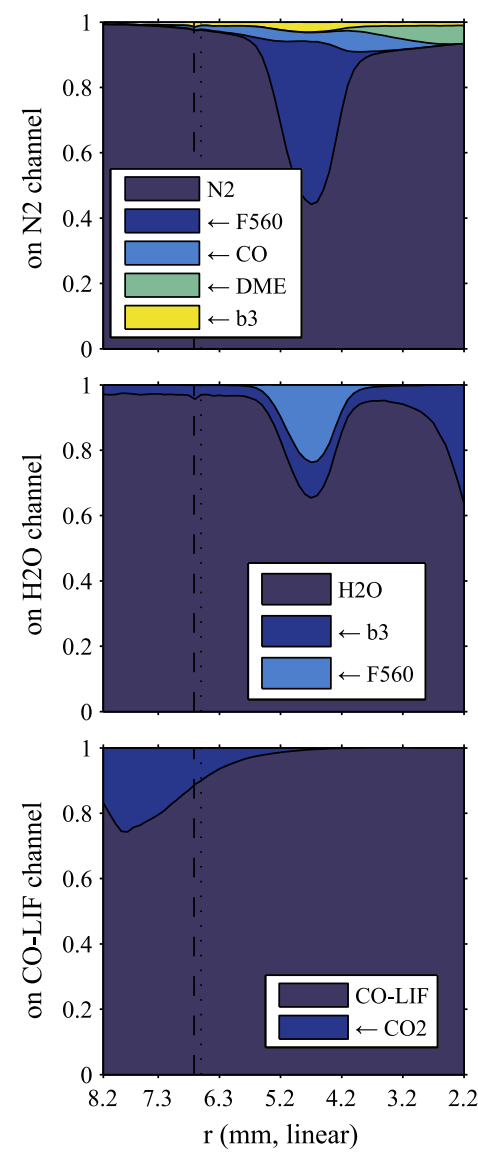
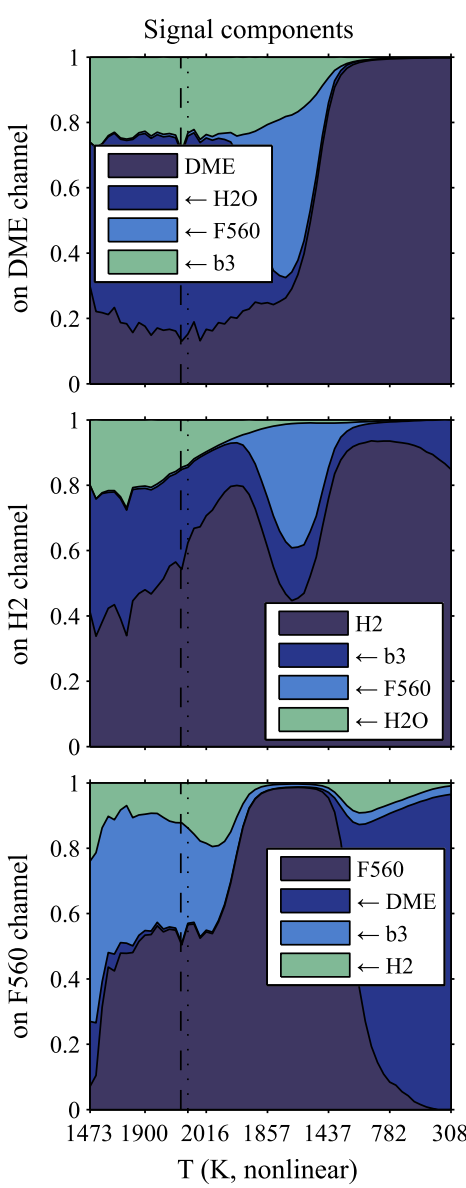
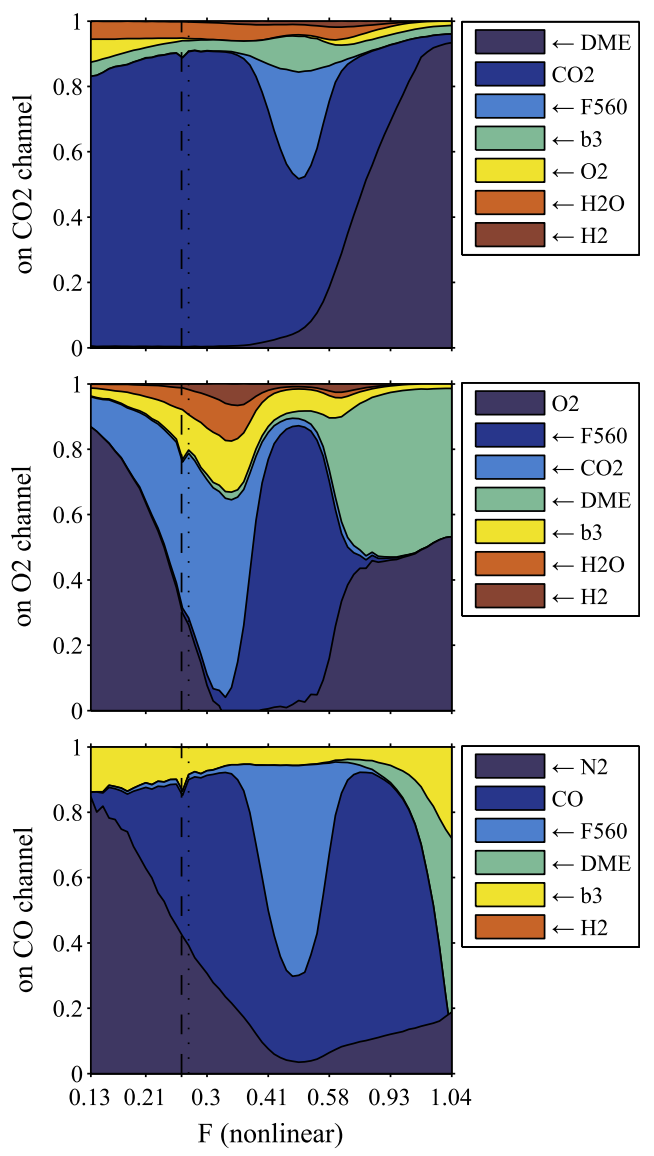

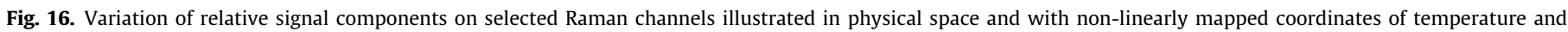

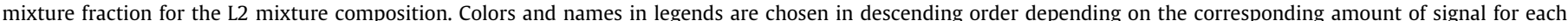

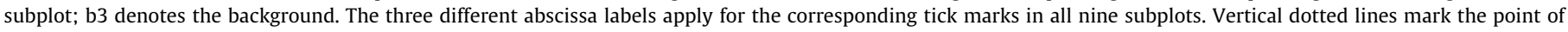
maximum temperature $(2030 \mathrm{~K})$. Dashed lines mark the stoichiometric mixture fraction $\left(F_{\mathrm{st}}=0.26\right)$.

in gradients at the rich side, particularly in the temperature, $\mathrm{O}_{2}$, DME $+4 \mathrm{HCs}$, or $\mathrm{H}_{2} \mathrm{O}$ profiles apparent at $r=0-2 \mathrm{~mm}$ are due to specifics of the calculation in Tsuji geometry, which are not precisely comparable to those present in the jet flame. Deviations at the right lean boundary, i.e. $\mathrm{N} / \mathrm{O}^{*}$ profile, are partly attributed to the missing water in the calculation.

Maximum interferences measured on the F560 channel are at $r=4.75 \mathrm{~mm}$, and interference on the Raman channels is generally well compensated for in the resulting species mole fractions. Slight deviations at the overlapping positions between the data from the three different measurement locations occur. This is attributed to variations in the index of refraction field causing different out-offocus effects at both ends of the line segment at different positions. This effect was accounted for in the throughput-normalizations of DME, $\mathrm{O}_{2}$ and $\mathrm{N}_{2}$ by a linear correction of up to $-1.2 \%,+2.1 \%$, and $+1.7 \%$, respectively. Mole fractions of $\mathrm{CO}$ and $\mathrm{CO}_{2}$ as well as the $\mathrm{C}^{*} / \mathrm{H}^{*}$ ratio are generally higher in the experiment. A similar trend is observed in the L1 configuration as well (Figs. 19 and 20), which may also be due to the use of $1 \mathrm{D}$ opposed flow calculations to approximate the scalar structure of a 2D laminar jet flame.

Results from the same L2 measurements are shown in mixture fraction space $F^{*}$ in Fig. 18, with the addition of temperature calculated from total number density and the measured laboratory pressure, the ratio of the two measured temperatures, and the differential diffusion parameter from Barlow et al. [8]. Here $z^{*}$ adapted to $F^{*}$, such that

$z^{*}=F_{\mathrm{H}}^{*}-F_{\mathrm{C}}^{*}$ where

$F_{\mathrm{H}}^{*}=\frac{Y_{\mathrm{H}}^{*}-Y_{\mathrm{H}, 2}^{*}}{Y_{\mathrm{H}, 1}-Y_{\mathrm{H}, 2}} \quad$ and $\quad F_{\mathrm{C}}^{*}=\frac{Y_{\mathrm{C}}^{*}-Y_{\mathrm{C}, 2}^{*}}{Y_{\mathrm{C}, 1}-Y_{\mathrm{C}, 2}}$

are local elemental mixture fractions based on hydrogen and carbon and subscripts 1 and 2 refer to the inflow conditions of the main jet and co-flowing air stream, respectively.

Due to the large amount of molecular hydrogen (twice that in methane/air flames), differential molecular diffusion is prominent in DME/air flames. Conditional average values are very close to the prediction by the laminar calculation assuming the detection of five hydrocarbon species. This provides additional confidence in the applied Rayleigh cross-section model as well as the correctness of the temperature dependence of all Raman response- and crosstalk-curves. Note that conditional averages are omitted for values of $F^{*}$ greater than unity, which result from strong differential diffusion effects in these laminar DME/air flames. Good agreement in the profile of the molecular diffusion parameter $z^{*}$ is observed over the entire mixture fraction space, but underpredicted significantly between $F^{*}=0.4$ and 0.6 , which is consistent with the deviation in the $\mathrm{C}^{*} / \mathrm{H}^{*}$ ratio.

All plots include simulated profiles for $6+(7)$ species (blue line), including $\mathrm{C}_{2} \mathrm{H}_{2}$ and $\mathrm{CH}_{2} \mathrm{O}$ and using the corresponding $F^{*}$ for $6+(7)$ species following the procedure in Section 3.6. However, better matching is obtained with the profiles comprising $6+(5)$ species. The mismatch of the simulation considering $6+(7)$ species 

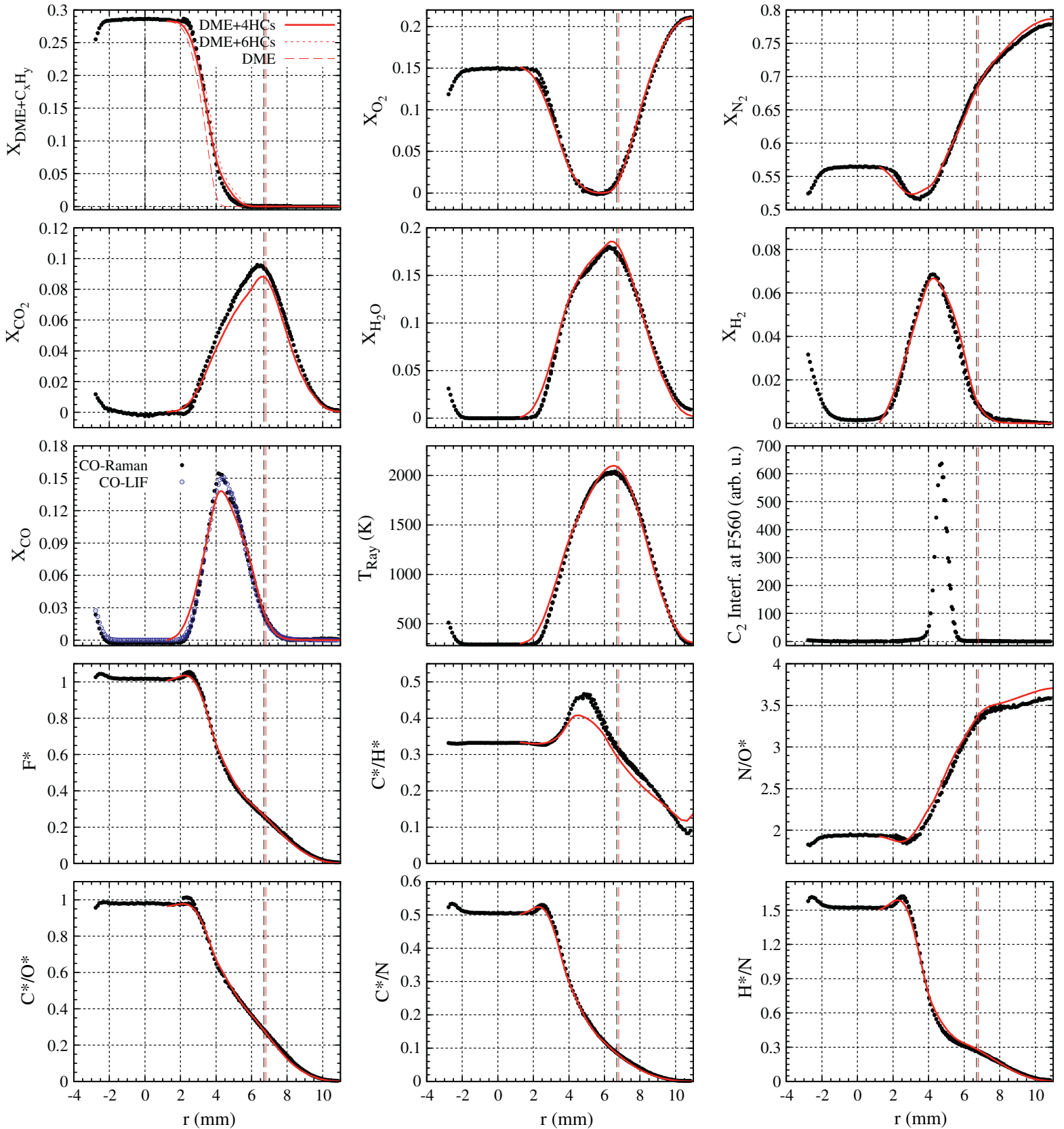

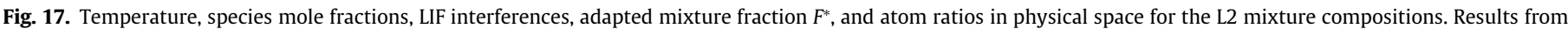

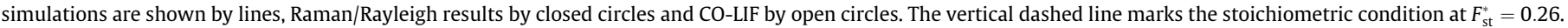

exemplifies the concentration difference due to the additional contributions from $\mathrm{C}_{2} \mathrm{H}_{2}$ and $\mathrm{CH}_{2} \mathrm{O}$.

LIF interferences in the L2 flame are most prominent for mixture fractions in the range of $0.4<F^{*}<0.6$. Large scatter is observed in this range, especially for $\mathrm{O}_{2}$, and is attributed to inherent photon shot-noise of the $\mathrm{O}_{2} \leftarrow \mathrm{F} 560$ crosstalk. Obviously, all atom ratios shown in the bottom line are less sensitive to any of the differences described above. Nearly perfect agreement between calculation and experiment is observed. The impact of the corrections of the crosstalk functions $\mathrm{CO}_{2} \leftarrow \mathrm{DME}+4 \mathrm{HCs}$ and $\mathrm{O}_{2} \leftarrow \mathrm{DME}+4 \mathrm{HCs}$ described in Section 4.1 was investigated and is discussed in the Appendix D.

Similarly, the premixed Bunsen configuration L1 is examined. Data were acquired at positions $r=0,3,6 \mathrm{~mm}$ corresponding to $3 \mathrm{~mm}$ overlap of the $6-\mathrm{mm}$ probe volumes. The flame structure is dominated by a central premixed cone. Accordingly, gradients in the reaction zone located around $r=2.5 \mathrm{~mm}$ are much steeper than for the L2 case. This poses high standards for precise Raman measurement at very high spatial resolution. Figures 19 and 20 show experimental results in comparison to laminar flame calculations in physical space and mixture fraction space $F^{*}$, respectively. The laminar flame calculation shown in this comparison is from the opposed jet geometry, with $a=50 \mathrm{~s}^{-1}$ using Zhao et al. mechanism, and multi-component transport. Perfect agreement between experiments and calculations is not expected, due to differences between jet and opposed-flow geometries and also because of the expected high sensitivity of the premixed reaction zone location to radiation as shown by Barlow et al. [19] for laminar methane/air flames, which is not included in the calculation. Here, the strain rate of the calculation was selected to best match the 

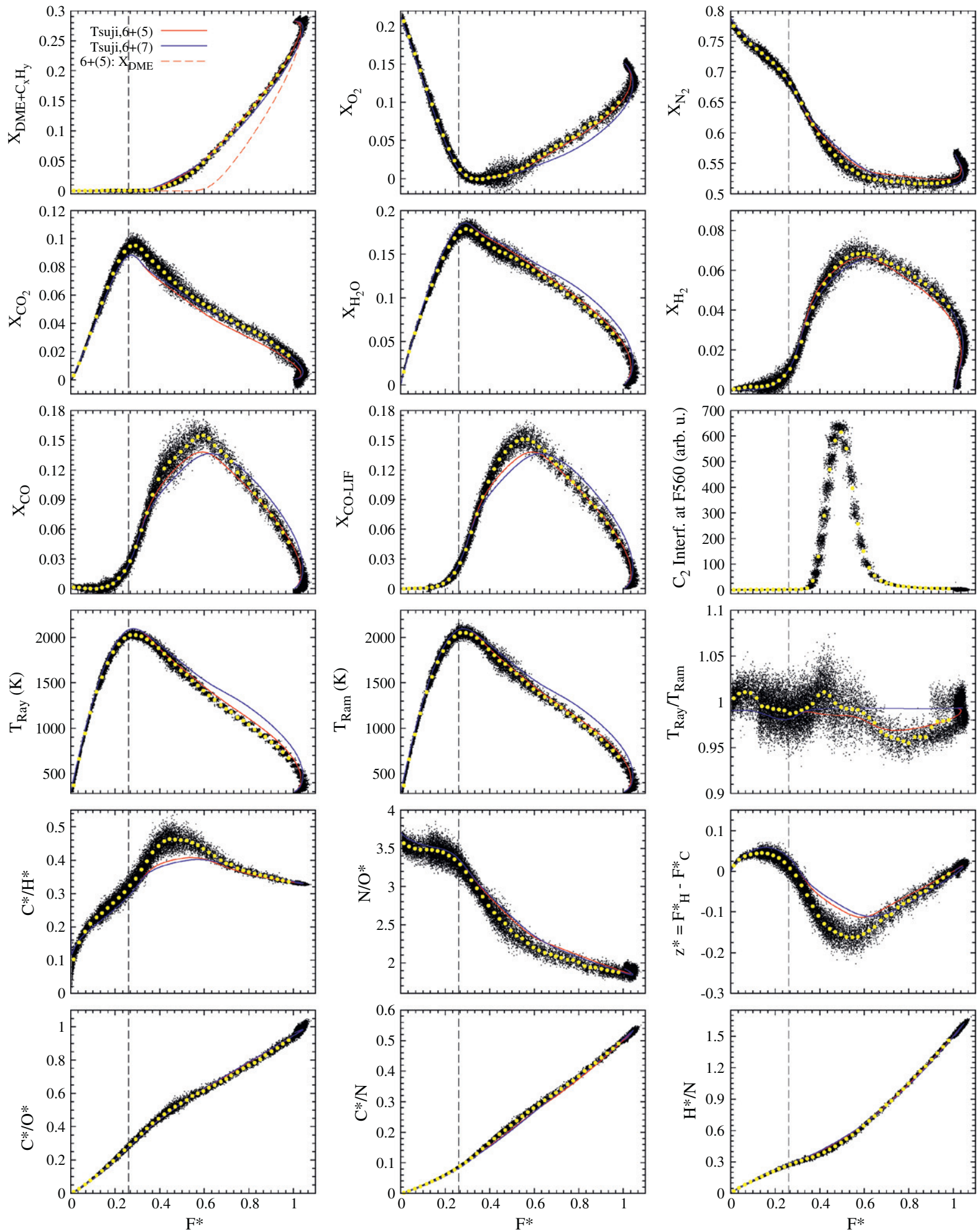

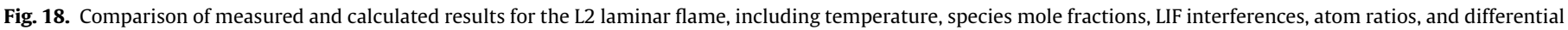

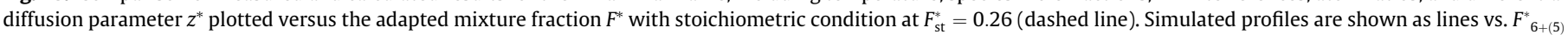

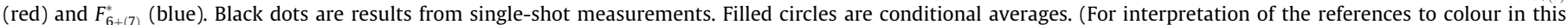
figure legend, the reader is referred to the web version of this article.)

separation between the premixed reaction zone and the stoichiometric condition, which is the portion of the flame important for evaluation of the hydrocarbon data evaluation scheme.

The maximum temperatures in experiment and simulation match within $30 \mathrm{~K}\left(T_{\text {max }, \text { calc. }}=2136 \mathrm{~K}\right)$. Again, the difference is attributed to radiation, a different inflow temperature in the calculation ( $290 \mathrm{~K}$ measured vs. $298 \mathrm{~K}$ in the calculation), and relative humidity. LIF interferences at the F560 channel are condensed to a much smaller region in physical space and are significantly lower (compare Fig. 14). As observed in the $\mathrm{L} 2$ configuration above $\mathrm{CO}_{2}$ 

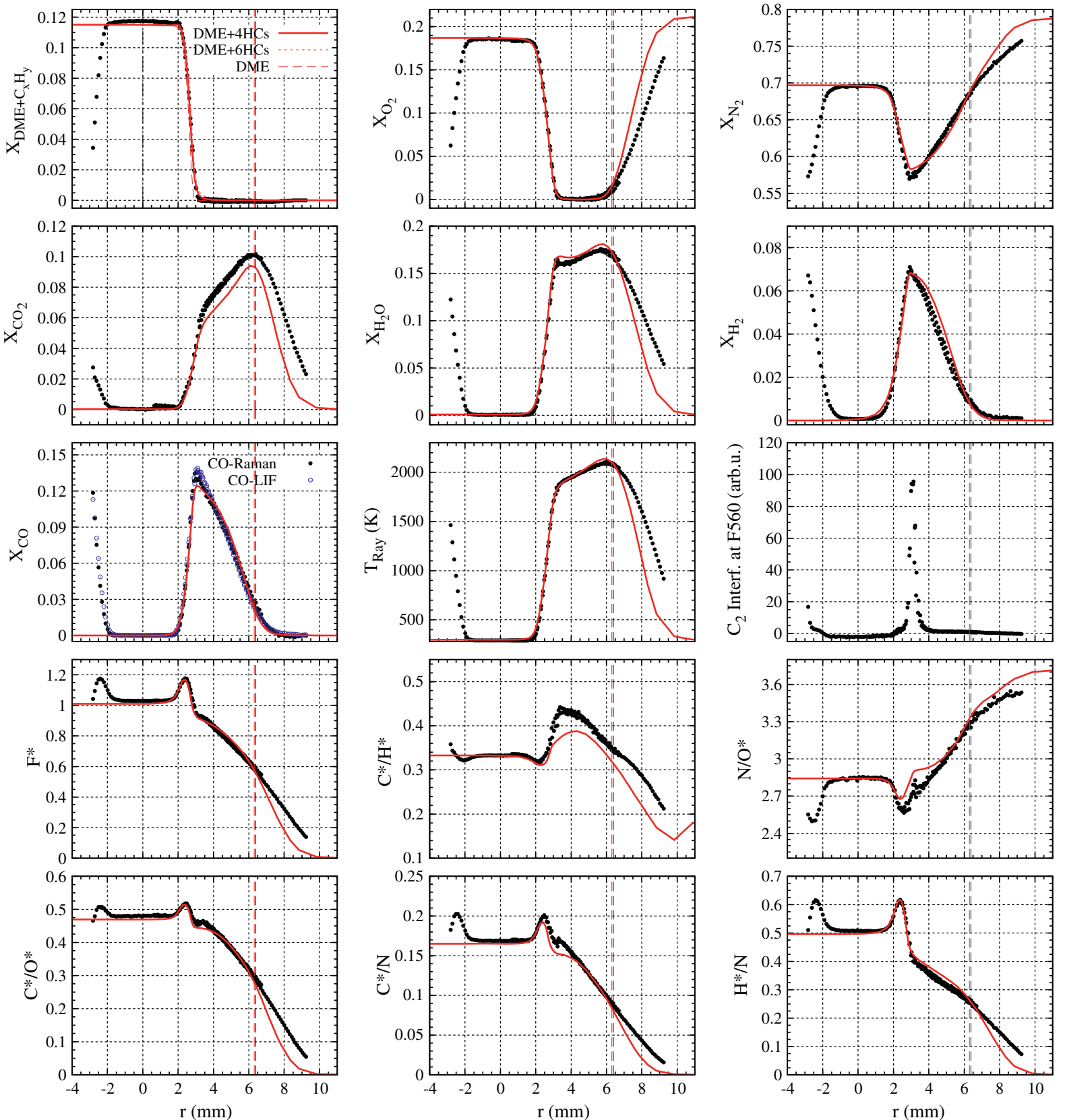

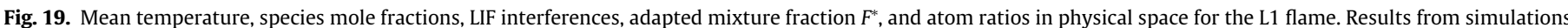
are shown by lines, experiments by circles. The vertical dashed line marks stoichiometric condition at $F_{\mathrm{st}}^{*}=0.59$.

and $\mathrm{CO}$ are both higher in the experiment. For $\mathrm{CO}_{2}$ the deviation at the peak is $+5 \%$, for CO-LIF $+9 \%$, whereas for $\mathrm{H}_{2} \mathrm{O}-4 \%$ is observed. Accordingly, the resulting $\mathrm{C}^{*} / \mathrm{H}^{*}$ ratio is too high. In the $\mathrm{L} 2$ configuration, better matching was observed in mixture fraction space with the calculation using the $F_{6+(5)}^{*}$-definition. For the L1 configuration some scalars are in between both definitions $F_{6+(5)}^{*}$ and $F_{6+(7)}^{*}$. However, this question is very sensitive especially to the measurement of $X_{\mathrm{DME}+\mathrm{CxHy}}$ which depends on the exact knowledge of the intermediate hydrocarbon composition, its corresponding Raman response curve and Rayleigh cross-section model and points towards limitations of the current approach.

Measurements in the two turbulent piloted DME/air flames were originally intended mainly for evaluation of levels of fluorescence interference and they were limited to 200-shot files at a single downstream location $x / D=15(D=7.2 \mathrm{~mm})$. Mixture compositions T2 (19.7 vol.\% DME in air) and T1 (11.4 vol.\% DME in air) were investigated at intermediate Reynolds-numbers corresponding roughly to flame D of the piloted $\mathrm{CH}_{4} /$ air flame series $[5,4,6-9]$. The probe volume was centered near the location of maximum fluorescence interference in each flame $(r=6 \mathrm{~mm}$ in T2 and $r=4 \mathrm{~mm}$ in T1). Despite higher measurement-noise (see Table 1) the data were acquired with full spectral resolution, to allow for spectroscopic analysis, and process by applying software binning before matrix inversion. So far, the Raman response regarding DME and intermediate hydrocarbon species was taken the same as for the laminar L2 configuration above. For the Rayleigh cross-section model, a laminar flame calculation with an intermediate strain rate of $a=400 \mathrm{~s}^{-1}$ and equal diffusivity transport in the Tsuji-geometry was used.

Figure 21 shows scatter plots of all measured scalars, atom ratios, and the molecular diffusion parameter $z^{*}$ versus the adapted mixture fraction $F_{6+(5)}^{*}$ for the case T2. Data at the single 1D probe 

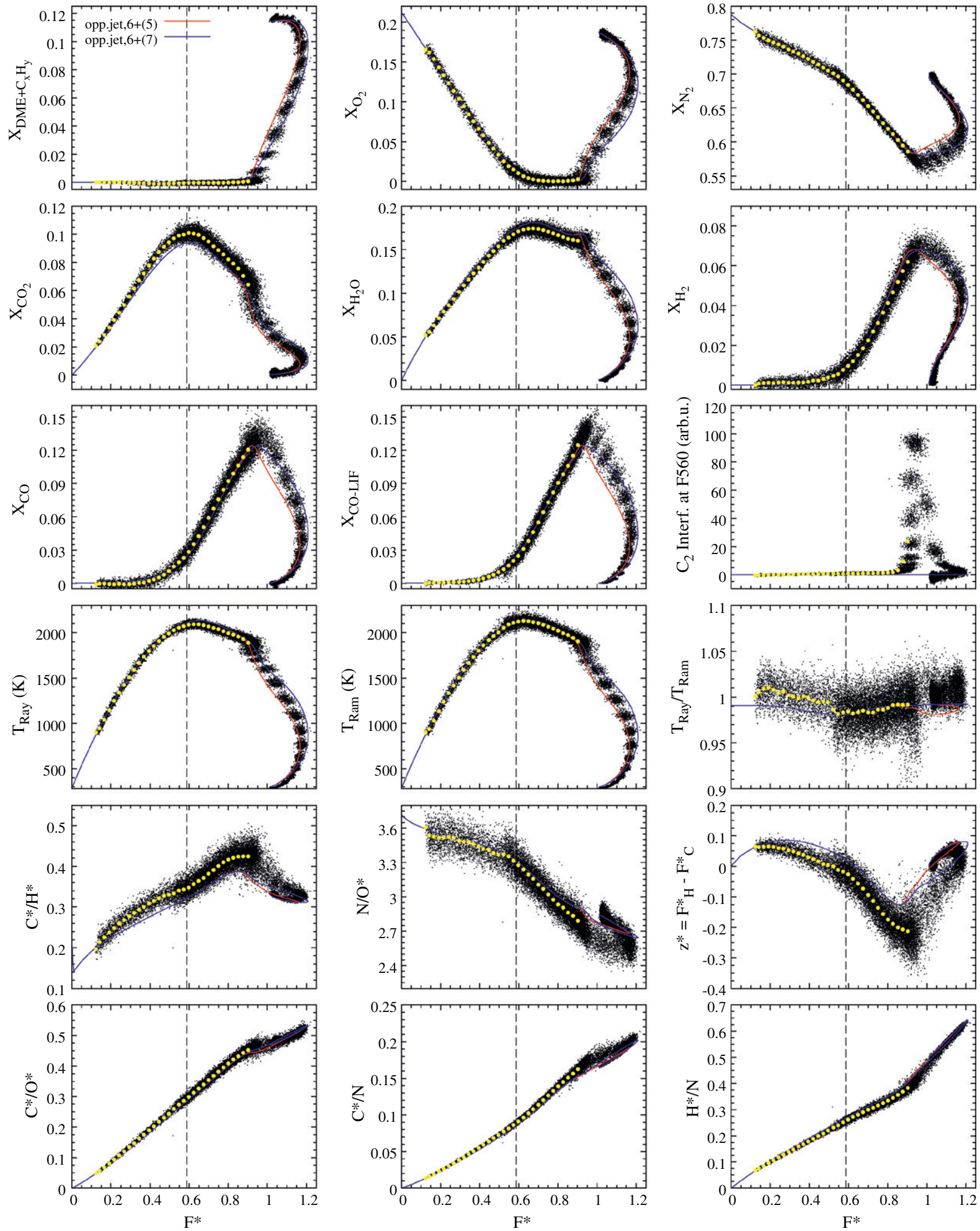

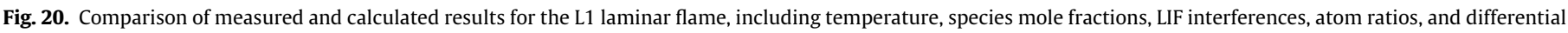

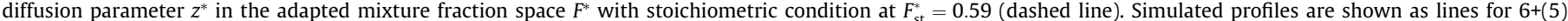

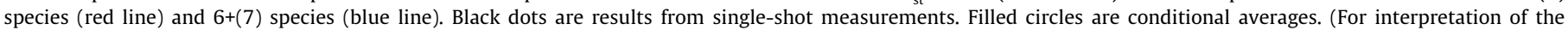
references to colour in this figure legend, the reader is referred to the web version of this article.)

volume location give rise to values for $F^{*}$ primarily in the range of $0.15<F^{*}<0.9$. Superimposed are profiles from various laminar flame calculations in the Tsuji-geometry, using either multi-component transport or equal diffusivities. For the multi-component transport cases the strain is varied, with $a=100,1000,1750 \mathrm{~s}^{-1}$, and for equal diffusivities $a=100,1000,2500 \mathrm{~s}^{-1}$. The highest strain rates correspond to the respective extinction limits.

The non-premixed flame structure is evident by the equally distributed scatter and gradual gradients in all scalars. Within a maximum deviation of $1.5 \%$ at $F^{*}=0.5$, temperatures determined 

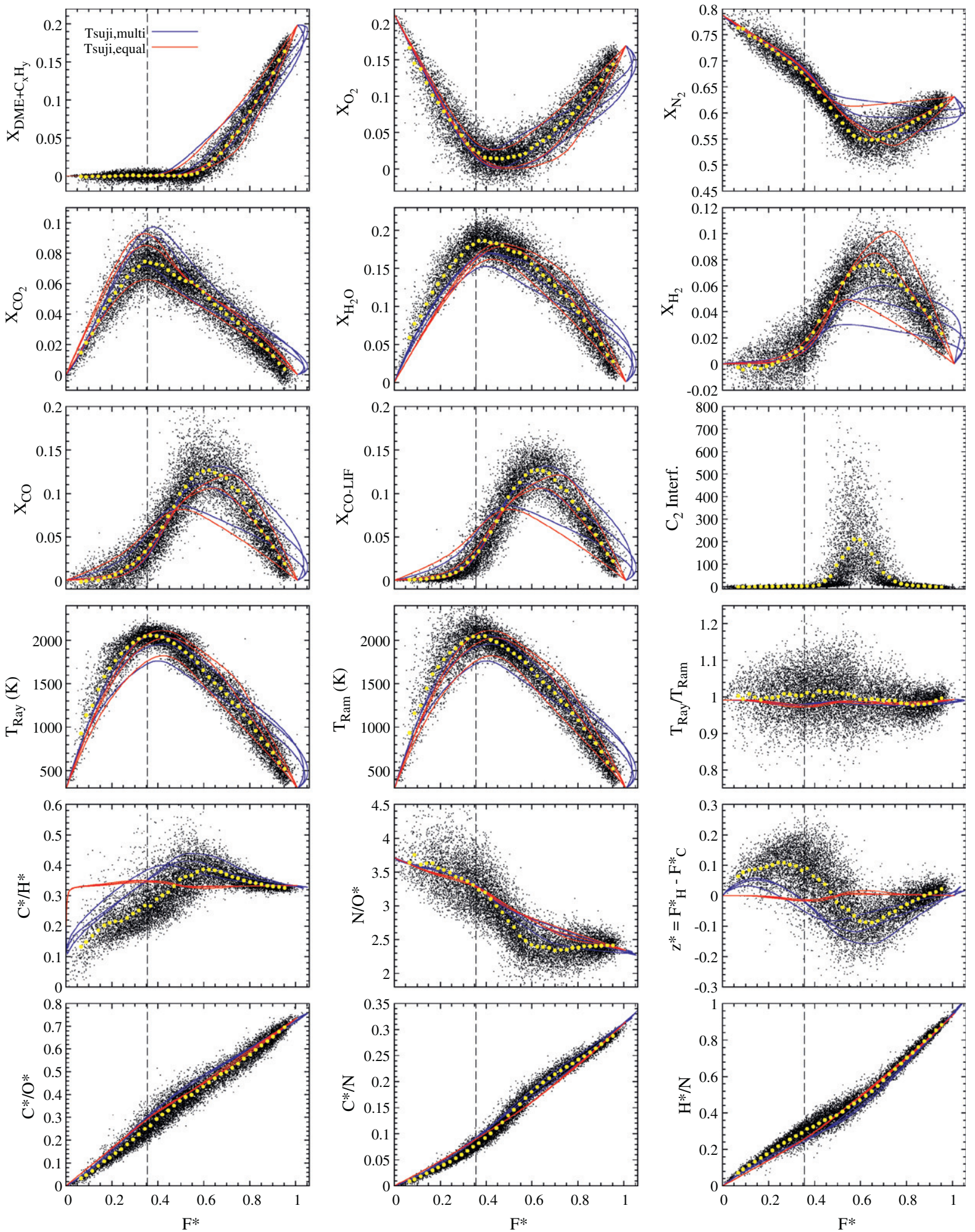

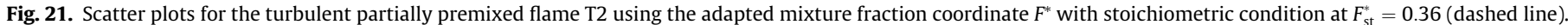

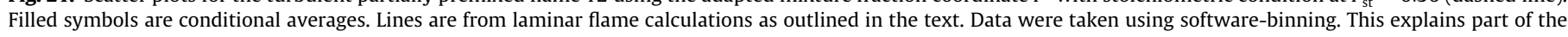
stronger scatter compared to the laminar cases.

via Rayleigh and Raman scattering agree very well (see $T_{\text {Ray }} / T_{\text {Ram }}$ ) supporting consistency in the data processing. Considering temperature and main species profiles, the conditional means are best matched by laminar flame calculations using equal diffusivities at intermediate strain. Different conclusions are drawn from both the
$\mathrm{C}^{*} / \mathrm{H}^{*}$ - and $z^{*}$-profiles, particularly in the range $0.5<F^{*}<0.8$, where differential diffusion effects are apparent, and the conditional mean profiles of these two quantities are clearly better matched by the multi-component transport model. It is apparent that both molecular diffusion and turbulent transport affect scalar transport 

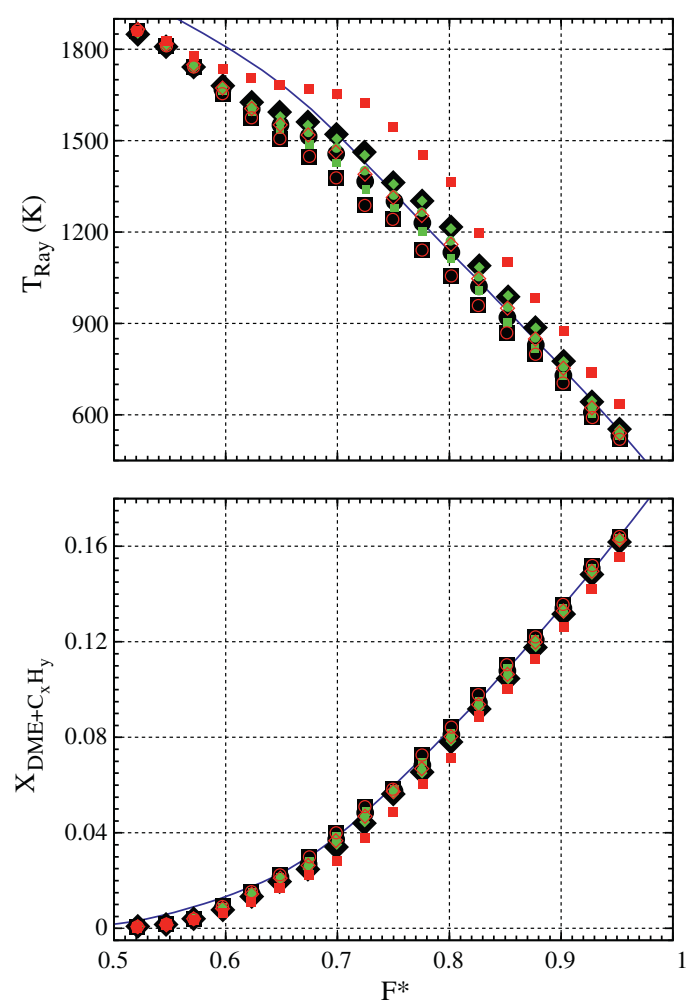

$$
\begin{aligned}
& \text { calculation: } \mathrm{T} 2, \mathrm{a}=400 \mathrm{~s}^{-1} \\
& \text { - } \mathrm{T} 2, \mathrm{a}=100 \mathrm{~s}^{-1} \text {,eq. } \\
& \text { - } \mathrm{T} 2, \mathrm{a}=400 \mathrm{~s}^{-1} \text {,eq. } \\
& \text { - T2,a }=2500 \mathrm{~s}^{-1} \text {,eq. } \\
& \text { - T2, } \mathrm{a}=100 \mathrm{~s}^{-1} \text {, mult. } \\
& \text { - } \quad \mathrm{T} 2, \mathrm{a}=400 \mathrm{~s}^{-1} \text {, mult. } \\
& \mathrm{T} 2, \mathrm{a}=1750 \mathrm{~s}^{-1} \text {, mult. } \\
& \text { w/o } \sigma_{\text {Ray,HC}}(\mathrm{T}) \\
& \mathrm{L} 2, \mathrm{a}=50 \mathrm{~s}^{-1} \text {, mult. } \\
& \mathrm{L} 1, \mathrm{a}=50 \mathrm{~s}^{-1} \text {, mult.,opp.jet. }
\end{aligned}
$$

Fig. 22. Various temperature dependent Rayleigh cross-section models applied to the data evaluation in the turbulent T2 measurement. One calculation (solid line) is plotted as a guide line for the experimental data shown as conditional average in $F^{*}$ space.

in this flame, which is qualitatively consistent with results on transport effects in the $\mathrm{CH}_{4}$ /air piloted flame at similar Reynolds number reported by Barlow et al. [8].

As mentioned in Section 3.3, Raman and Rayleigh results are interlinked due to the iterative data evaluation scheme. This was neglected in the Rayleigh cross-section study in Section 3.4. Here, the sensitivity of results from the T2 flame to the Rayleigh crosssection model is examined within the complete data processing scheme. Figure 22 compares conditional average temperature results within the range $0.5<F^{*}<1$, based on Rayleigh cross-section models derived from different laminar calculations. The calculation giving the overall best match in Fig. $21\left(a=400 \mathrm{~s}^{-1}\right.$, equal diffusivity) is shown as a guide line in Fig. 22. First, an unacceptable distortion of the temperature profile is found for data evaluation without applying any Rayleigh cross-section model, but using the constant Rayleigh cross-section of DME. This would lead to an over estimation of the temperature of up to $20 \%$. Still up to $10 \%$ difference is found between models composed of the lowest and highest strain rates, where higher strain rates cause higher temperatures. A few percent higher temperatures are found for the models with underlying multi-component transport calculations. Hence, choosing an intermediate strain rate of $a=400 \mathrm{~s}^{-1}$ for the Rayleigh cross-sec- tion model seems to be the best compromise for the T2 configuration to minimize the uncertainty on the average values of the Rayleigh temperature measurement. It is of course a significant sensitivity and must be kept in mind as a possible systematic influence parameter when evaluating experimental Raman/Rayleigh data from DME flames, especially close to extinction and when even deriving observations from single-shot measurements.

Additionally, in Fig. 22 the impact of the Rayleigh cross-section model on the hydrocarbon measurement is shown to be rather small. Interestingly, the amount of hydrocarbons is smaller for higher Rayleigh temperatures measured. From the decrease of the Raman response versus temperature (Fig. 4) the opposite would be expected. The explanation of this apparent contradiction is to be sought in the fact that the measured amount of hydrocarbons in physical space is actually increasing as expected, but at the same time, its impact on the mixture fraction calculation is dominating and causing a shift of the coordinate to larger values. Finally, it is worth noting that the same comparison in physical space is different. There, deviations in time-averages of temperature are strongly attenuated due to intermittency and are found below $2 \%$ between models of strain rates $a=100 \mathrm{~s}^{-1}$ and $a=2500 \mathrm{~s}^{-1}$. However, this of course is not true for evaluation of single-shots and generally, a good agreement with the simplified analysis presented at the end of Section 3.4 is found.

Data measured in the T1 configuration are shown in Fig. 23. These data were processed using response curves and Rayleigh cross-section model from the laminar calculation using the opposed jet geometry, L1 composition, $a=100 \mathrm{~s}^{-1}$, and multi-component transport. This calculation and those from the Tsuji geometry for both transport models at different strain rates $(a=100-$ $2250 \mathrm{~s}^{-1}$ ) are superimposed. The opposed jet geometry clearly better match premixed flames. The probe volume is centered at $r=4 \mathrm{~mm}$ and comprises mostly mixture fractions $F^{*}>0.6$.

For temperature and main species mole fractions a bimodal distribution appears that is typical for premixed flames: The reaction can occur without further mixing of fuel and oxidizer at almost identical values of mixture fraction. Spatially thin reaction zones reduce the probability measuring temperatures, educts, and products at intermediate states. Broadband and $\mathrm{C}_{2}$-interferences are reduced significantly compared to the $\mathrm{T} 2$ flame (same relative units in Figs. 21 and 23 in the scatter plot showing the level and positions of interferences). Conditional means are plotted only up to $F^{*}=0.9$ to avoid the mixed influence from burned and unburned samples. Differential diffusion effects are well observable in all profiles. In addition to the $\mathrm{C}^{*} / \mathrm{H}^{*}$ and $z^{*}$-profiles that are well reproduced by the multi-component opposed jet calculations, mixture fractions $F^{*}>1$ are regularly measured and laminar-like behavior shows up for all species. A calculation with a higher strain in opposed jet geometry would probably better match the results. In contrast to $\mathrm{T} 2$, the agreement with characteristics of differential diffusion is as well observed for the most sensitive $\mathrm{H}_{2}$-profile. To exclude possible errors in the data processing as a reason for measuring $F^{*}>1$, its sensitivity was investigated against different hydrocarbon Raman responses, Rayleigh cross-section models, and variations in the interference-corrections. But neither of these was found to influence the results shown in Fig. 23 significantly. The influence of differential diffusion, however, should be investigated in more depth in future studies.

\section{Summary and conclusions}

The feasibility of measurements using line-imaged Raman/Rayleigh scattering and line-imaged CO-LIF in laminar and turbulent DME/air flames was investigated. DME was chosen as the next more complex fuel-candidate beyond methane due to significant 

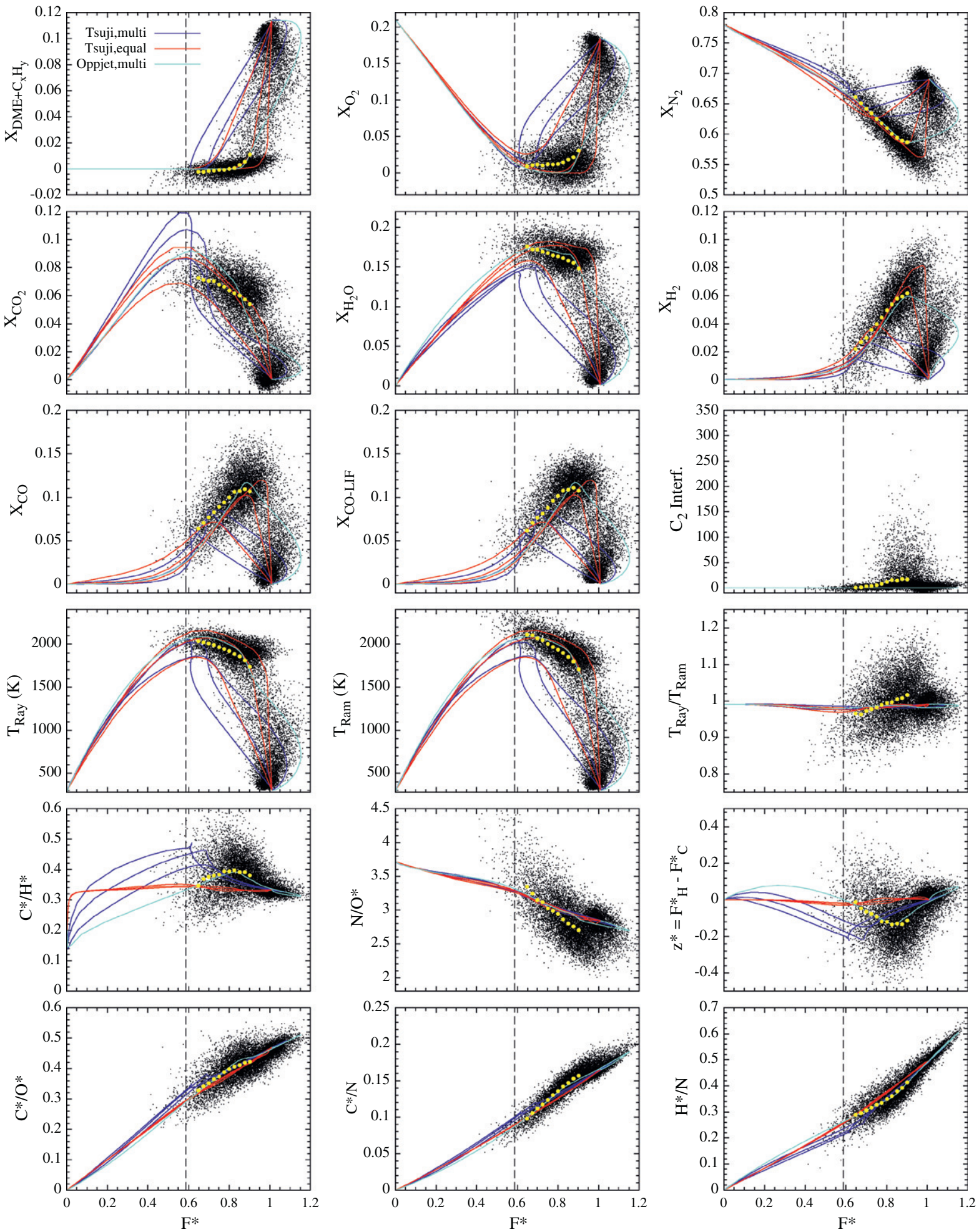

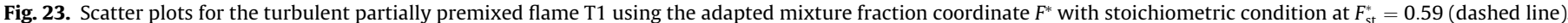

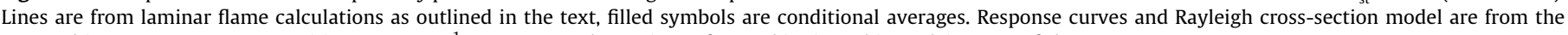
opposed jet geometry, L1 composition, $a=100 \mathrm{~s}^{-1}$. Data were taken using software-binning. This explains part of the stronger scatter.

lower interference levels than observed in flames of ethylene, ethane, and propane. The objective was to extend well-established methods applied to methane/air flames to allow for quantitative measurements of major species concentrations and temperature in DME/air flames.

In DME/air flames a number of additional complications were quantified by using 1D laminar flame computations. Much higher levels of intermediate hydrocarbons arise in the reaction zone than in similar methane/air flames. In the present measurements important intermediate hydrocarbons, i.e. methane, ethylene, and ethane were not distinguished from DME due to very similar Raman shifts. Formaldehyde and acetylene have different Raman shifts and were not detected at all. This impacted both, the measurement of major species by Raman scattering and the 
temperature measurement by Rayleigh scattering. In order to account for this fact, distributions of hydrocarbons were taken from 1D laminar flame calculations to provide additional information for the data processing of the measured Raman and Rayleigh signals. For the processing of both signals, temperature dependent models were derived to account for very different scattering properties of DME and intermediate hydrocarbons.

Measurements were obtained in two laminar jet flames of DME/ air with stoichiometric values of mixture fraction $F_{\mathrm{st}}=0.59$ and $F_{\mathrm{st}}=0.26$. The proposed temperature dependent models were applied to the processing of the Raman and Rayleigh signals. Generally, good agreement of species mole fractions and temperature with 1D laminar flame calculations was observed for both flames in physical space. Locally, major differences are found in values of $\mathrm{CO}_{2}, \mathrm{CO}$, and the $\mathrm{C} / \mathrm{H}$ atom ratio, which were all underpredicted by the calculation. The highest temperatures were overpredicted due to negligence of radiation in the calculation. Some of the observed differences may be due to 2D-effects apparent in jet flames, which cannot be accounted for in 1D opposed-flow calculations. In particular, at the oxidizer side of the premixed Bunsen configuration $\left(F_{\mathrm{st}}=0.59\right)$ all scalar gradients are more gradual in the measurement. The approach to select the strain rate in the calculation to best match the separation between the premixed reaction zone and the stoichiometric condition is not able to predict correct gradients at both sides of this flame.

Another complication was identified for the conversion from measured species mole fractions to species mass fractions and corresponding mixture fraction. The difference between the molar mass of DME and the molar masses of intermediate species is large and additional assumptions were introduced to provide consistent comparison between calculations and experiments in an adapted mixture fraction space. Thereafter, good agreement was also found for the two laminar cases in this adapted mixture fraction space.

Towards measurements in turbulent DME/air flames sensitivities of the introduced models for the Raman and Rayleigh data processing were investigated with respect to strain rate and transport model. Significant differences were observed between models based on lowest and highest strain rates, whereas smaller differences were found between multi-component and equal diffusivity transport models.

Data from first measurements obtained in turbulent DME/air jet flames with stoichiometric values of mixture fraction $F_{\mathrm{st}}=0.59$ and $F_{\text {st }}=0.36$ and Reynolds numbers of $\sim 25,000$ were processed with the proposed approach and compared with results from laminar flame calculations in the adapted mixture fraction space. As for previously studied methane/air jet flames at similar conditions, the turbulent DME/air flame results showed some areas of agreement with laminar calculations based on equal diffusivities and some areas of agreement with calculations based on multi-component transport, indicating the importance of both turbulent transport and molecular diffusion. A higher impact of differential diffusion is generally observed in all DME/air flames due to much higher levels of molecular hydrogen.

\section{Acknowledgments}

F. Fuest and A. Dreizler kindly acknowledge financial support by Deutsche Forschungsgemeinschaft SFB 568 and EXC 259. Work performed at Sandia was supported by the Division of Chemical Sciences, Geosciences and Biosciences, Office of Basic Energy Sciences, US Department of Energy. Sandia National Laboratories is a multiprogram laboratory operated by Sandia Corporation, a Lockheed Martin Company, for the United States Department of Energy under Contract DE-AC04-94-AL85000. The help of R. Harmon during the experiments is gratefully acknowledged.

\section{Appendix A. Rayleigh cross-sections of major species and intermediate species ( $>0.001$ mole fractions)}

In DME/air flames various intermediate species in addition to educts and products are identified that contribute to Rayleigh scattering (see Section 3.1). Referring to Eq. (5) the effective Rayleigh cross-section contains mole fraction weighted species-specific cross-sections. These cross-sections are needed as a basis for the discussions in Section 3.3.

In this study data from the literature were screened. For a few hydrocarbons additional measurements were performed. Table A.5 summarizes Rayleigh cross-sections and depolarization ratios relative to $\mathrm{N}_{2}$ for different excitation wavelengths. Values in bold type were used for the Rayleigh cross-section model discussed in Section 3.4. DME was substituted by 8.9, the average value measured in laminar jet flows. Some values for common species like $\mathrm{C}_{3} \mathrm{H}_{8}$, $\mathrm{He}, \mathrm{NO}, \mathrm{C}_{2} \mathrm{H}_{5} \mathrm{OH}, \mathrm{C}_{2} \mathrm{H}_{4} \mathrm{O}, \mathrm{C}_{3} \mathrm{H}_{6} \mathrm{O}$ were actually not used in this study but derived and listed as well.

Miles et al. [37] reviewed methods for deriving Rayleigh crosssections. Three components contribute to Rayleigh signals: Placzek trace scattering, Q-branch rotational Raman scattering, and O- and S-branches rotational Raman scattering. For the case of monochromatic excitation polarized linearly and perpendicularly to the plane spanned by laser beam and detection directions, and an arrangement of the detection direction perpendicular to the laser beam propagation, Eq. (A.1) provides the (differential) Rayleigh cross-section in dependence on refractive index $n$, excitation wavelength $\lambda_{0}$, number density $N$, and depolarization ratio $\rho_{0}$ for unpolarized (natural) incident light. This expression has been taken from Miles et al. [37, Eq. (5.2) from Table 5 and Eq. (1.1) from Table 1] for the total components of the scattered light:

$\frac{\partial \sigma_{\text {Ray }}}{\partial \Omega}=\frac{4 \pi^{2}(n-1)^{2}}{N^{2} \lambda_{0}^{4}}\left(\frac{6}{6-7 \rho_{0}}\right)$.

In molecular hydrogen pure rotational Raman lines are spectrally well separated from the Rayleigh line $(S(0) \sim 10 \mathrm{~nm}$ for $532 \mathrm{~nm}$ excitation) and do not contribute because of the 10-nm bandpass filter used during all experiments in front of the Rayleigh camera. For $\mathrm{H}_{2}$ therefore the following Eq. (A.2) was used excluding the pure rotational $\mathrm{O}-$ and S-branch Raman scattering:

$\frac{\partial \sigma_{\text {Ray }}}{\partial \Omega}=\frac{4 \pi^{2}(n-1)^{2}}{N^{2} \lambda_{0}^{4}}\left(\frac{6}{6-7 \rho_{0}}\right)\left(\frac{8-7 \rho_{0}}{8}\right)$

This equation was derived from Miles et al. [37, Eq. (5.1) from Table 5, Eq. (1.1) from Table $1,{ }^{\mathrm{V}^{\prime}} \mathrm{K}_{0}+{ }^{\prime} \mathrm{V}_{0}^{\prime \prime}=180+7 \epsilon$ from Table 4, and Eq. (51)].

In the literature the depolarization ratio for particular molecules is mostly listed for linearly polarized incident light. However, both can be expressed in terms of spatially-averaged polarizability properties of the scattering molecule and can be converted into their corresponding counterpart. For the specific detection geometry described above, the depolarization ratio for unpolarized incident light is given by

$\rho_{0}=\frac{6 \Delta \alpha^{2}}{45 \bar{\alpha}^{2}+7 \Delta \alpha^{2}}$

and for linearly polarized incident light

$\rho=\frac{3 \Delta \alpha^{2}}{45 \bar{\alpha}^{2}+4 \Delta \alpha^{2}}$

where $\bar{\alpha}$ is the mean polarizability, $\Delta \alpha$ is the anisotropy, both being invariants of the polarizabilty tensor of a molecule, see Long [38]. Using Eqs. (A.3) and (A.4), the following expression is found 
Table A.5

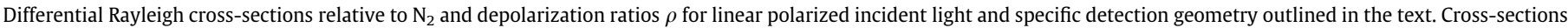
used in the present work are highlighted by bold types and are based on Eqs. (A.6) and (A.7).

\begin{tabular}{|c|c|c|c|c|}
\hline \multirow[t]{2}{*}{ Molecule } & \multirow[t]{2}{*}{$100 \rho^{\mathrm{b}, \mathrm{g}, \mathrm{h}, \mathrm{i}, \mathrm{j}, \mathrm{k}}$} & \multicolumn{2}{|c|}{$\underline{(\partial \sigma / \partial \Omega) /(\partial \sigma / \partial \Omega)_{\mathrm{N}_{2}}}$} & \multirow[b]{2}{*}{$532 \mathrm{~nm}^{\mathrm{e}, \mathrm{f}}$} \\
\hline & & $532 \mathrm{~nm}^{\exp }$ & $488 \mathrm{~nm}^{\mathrm{a}}, 632 \mathrm{~nm}^{\mathrm{b}, \mathrm{c}}$, static $^{\mathrm{d}}$ & \\
\hline $\mathrm{CO}_{2}$ & $4.0798^{\mathrm{g}}$ & & $2.32^{\mathrm{a}}, 2.3866^{\mathrm{c}}$ & 2.3907 \\
\hline $\mathrm{O}_{2}$ & $2.9434^{\mathrm{h}}$ & & $0.85^{\mathrm{a}}, 0.855^{\mathrm{b}}$ & 0.8592 \\
\hline $\mathrm{CO}$ & $0.5132^{g}$ & & $1.25^{\mathrm{a}}, 1.237^{\mathrm{b}}, 1.2346^{\mathrm{c}}$ & 1.2446 \\
\hline $\mathrm{N}_{2}$ & $1.0612^{\mathrm{h}}$ & 1 & 1 & 1 \\
\hline $\mathrm{CH}_{4}$ & $0.02^{\mathrm{k}}$ & $2.14 \pm 0.3$ & $2.16^{\mathrm{a}}$ & 2.1337, $2.2016^{f}$ \\
\hline $\mathrm{H}_{2} \mathrm{O}$ & $0.03^{\mathrm{i}}$ & & $0.71^{\mathrm{a}}$ & 0.6946 \\
\hline $\mathrm{H}_{2}$ & $0.9044^{\mathrm{h}}$ & & $0.22^{\mathrm{a}}, 0.216^{\mathrm{b}}$ & 0.2124 \\
\hline $\mathrm{OH}$ & & & & 1.4859 \\
\hline $\mathrm{Ar}$ & 0 & & $0.87^{\mathrm{a}}$ & 0.8650 \\
\hline 0 & 0 & & $0.17^{\mathrm{a}}$ & 0.1713 \\
\hline $\mathrm{H}$ & 0 & & $0.15^{\mathrm{a}}$ & 0.1479 \\
\hline DME & $0.3679^{g}$ & $8.9 \pm 0.35$ & $8.5841^{\mathrm{c}}$ & 8.6473 \\
\hline $\mathrm{C}_{2} \mathrm{H}_{4}$ & $1.2411^{\mathrm{g}}$ & $4.7 \pm 0.7$ & $5.85^{\mathrm{a}}, 5.776^{\mathrm{b}}, 5.7312^{\mathrm{c}}$ & 5.8029 \\
\hline $\mathrm{C}_{2} \mathrm{H}_{6}$ & $0.1847^{g}$ & $6.22 \pm 0.9$ & $6.33^{\mathrm{b}}, 6.3558^{\mathrm{c}}$ & 6.2984 \\
\hline $\mathrm{C}_{3} \mathrm{H}_{8}$ & $0.2061^{g}$ & $12.2 \pm 1.7$ & $12.6835^{c}$ & 12.7542 \\
\hline $\mathrm{CH}_{2} \mathrm{O}$ & $0.95^{\mathrm{j}}$ & & $1.99^{\mathrm{d}}$ & \\
\hline $\mathrm{C}_{2} \mathrm{H}_{2}$ & $1.8834^{\mathrm{g}}$ & & $4.01^{b}, 3.9658^{c}$ & 4.0096 \\
\hline $\mathrm{CH}_{3}$ & & & & $1.5770^{f}$ \\
\hline $\mathrm{He}$ & 0 & & $0.013^{\mathrm{a}}$ & 0.0132 \\
\hline NO & $1.54^{\mathrm{b}}$ & & & 0.9834 \\
\hline $\mathrm{C}_{2} \mathrm{H}_{5} \mathrm{OH}$ (ethanol) & & & & 8.0026 \\
\hline $\mathrm{C}_{2} \mathrm{H}_{4} \mathrm{O}$ (acetaldehyde) & $0.3292^{\mathrm{g}}$ & & & 6.7971 \\
\hline $\mathrm{C}_{3} \mathrm{H}_{6} \mathrm{O}$ (acetone) & $0.5862^{g}$ & & & 13.2247 \\
\hline
\end{tabular}

a From Carter [39].

b Exp. at $632.8 \mathrm{~nm}$ from Bridge and Buckingham [40].

c Exp. at $632.8 \mathrm{~nm}$ from Bogaard et al. [42].

d Static calc. from Bacskay et al. [33], referenced on calculated static value for $\mathrm{N}_{2}$ from Pecul and Rizzo [44], Table 1, d-aug-cc-pVQZ

e From exp. refractive indices at $532 \mathrm{~nm}$ from Gardiner et al. [32].

exp Present measurements.

${ }^{\mathrm{f}}$ From refractive indices based on atomic and bond refractivities at $532 \mathrm{~nm}$ from Gardiner et al. [32].

g Linear interpolation to $532 \mathrm{~nm}$ from exp. using $514.5 \mathrm{~nm}$ and $632.8 \mathrm{~nm}$ from Bogaard et al. [42].

$\mathrm{h}$ Linear interpolation to $532 \mathrm{~nm}$ from exp. using $488 \mathrm{~nm}$ and $632.8 \mathrm{~nm}$ from Rowell et al. [41].

${ }^{\mathrm{i}}$ From exp. at $515.5 \mathrm{~nm}$ from Murphy [43].

j Derived from static calc. by Bacskay et al. [33], $\rho=\Delta \alpha^{2} /\left(15 \bar{\alpha}^{2}+4 / 3 \Delta \alpha^{2}\right)$.

${ }^{\mathrm{k}}$ From Sneep and Ubachs [45].

$\rho_{0}=\frac{2 \rho}{1+\rho}$

Insertion of Eq. (A.5) in (A.1) yields the expression for the Rayleigh cross-section in terms of the depolarization ratio $\rho$ for linear polarized incident light with all three components included

$\frac{\partial \sigma_{\text {Ray }}}{\partial \Omega}=\frac{4 \pi^{2}(n-1)^{2}}{N^{2} \lambda_{0}^{4}}\left(\frac{6+6 \rho}{6-8 \rho}\right)$

and insertion of Eq. (A.5) in (A.2), the expression excluding the pure rotational O- and S-branch Raman scattering

$\frac{\partial \sigma_{\text {Ray }}}{\partial \Omega}=\frac{4 \pi^{2}(n-1)^{2}}{N^{2} \lambda_{0}^{4}}\left(\frac{6+6 \rho}{6-8 \rho}\right)\left(\frac{4-3 \rho}{4+4 \rho}\right)$.

These two latter equations are the base to calculate values in the rightmost column in Table A.5. All values are listed normalized to nitrogen. Following the procedure applied for $\lambda_{0}=488 \mathrm{~nm}$ by Carter [39] refractive indices were calculated from Gardiner et al. [32] except for $\mathrm{CH}_{2} \mathrm{O}$ where no data on the refractive index are available - using $(n-1)=a /\left(b-\lambda_{0}^{-2}\right)$ with $\lambda_{0}=532 \mathrm{~nm}$. Depolarization ratios for linear polarized incident light are listed in the second column of Table A.5 based on experimental values from Bridge and Buckingham [40], Rowell et al. [41], Bogaard et al. [42], Murphy [43], and a static calculation by Bacskay et al. [33]. Most of them were derived from interpolation to $532 \mathrm{~nm}$ using values for $488 \mathrm{~nm}$ and $632.8 \mathrm{~nm}$ or $514.5 \mathrm{~nm}$ and $632.8 \mathrm{~nm}$. In the following some more background information is provided detailing assump- tions and sensitivities regarding depolarization ratios, treatments of $\mathrm{CH}_{3}$ and $\mathrm{CH}_{2} \mathrm{O}$ and the experimental measurements performed to cross-check the Rayleigh cross-sections of DME, $\mathrm{CH}_{4}, \mathrm{C}_{2} \mathrm{H}_{4}$, and $\mathrm{C}_{2} \mathrm{H}_{6}$ versus values listed in the rightmost column of Table A.5.

\section{A.1. Impact of uncertainties in depolarization ratios upon Rayleigh cross-sections}

The contribution of the depolarization ratio $\rho$ on a speciesspecific cross-section constitute a few percent only. Thereby the sensitivity of species-specific total Rayleigh cross-sections upon the depolarization ratio generally is low. Uncertainties in $\rho$ resulting from measurement uncertainties are of minor impact and negligible. For example $\mathrm{CO}_{2}$ exhibits the largest depolarization ratio. Even assuming an error of $\pm 10 \%$ in $\rho_{\mathrm{CO}_{2}}$, which is five times larger than given by Bogaard et al. [42] for the experimental uncertainty in $\rho_{\mathrm{CO}_{2}}$ impacts $\sigma_{\mathrm{Ray}, \mathrm{CO}_{2}}$ by just $\pm 1 \%$ using Eq. (A.6).

\section{A.2. Linear interpolation of depolarization values}

As mentioned values for depolarization ratios $\rho$ were derived by interpolation using values at $488 \mathrm{~nm}$ or $514.5 \mathrm{~nm}$ and $632.8 \mathrm{~nm}$. Exemplified by $\mathrm{N}_{2}$, interpolation errors are negligible. Using the dispersion relation for $\mathrm{N}_{2}$ calculated by Pecul and Rizzo [44] from quantum mechanical ab initio methods, values for 488, 532 and $632.8 \mathrm{~nm}$ were derived. The linear interpolation using 488 and $632.8 \mathrm{~nm}$ mismatches the value at $532 \mathrm{~nm}$ by less than $0.05 \%$, which is below the smallest experimental uncertainties discussed 
by Bogaard et al. [42] and does not impact the calculation of the $\mathrm{N}_{2}$ Rayleigh cross-section significantly.

\section{A.3. Treatment of $\mathrm{CH}_{3}$}

For the methyl radical $\mathrm{CH}_{3}$ no measurements of refractive index and depolarization ratio are available. Therefore the refractive index was estimated using atomic and bond refractivities from Gardiner et al. [32]. Applied to $\mathrm{CH}_{4}$ indeed this estimation provides values quite close to the value derived from Eq. (A.6) based on a measured refractive index (rightmost column in Table A.5 for $\mathrm{CH}_{4}$ : cross-section derived by atomic and bond refractivities is 2.2016 and deviates by less than $4 \%$ from the value based on measured refractive index 2.1337). This provides confidence that the calculated value 1.5770 of the relative cross-section for $\mathrm{CH}_{3}$ is trustworthy. The depolarization ratio of $\mathrm{CH}_{3}$, however, is arbitrarily set to zero. This is justified by the generally low impact of the depolarization ratio upon the cross-section that is negligible compared to the uncertainties in the refractive index.

\section{A.4. Treatment of $\mathrm{CH}_{2} \mathrm{O}$}

The Rayleigh cross-section for $\mathrm{CH}_{2} \mathrm{O}$ was derived from calculations of static polarizabilities by Bacskay et al. [33] in the molecule fixed coordinate system. These were converted to the polarizability tensor invariants by

$\bar{\alpha}^{2}=\frac{1}{9}\left(\alpha_{\mathrm{xx}}+\alpha_{\mathrm{yy}}+\alpha_{\mathrm{zz}}\right)^{2}$

and

$\Delta \alpha^{2}=\frac{1}{2}\left\{\left(\alpha_{\mathrm{xx}}-\alpha_{\mathrm{yy}}\right)^{2}+\left(\alpha_{\mathrm{yy}}-\alpha_{\mathrm{zz}}\right)^{2}+\left(\alpha_{\mathrm{zz}}-\alpha_{\mathrm{xx}}\right)^{2}\right\}$

These were inserted into

$\frac{\left(\partial \sigma_{\text {Ray }} / \partial \Omega\right)_{i}}{\left(\partial \sigma_{\text {Ray }} / \partial \Omega\right)_{\mathrm{N}_{2}}}=\frac{\bar{\alpha}_{i}^{2}+(7 / 45) \Delta \alpha_{i}^{2}}{\bar{\alpha}_{\mathrm{N}_{2}}^{2}+(7 / 45) \Delta \alpha_{\mathrm{N}_{2}}^{2}}$

to obtain the differential Rayleigh cross-section for $\mathrm{CH}_{2} \mathrm{O}$ relative to nitrogen. To minimize systematic deviations due to use of polarizabilities of different excitation wavelengths as well static $\mathrm{N}_{2}$-values for $\bar{\alpha}$ and $\Delta \alpha$ were used from Pecul and Rizzo [44]. With this procedure one obtains a relative $\mathrm{CH}_{2} \mathrm{O}$ Rayleigh cross-section of 1.99 listed in the forth column of Table A.5. The depolarization ratio was calculated by Eq. (A.4). Note that in these calculations a static polarizability was used because of lack of values at $532 \mathrm{~nm}$. However, the wavelength dependence is rather small. Comparing for example polarizabilities of $\mathrm{N}_{2}$ at $315 \mathrm{~nm}$ versus the static value the deviation is about 4\% Pecul and Rizzo [44]. The impact is even smaller when cross-sections relative to $\mathrm{N}_{2}$ are considered, as the mean polarizability $\bar{\alpha}$ rises with increasing excitation frequencies similarly for the other molecules. The change in the anisotropy $\Delta \alpha$ in this context can be completely neglected.

Based on Eq. (A.10) differential Rayleigh cross-sections were calculated additionally for $\mathrm{CO}_{2}, \mathrm{O}_{2}, \mathrm{CO}, \mathrm{H}_{2}, \mathrm{C}_{2} \mathrm{H}_{4}, \mathrm{C}_{2} \mathrm{H}_{6}$, and $\mathrm{C}_{2} \mathrm{H}_{2}$ using literature values from Bridge and Buckingham [40] and Bogaard et al. [42] for an excitation wavelength of $632 \mathrm{~nm}$. The anisotropy $\Delta \alpha$ of $\mathrm{C}_{2} \mathrm{H}_{4}$ is not listed by Bridge and Buckingham and was calculated using Eq. (A.4). Resulting values are listed in the forth column of Table A.5. A comparison to the values based on Eq. (A.6) and $532 \mathrm{~nm}$ in the fifth column shows a close agreement with typical deviations in the order of $1 \%$.

\section{A.5. Experimental determination of Rayleigh cross-sections for DME} and selected hydrocarbons

Combined Raman/Rayleigh scattering measurements were performed in air, $\mathrm{DME} / \mathrm{N}_{2}$ and $\mathrm{DME} /$ air mixtures issuing from the jet nozzle. Using pure DME jets was not possible with the present focusing of the laser beam because of optical breakdown, i.e. described by Raizer [46], even at the lowest laser pulse energy. Measurements of DME/air and DME/ $\mathrm{N}_{2}$ were necessary to evaluate the unknown Raman crosstalk from DME on $\mathrm{N}_{2}$ (quantification of this crosstalk was complicated by the fact that no data without presence of $\mathrm{N}_{2}$ was available in the present investigations). This was achieved by the following steps. First, the crosstalk of DME upon the $\mathrm{O}_{2}$-channel $\left(\mathrm{O}_{2} \leftarrow\right.$ DME) was quantified from the DME/ $\mathrm{N}_{2}$ jet measurements. Second, the DME/air jet was examined. Using the corrected $\mathrm{O}_{2}$ mole fractions based on the crosstalk $\mathrm{O}_{2} \leftarrow$ DME, the crosstalk of DME upon the $\mathrm{N}_{2}$-channel was adjusted to recover the correct ratio of $\mathrm{N}_{2} / \mathrm{O}_{2}$ mole fractions in air. For each mixture composition and temperature setting 100 single shots were recorded. The reference gas temperature was monitored by a thermocouple. Inaccuracies of the flow controllers were avoided by measuring absolute Raman scattering from $\mathrm{O}_{2}$ before recording the different DME/air mixtures. The DME/ $\mathrm{N}_{2}$ measurement was used to quantify the crosstalk from DME on $\mathrm{O}_{2}$ and accounted for it in the DME/air measurements. The mole fraction of DME was specified by $1-X_{\text {air }}$, where $X_{\text {air }}$ was determined from the measured $\mathrm{O}_{2}$ concentration adding the corresponding parts of $\mathrm{N}_{2}, \mathrm{CO}_{2}, \mathrm{Ar}$ and $\mathrm{H}_{2} \mathrm{O}$ in air. By this procedure mole fractions of DME, $\mathrm{O}_{2}, \mathrm{~N}_{2}, \mathrm{CO}_{2}, \mathrm{Ar}$, and $\mathrm{H}_{2} \mathrm{O}$ in the jet were known and subsequently used to compute the Rayleigh cross-section of DME from the corresponding Rayleigh measurement to match the temperature reading of the thermocouple. The corresponding Eqs. (A.11)-(A.16) used for these calculations are given below. This procedure was repeated for various DME/air ratios on different days, comparing shot-averaged and single-shot evaluation. Finally, the resulting value for the Rayleigh cross-section of DME relative to $\mathrm{N}_{2}$ was $8.9 \pm 0.35$. Within the error margins this value coincides with values listed in the rightmost column of Table A.5. Uncertainties of this method are dominated by the remaining uncertainty in the $\mathrm{O}_{2}$ concentration. This uncertainty was below $0.5 \%$ difference in successive measurements of $\mathrm{O}_{2}$ in air. Assuming $\pm 0.5 \%$ in the $\mathrm{O}_{2}$ concentration yields an uncertainty in the relative DME cross-section of \pm 0.35 . This is in agreement with deviations between different measurements.

$$
\begin{aligned}
\sigma_{\text {eff }}= & T I_{\text {Ray }} / c_{\text {Ray }} \\
\sigma_{\text {eff }}= & X_{\text {air }} \sigma_{\text {air }}+\left(1-X_{\text {air }}\right) \sigma_{\mathrm{DME}} \\
X_{\mathrm{air}}= & \frac{1}{0.20914} X_{\mathrm{O}_{2}} \\
X_{\mathrm{O}_{2}}= & C_{\mathrm{O}_{2}} \cdot 22.413996 \cdot 10^{-3} \mathrm{~m}^{3} \mathrm{~mol}^{-1} \frac{T}{273.15 \mathrm{~K}} \frac{101.325 \mathrm{kPa}}{p} \\
C_{\mathrm{O}_{2}}= & \frac{1}{c_{\mathrm{Ram}, \mathrm{O}_{2}}}\left(I_{\text {Ram }, \mathrm{O}_{2}}-\frac{c_{\mathrm{Ram}, \mathrm{O}_{2} \leftarrow \mathrm{DME}}}{c_{\mathrm{Ram}, \mathrm{DME}}}\left(I_{\mathrm{Ram}, \mathrm{DME}}\right.\right. \\
& \left.\left.-I_{\text {Ram }, \mathrm{bgr}} \frac{n_{\mathrm{pix}, \mathrm{DME}}}{n_{\mathrm{pix}, \mathrm{bgr}}}\right)-I_{\mathrm{Ram}, \mathrm{bgr}} \frac{n_{\mathrm{pix}, \mathrm{O}_{2}}}{n_{\mathrm{pix}, \mathrm{bgr}}}\right) \\
\Rightarrow & \sigma_{\mathrm{DME}}=\frac{T I_{\text {Ray }}-c_{\mathrm{Ray}} X_{\mathrm{air}} \sigma_{\mathrm{air}}}{c_{\mathrm{Ray}}\left(1-X_{\mathrm{air}}\right)}
\end{aligned}
$$

$\sigma_{\text {eff }}$

$T$
Effective Rayleigh cross-section in the probe volume Temperature in probe volume determined by thermocouple (continued on next page) 


\begin{tabular}{|c|c|}
\hline$I_{\text {Ray }}$ & $\begin{array}{l}\text { Integrated Rayleigh scattering } \\
\text { signal }\end{array}$ \\
\hline$c_{\text {Ray }}$ & $\begin{array}{l}\text { Rayleigh temperature calibration } \\
\text { constant, determined in pure air }\end{array}$ \\
\hline$X_{i}$ & $\begin{array}{l}\text { Mole fraction of species } i \text { in probe } \\
\text { volume }\end{array}$ \\
\hline$\sigma_{\text {air }}$ & $\begin{array}{l}\text { Relative Rayleigh cross-section of } \\
\text { air }(0.96925)\end{array}$ \\
\hline$\sigma_{\mathrm{DME}}$ & $\begin{array}{l}\text { Relative Rayleigh cross-section of } \\
\text { DME }\end{array}$ \\
\hline 0.20914 & $\begin{array}{l}\text { Mole fraction of } \mathrm{O}_{2} \text { in air } \\
\text { containing } 0.0015 \text { water }\end{array}$ \\
\hline$C_{\mathrm{O}_{2}}$ & $\begin{array}{l}\text { Concentration of } \mathrm{O}_{2} \text { in } \\
10^{3} \mathrm{~m}^{-3} \mathrm{~mol}(\mathrm{~mol} / \mathrm{l})\end{array}$ \\
\hline$p$ & $\begin{array}{l}\text { Pressure in laboratory, measured } \\
\text { with manometer }\end{array}$ \\
\hline$C_{\mathrm{Ram}, \mathrm{O}_{2}}$ & $\begin{array}{l}\text { Raman calibration constant for } \\
\mathrm{O}_{2} \text {, determined in pure air }\end{array}$ \\
\hline$\underline{c_{\text {Ram }, O_{2}} \leftarrow \text { DME }}$ & Ratio of Raman calibration \\
\hline$\overline{c_{\text {Ram, DME }}}$ & $\begin{array}{l}\text { constants for crosstalk of DME on } \\
\mathrm{O}_{2}\left(c_{\text {Ram }}, \mathrm{O}_{2} \leftarrow \text { DME }\right) \text { and DME } \\
\left(c_{\text {Ram,DME }}\right) \text {. Determined in DME } / \mathrm{N}_{2} \\
(\sim 9 \% \text { DME }) \text { mixture. }\end{array}$ \\
\hline$I_{\mathrm{Ram}, \mathrm{O}_{2}}$ & $\begin{array}{l}\text { Signal (counts - (averaged dark } \\
\text { image)) on Raman } \mathrm{O}_{2} \text { channel }\end{array}$ \\
\hline$I_{\mathrm{Ram}, \mathrm{DME}}$ & Signal on Raman DME channel \\
\hline$I_{\text {Ram,bgr }}$ & $\begin{array}{l}\text { Signal on Raman background } \\
\text { channel }\end{array}$ \\
\hline$n_{\mathrm{pix}, \mathrm{i}}$ & $\begin{array}{l}\text { Number of pixels of Raman } \\
\text { channel } i\end{array}$ \\
\hline $22.143996 \cdot 10^{-3} \mathrm{~m}^{3} \mathrm{~mol}^{-1}$ & $\begin{array}{l}\text { Molar volume of ideal gas } \\
(273.15 \mathrm{~K}, 101.325 \mathrm{kPa})\end{array}$ \\
\hline
\end{tabular}

The relative Rayleigh cross-sections of $\mathrm{CH}_{4}, \mathrm{C}_{2} \mathrm{H}_{4}, \mathrm{C}_{2} \mathrm{H}_{6}$, or $\mathrm{C}_{3} \mathrm{H}_{8}$ were determined by diluting these gases with $91 \pm 1.5 \% \mathrm{~N}_{2}$. The mixture composition was determined by relying on the flow controller settings. Thus, differences to literature values particularly for $\mathrm{C}_{2} \mathrm{H}_{4}$ and $\mathrm{C}_{2} \mathrm{H}_{6}$ may be caused by flow controller uncertainties.

\section{A.6. Other possible sources of experimental errors}

The large solid angle of the first collection lense has a different impact on the angular dependence of the Rayleigh signal for species with different depolarization ratios. Therefore, it affects even values normalized to nitrogen. The effect was computed using Eqs. (53)-(55) from Miles et al. [37] and appropriate integration over $\pm 15^{\circ}$ detection angle corresponding to the used collection lense. It is found $+0.1 \%$ for the values of oxygen and carbon dioxide and much smaller for all other molecules. Accordingly, this effect is negligible compared to other experimental uncertainties. A slightly bigger impact $(<0.5 \%)$ can be due to variations in the index of refraction in the beam path of the laser and the scattered light which cause slight differences in the optical imaging for different gases measured. In the same order all experimentally derived values were particularly affected by the background treatment of the Rayleigh image. Here background contributions to the Rayleigh signal were estimated from pixel rows above and below the line Rayleigh image: representative background intensities were calculated by averaging few rows that are clearly separated from the Rayleigh image. Pixel-wise interpolation in vertical pixel direction provided then an estimation of the background underlying the Rayleigh image and was subtracted as the first step in data postprocessing. Another source for minor deviations between mea- sured and literature data may result from impurities of the gases as remarked in Bogaard et al. [42].

\section{Appendix B. Raman scattering from DME and intermediate species $\left(\mathrm{CH}_{4}, \mathrm{CH}_{2} \mathrm{O}, \mathrm{OH}, \mathrm{C}_{2} \mathrm{H}_{2}, \mathrm{C}_{2} \mathrm{H}_{4}, \mathrm{C}_{2} \mathrm{H}_{6}, \mathrm{CH}_{3}\right)$}

\section{B.1. Raman spectra}

This section provides the spectroscopic details on Raman scattering from DME and important intermediate species. This information is essential for all conclusions derived in Section 3 regarding the data processing of the present Raman/Rayleigh measurement in DME/air flames. In the following treatment selected hydrocarbon Raman bands and crosstalks to other Raman channels are examined. For this purpose Raman scattering from DME, $\mathrm{CH}_{4}, \mathrm{C}_{2} \mathrm{H}_{4}$, or $\mathrm{C}_{2} \mathrm{H}_{6}$ diluted by $\sim 91 \% \mathrm{~N}_{2}$ were measured in electrically heated jets. The temperature was varied in steps of $\sim 100 \mathrm{~K}$ from 295 to $820 \mathrm{~K}$ and measured by Rayleigh-scattering. A thin-film polarizer was placed in front of the Raman spectrometer, such that only the polarized or depolarized part was detected, respectively. Figure B.24 shows two relevant spectral ranges at $295 \mathrm{~K}$ (top) and $820 \mathrm{~K}$ (bottom), respectively. The spectra comprise Raman shifts from 800 to $1800 \mathrm{~cm}^{-1}$ and 2650 to $3300 \mathrm{~cm}^{-1}$ containing the most intense Raman bands. Relative signal ratios between the molecules scatter within $\pm 10 \%$. These uncertainties were caused inter alia by flow controllers, remaining uncertainties in crosstalks, temperature measurements via Rayleigh scattering, and laser shot energy correction. Signals at the low wavenumber end were attenuated by decreasing transmission/detection efficiency by roughly $15 \%$. From Fig. B.24 it is obvious that DME and the intermediate species $\mathrm{C}_{2} \mathrm{H}_{4}$, $\mathrm{C}_{2} \mathrm{H}_{6}$ cause significant crosstalks at lower Raman shifts. The $\mathrm{C}_{2}$ fluorescence/broadband interference channel around 760 to $1090 \mathrm{~cm}^{-1}$ is affected particularly by DME and $\mathrm{C}_{2} \mathrm{H}_{6}$. The $\mathrm{CO}_{2}$ and $\mathrm{O}_{2}$ channels are heavily influenced by $\mathrm{C}_{2} \mathrm{H}_{4}$, DME, and $\mathrm{C}_{2} \mathrm{H}_{6}$ but much less by $\mathrm{CH}_{4}$. For this reason $\mathrm{CH}_{4}$ /air flames are less sensitive to this specific crosstalk. Another crosstalk on $\mathrm{N}_{2}$ was observed in DME/air mixtures, causing a systematic increase of the $\mathrm{N}_{2} / \mathrm{O}_{2}$ ratio by approximately 5\% (for 28.1\% DME in air, see $\mathrm{N}_{2}$ channel in Fig. 16).

Due to the limited spectral resolution of the transmission spectrometer and the complexity of the DME molecule, exact assignments of the DME Raman bands evident from Fig. B.24 are difficult. However, four separated bands I-IV are observed here and are briefly discussed relying on bands assignments by Allan et al. [47], Blom et al. [48], and Hameka [49]:

I. $2750-3100 \mathrm{~cm}^{-1}$ : This is the $\mathrm{CH}$-stretching region that is mainly constituted of five strongly polarized Raman peaks at $2823 \mathrm{~cm}^{-1}, 2872 \mathrm{~cm}^{-1}, 2926 \mathrm{~cm}^{-1}, 2963 \mathrm{~cm}^{-1}$ and $2999 \mathrm{~cm}^{-1}$ as reported by Blom et al. [48]. Here, two Raman peaks are most notably because of their apparent change in relative signal intensities at higher temperature. First, the dominating peak in cold gas here observed at $2820 \mathrm{~cm}^{-1}$, which probably results from Fermi resonance of symmetric out-of-plane (C-O-C plane) $\mathrm{CH}_{2}$ stretch and in-plane $\mathrm{CH}$ stretch vibrations as stated by Allan et al. [47]. Second, the peak at $2926 \mathrm{~cm}^{-1}$ which is very likely assigned to the asymmetric $\mathrm{CH}_{2}$ out-of-plane stretch mode (Allan et al.). This peak is notable because it is increasing with temperature, even exceeding the peak at $2820 \mathrm{~cm}^{-1}$ for temperatures above $1300 \mathrm{~K}$. This observation is not compulsory an attribute of DME alone, as species such as $\mathrm{CH}_{4}$ and $\mathrm{C}_{2} \mathrm{H}_{6}$ are formed at higher temperatures. The superposition of $\mathrm{CH}_{4}$ and $\mathrm{C}_{2} \mathrm{H}_{6}$ Raman spectra can be estimated from chemical kinetic calculations evaluating gas compositions 

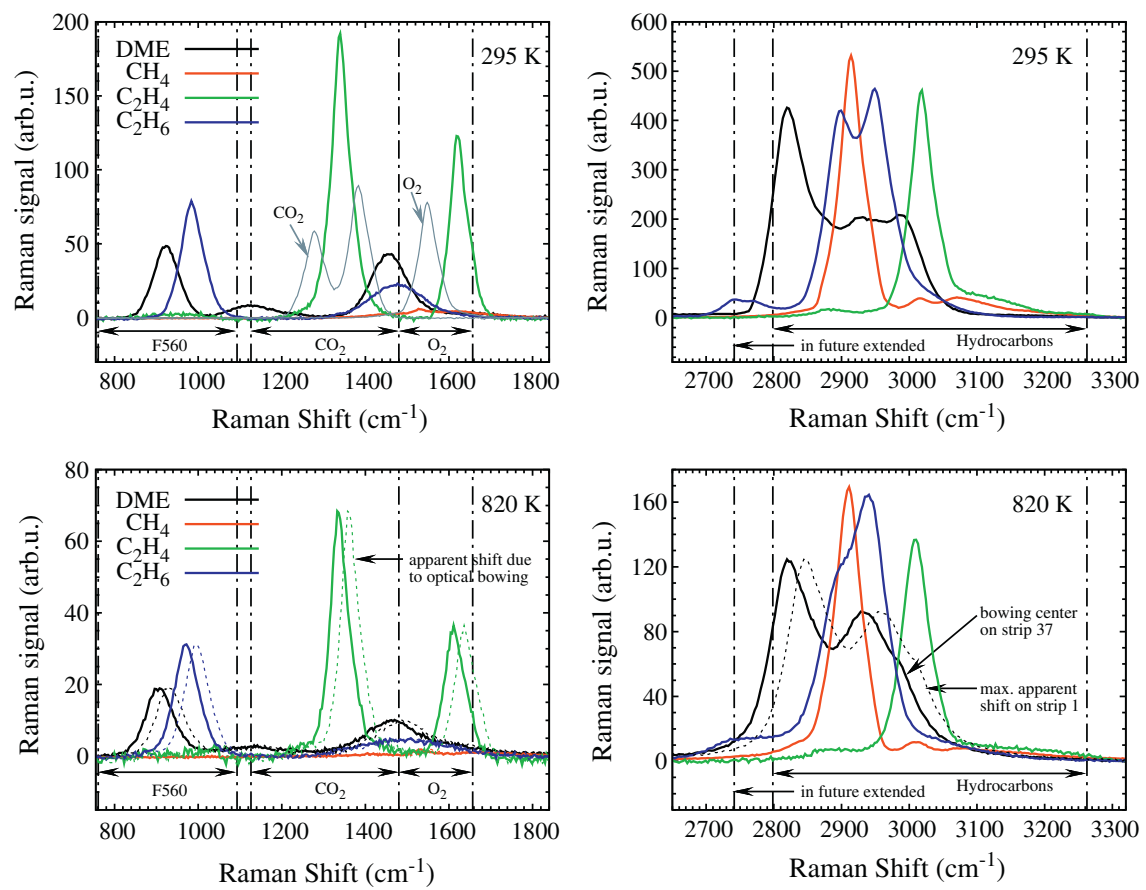

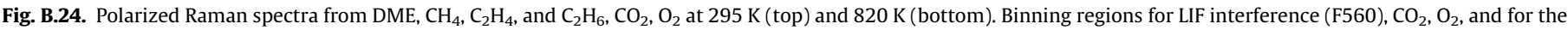

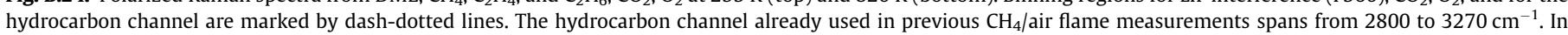

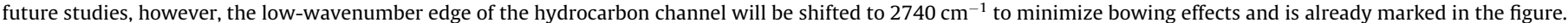

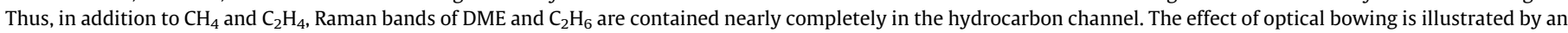
apparent shift $\left(25 \mathrm{~cm}^{-1}\right)$ of the spectra (bottom, dotted lines) with respect to the binning regions. On bottom right just shown for DME for the sake of clarity.

at intermediate temperatures around $1300 \mathrm{~K}$ and corresponding pure gas spectra. This is supported experimentally by comparing to Raman spectra from laminar jet flames.

II. 1300-1600 $\mathrm{cm}^{-1}$ : This range is due to $\mathrm{CH}_{3}$ deformation modes. The observed DME-peak at $1453 \mathrm{~cm}^{-1}$ is formed by three overlapping $\mathrm{CH}_{3}$ deformation modes, two symmetric and one asymmetric at $1442 \mathrm{~cm}^{-1}, 1453 \mathrm{~cm}^{-1}$, and 1462.5 $\mathrm{cm}^{-1}$, respectively.

III. 1050-1300 $\mathrm{cm}^{-1}$ : $\mathrm{CH}_{3}$ rocking mode $\mathrm{rCH}_{3}\left(a_{2}\right)$ with a peak at $1131 \mathrm{~cm}^{-1}$ and $v \mathrm{COC}+r \mathrm{CH}_{3}\left(b_{1}\right)$ at $1099 \mathrm{~cm}^{-1}$, which are both comparably weak.

IV. $800-1050 \mathrm{~cm}^{-1}$ : COC-stretching region and a peak at $930 \mathrm{~cm}^{-1}$.

Another very weak and polarized Raman scattering feature is observed around $2550 \mathrm{~cm}^{-1}$ (not shown) that is not mentioned in the literature cited above. However, a very similar but narrower feature is observed for $\mathrm{CH}_{4}$, too, which is assigned to a sublevel of the pentad polyad (Boudon et al. [50]).

The other species $\mathrm{CH}_{4}, \mathrm{C}_{2} \mathrm{H}_{4}$, and $\mathrm{C}_{2} \mathrm{H}_{6}$ contribute differently to the regions denoted by I to IV. The $v_{3}$ vibration at $994.6 \mathrm{~cm}^{-1}$ and $v_{11}$ at $1468.1 \mathrm{~cm}^{-1}$ of $\mathrm{C}_{2} \mathrm{H}_{6}$ coincide with the regions IV, III, and II from DME, respectively. The first very strong $v_{3}$ peak of $\mathrm{C}_{2} \mathrm{H}_{4}$ at $1342.4 \mathrm{~cm}^{-1}$ from symmetrical $\mathrm{CH}_{2}$ deformation/bending vibration contributes to regions III and II. The $v_{2}$ peak at $1623.3 \mathrm{~cm}^{-1}$ from $\mathrm{C}=\mathrm{C}$ vibration (see [51]) causes severe crosstalk on $\mathrm{O}_{2}$, especially at higher temperatures and small $\mathrm{O}_{2}$-concentrations which is extremely difficult to compensate. The crosstalk from $v_{2}$ from $\mathrm{CH}_{4}$ [52] on $\mathrm{O}_{2}$ around $1530 \mathrm{~cm}^{-1}$ is quite small compared to the other hydrocarbons. The $v_{1}$ band from $\mathrm{CH}_{3}$ has a Raman shift of $3002 \mathrm{~cm}^{-1}$. The $2 v_{2}$ band at $1284 \mathrm{~cm}^{-1}$ scatters on the $\mathrm{CO}_{2}$ channel, and $v_{1}+2 v_{2}$ is observed at $4286 \mathrm{~cm}^{-1}$ [53], where the channel to monitor the background starts. The relative intensity of the $\mathrm{CH}_{3}-v_{1}$ band has been measured by CARS by Hädrich et al. [36] and is one quarter relative to $\mathrm{CH}_{4}$. The transferability from this narrow peak value to the relative intensity across the entire hydrocarbon channel is somehow speculative and causes uncertainties. However, the methyl radical occurs only at low concentrations (Fig. 3), and its contribution to the hydrocarbon channel at intermediate temperatures is rather small. At high temperatures, however, its concentration relative to other hydrocarbons is high but its absolute concentration level is very low.

\section{B.2. Relative Raman signal intensities}

Following these general discussions of species-specific Raman spectra, this section provides relative Raman signal intensities that were obtained from integration of the different detection channels at one center strip. In addition to the species DME, $\mathrm{CH}_{4}, \mathrm{C}_{2} \mathrm{H}_{4}$, and $\mathrm{C}_{2} \mathrm{H}_{6}$ measured in this study, contributions by other species such as $\mathrm{CH}_{2} \mathrm{O}, \mathrm{C}_{2} \mathrm{H}_{2}, \mathrm{OH}$, and indirect contributions from $\mathrm{Ar}, \mathrm{O}$, and $\mathrm{H}$ are discussed. Tables B.6, B.7, B.8, B.9 summarize integrated Raman signal intensities $I_{\text {Ram,i }} / I_{\text {Ram,DME }}$ of species $i$ relative to DME. Information on species not measured in this work is addressed below.

$\mathrm{CH}_{2} \mathrm{O}$ : Information on the Raman scattering from formaldehyde is available for a temperature of $423 \mathrm{~K}$ measured by Wiegeler and Bleckmann [54] while Bruna et al. [55] report on ab intio calculations. All six normal mode vibrations are Raman active, but only three of them exhibit significant intensities. The strongest one originates from the symmetric C-H stretch $v_{1}$ at $2782.2 \mathrm{~cm}^{-1}$ and contributes partly to the blue end to the hydrocarbon channel but only at the outside strips (approximately strip 1-5), due to the optical bowing effect. This peak were searched in from shot-averaged and spectrally resolved data recorded in laminar jet flames of various fuels $\left(\mathrm{CH}_{4}\right.$, DME, $\left.\mathrm{C}_{2} \mathrm{H}_{4}, \mathrm{C}_{2} \mathrm{H}_{6}, \mathrm{C}_{3} \mathrm{H}_{8}\right)$. Only in case of $\mathrm{C}_{2} \mathrm{H}_{4}$ with the most separated Raman band located around $3020 \mathrm{~cm}^{-1}$, a small peak is observable near $2780 \mathrm{~cm}^{-1}$. This might be explained by the fact that $\mathrm{CH}_{2} \mathrm{O}$ is mainly occurring at temperatures below 
Table B.6

Relative integrated Raman signals $I_{\mathrm{Ram}, i} / I_{\mathrm{Ram}, \mathrm{DME}}$ for the hydrocarbon channel.

\begin{tabular}{lll}
\hline \multirow{2}{*}{ Molecule } & \multicolumn{2}{c}{ Relative integrated Raman signalsfor $2798-3263 \mathrm{~cm}^{-1}$} \\
\cline { 2 - 3 } & $295 \mathrm{~K}$ & $820 \mathrm{~K}$ \\
\hline $\mathrm{DME}$ & 1 & 1 \\
$\mathrm{CH}_{4}$ & 0.64 & 0.64 \\
$\mathrm{C}_{2} \mathrm{H}_{4}$ & 0.55 & 0.57 \\
$\mathrm{C}_{2} \mathrm{H}_{6}$ & 1 & 1 \\
$\mathrm{CH}_{3}$ & & $0.16^{\mathrm{a}}$ \\
$\mathrm{C}_{2} \mathrm{H}_{2}$ & & 0 \\
$\mathrm{CH}_{2} \mathrm{O}$ & & 0
\end{tabular}

a From Hädrich et al. [36], $v_{1}, 450 \mathrm{~K}$.

Table B.7

Relative integrated Raman signals $I_{\text {Ram, },} / I_{\text {Ram,DME }}$ for crosstalk on the F560 channel.

\begin{tabular}{lll}
\hline Molecule & \multicolumn{2}{c}{ Relative integrated Raman signals for $761-1093 \mathrm{~cm}^{-1}$} \\
\cline { 2 - 3 } & $295 \mathrm{~K}$ & $820 \mathrm{~K}$ \\
\hline $\mathrm{DME}$ & 1 & 1 \\
$\mathrm{CH}_{4}$ & 0 & 0.003 \\
$\mathrm{C}_{2} \mathrm{H}_{4}$ & 0.203 & 0.91 \\
$\mathrm{C}_{2} \mathrm{H}_{6}$ & 1.43 & 1.37 \\
$\mathrm{CH}_{3}$ & & 0 \\
\hline
\end{tabular}

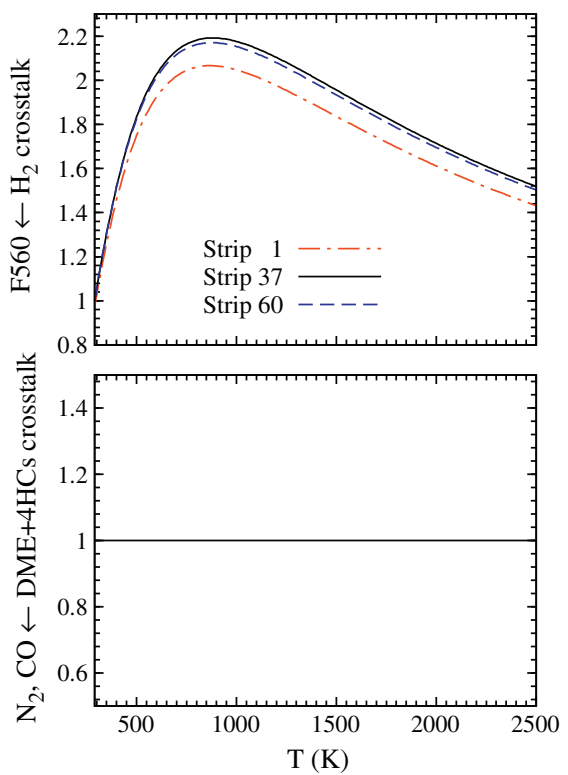

Fig. C.25. Crosstalk curves supplementing information provided in Section 4.1.

$1800 \mathrm{~K}$ and the spectral region below $2800 \mathrm{~cm}^{-1}$ is dominated by scattering from other intermediate hydrocarbons. The peaks from the $\mathrm{C}-\mathrm{O}$ stretch $v_{2}$ at $1745.1 \mathrm{~cm}^{-1}$ (between $\mathrm{O}_{2}$ and $\mathrm{CO}$ ) and $\mathrm{CH}_{2}$ stretch $v_{3}$ at $1500.2 \mathrm{~cm}^{-1}$ (on $\mathrm{O}_{2}$ ) are ten times weaker than the feature at $2780 \mathrm{~cm}^{-1}$ and were neglected here.

$\mathrm{C}_{2} \mathrm{H}_{2}$ : Acetylene is considered separately here because it does not contribute to any Raman channels in the present experiments. Information on fundamental vibration modes and corresponding Raman shifts for acetylene were taken from Herzberg [51]. The $\mathrm{C} \equiv \mathrm{C}$ vibration Raman shift of $1973.8 \mathrm{~cm}^{-1}$ is positioned between the channels of $\mathrm{O}_{2} \quad\left(\mathrm{O}_{2}\right.$ channel ends between 1635 and $1657 \mathrm{~cm}^{-1}$ ) and CO (CO channel starts between 1990 and $2015 \mathrm{~cm}^{-1}$ ). The Raman band of the $\mathrm{C}-\mathrm{H}$ vibration is about nine times weaker and has a Raman shift of $3373.7 \mathrm{~cm}^{-1}$, which is located close to the $\mathrm{H}_{2} \mathrm{O}$ channel starting at $3409-3430 \mathrm{~cm}^{-1}$. Con-

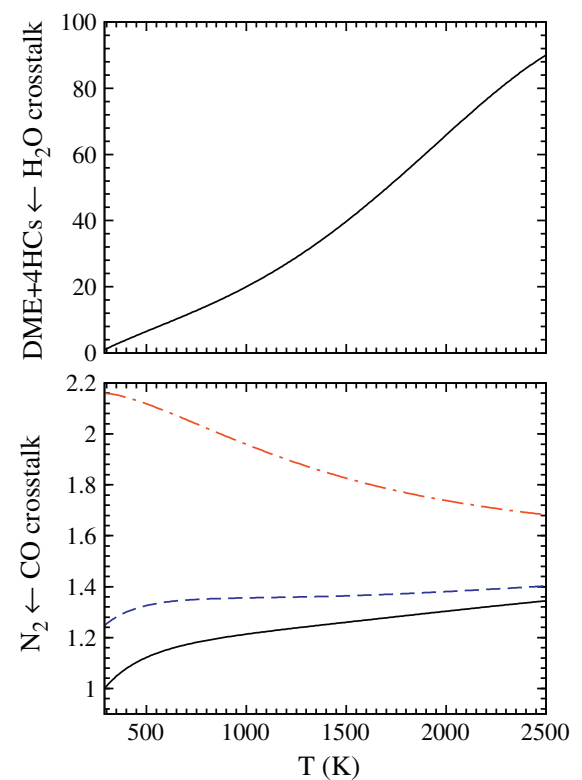

Table B.8

Relative integrated Raman signals $I_{\mathrm{Ram}, i} / I_{\mathrm{Ram}, \mathrm{DME}}$ for crosstalk on the $\mathrm{CO}_{2}$ channel.

\begin{tabular}{lll} 
Molecule & \multicolumn{2}{l}{ Relative integrated Raman signals for $1127-1481 \mathrm{~cm}^{-1}$} \\
\cline { 2 - 3 } & $295 \mathrm{~K}$ & $820 \mathrm{~K}$ \\
\hline $\mathrm{DME}$ & 1 & 1 \\
$\mathrm{CH}_{4}$ & 0.064 & 0.09 \\
$\mathrm{C}_{2} \mathrm{H}_{4}$ & 2.83 & 3.28 \\
$\mathrm{C}_{2} \mathrm{H}_{6}$ & 0.51 & 0.54 \\
$\mathrm{CH}_{3}$ & & $0.02^{\mathrm{a}}$ \\
\hline
\end{tabular}

a From Hädrich et al. [36], v $1,450 \mathrm{~K}$.

Table B.9

Relative integrated Raman signals $I_{\text {Ram,i } i} / I_{\text {Ram,DME }}$ for crosstalk on the $\mathrm{O}_{2}$ channel.

\begin{tabular}{lll}
\hline Molecule & \multicolumn{2}{c}{ Relative integrated Raman signals for 1484 to $1657 \mathrm{~cm}^{-1}$} \\
\cline { 2 - 3 } & $295 \mathrm{~K}$ & $820 \mathrm{~K}$ \\
\hline $\mathrm{DME}$ & 1 & 1 \\
$\mathrm{CH}_{4}$ & 0.53 & 0.27 \\
$\mathrm{C}_{2} \mathrm{H}_{4}$ & 4.41 & 3.21 \\
$\mathrm{C}_{2} \mathrm{H}_{6}$ & 1.19 & 0.85 \\
$\mathrm{CH}_{3}$ & & $0.07^{\mathrm{a}}$ \\
\hline
\end{tabular}

a From Hädrich et al. [36], v $1,450 \mathrm{~K}$.

sidering the intensity ratio of acetylene [54,56], its spectral broadening at flame temperature [57], maximum concentrations deduced from laminar flame calculations, and experimental spectra, it was concluded that no signal will be detected on any of the adjacent channels.

$\mathrm{Ar}, \mathrm{O}, \mathrm{H}, \mathrm{OH}$ : The atomic species $\mathrm{Ar}, \mathrm{O}$, and $\mathrm{H}$ are not Raman active but contribute to Rayleigh scattering. Assuming room temperature, $\mathrm{N}_{2}$, and $\mathrm{O}_{2}$ calibration on exact concentrations in air, neglecting Argon would result in a $0.5 \%$ too high effective Rayleigh cross-section and temperature in the unburnt DME/air mixture of T2. This deviation decreases to about $0.1 \%$ at flame temperature. $\mathrm{O}$ and $\mathrm{H}$ atoms occur only in a narrow temperature band around $2100 \mathrm{~K}$ and their negligence would evoke an error at these high temperatures of about $+0.8 \%$. However, the major part of this inaccuracy will decrease to $0-0.3 \%$ when concurrently assuming parts 

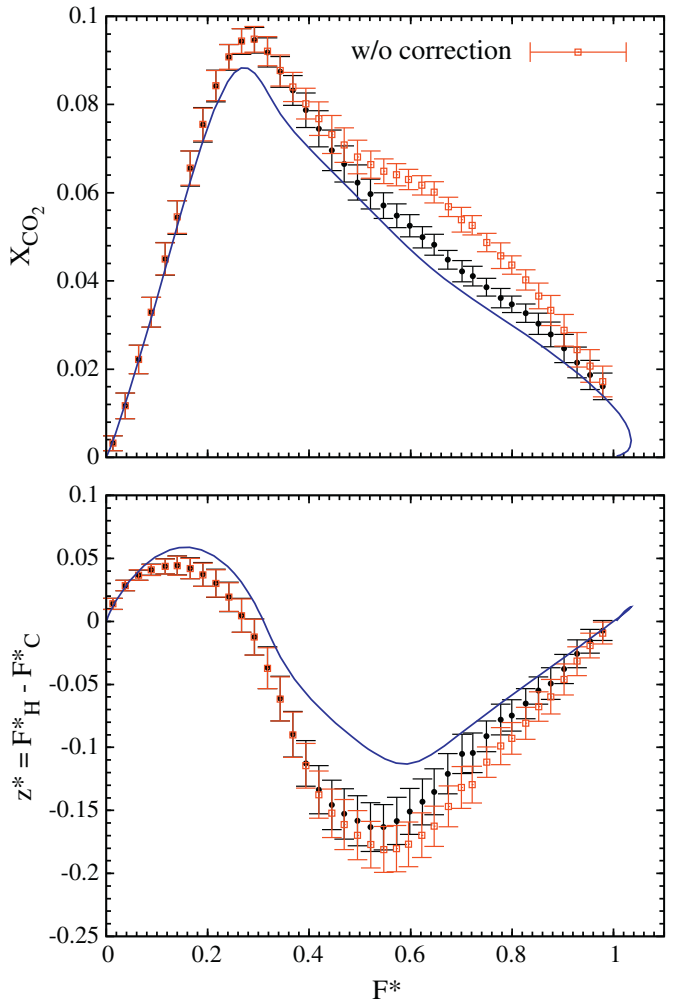

Fig. D.26. Sensitivity of the additional correction on $\mathrm{CO}_{2} \leftarrow \mathrm{DME}+4 \mathrm{HCs}$ crosstalk, which was applied on the crosstalk derived from experimental spectra and species distributions from laminar flame calculations following Eq. (4). Errorbars denote the measurement precision as one standard deviation from 100 single laser shots.

of the hydroxyl radical being detected on the Raman channel for water or when even neglecting the $\mathrm{OH}$ contribution completely as in Sutton et al. [31]. In fact, the main Raman band from $\mathrm{OH}$ at $3568.4 \mathrm{~cm}^{-1}$ coincides with the Raman channel for water. Assuming $I_{\mathrm{Ram}, \mathrm{OH}}=0.5 I_{\mathrm{Ram}, \mathrm{H}_{2} \mathrm{O}}$ as described by Linow et al. [58], considering common $\mathrm{OH} / \mathrm{H}_{2} \mathrm{O}$ ratios around 5-6\% at locations of the highest $\mathrm{OH}$ concentrations would lead to a maximum overestimation of $X_{\mathrm{H}_{2} \mathrm{O}}$ of $2-3 \%$. Generally, this Raman crosstalk on $\mathrm{H}_{2} \mathrm{O}$ was partly compensated due to a $\mathrm{H}_{2} \mathrm{O}$ calibration in flat flames with similar equilibrium $\mathrm{OH}$ concentrations, and was not treated particularly here, too.

\section{Appendix C. Supplementary crosstalk curves}

Additional crosstalk curves are presented completing the information provided in Section 4.1. The crosstalks F560 $\leftarrow \mathrm{H} 2$ and $\mathrm{N}_{2} \leftarrow \mathrm{CO}$ were calculated following the procedure outlined by Fuest et al. [21]. The crosstalk curve for DME $+4 \mathrm{HCs} \leftarrow \mathrm{H}_{2} \mathrm{O}$ was transferred from previous $\mathrm{CH}_{4}$ /air flame measurements. So far, no measurements without $\mathrm{N}_{2}$ were taken. Hence, the calibration of the crosstalk from DME $+4 \mathrm{HCs}$ on $\mathrm{N}_{2}$ relies on a procedure that follows two steps: at first crosstalk upon the $\mathrm{O}_{2}$ channel was estimated from DME/ $\mathrm{N}_{2}$ flows, then DME/air flows were investigated using the crosstalk-corrected $\mathrm{O}_{2}$ mole fraction to estimate DME contributions to the $\mathrm{N}_{2}$ channel. Because the relative $\mathrm{O}_{2} / \mathrm{N}_{2}$ concentrations in air are known, excessive signal on the $\mathrm{N}_{2}$ channel was attributed to DME-contributions. A more straight forward strategy would be to measure $\mathrm{DME} / \mathrm{He}$ jets and will be done in future experiments. Note that the crosstalk contribution $\mathrm{N}_{2} \leftarrow$ DME $+4 \mathrm{HCs}$ is assumed to be independent on temperature because of lack of more detailed information (see Fig. C.25).

\section{Appendix D. Sensitivity of change in the Raman crosstalks $\mathrm{CO}_{2} \leftarrow \mathrm{DME}+4 \mathrm{HCs}$ and $\mathrm{O}_{2} \leftarrow \mathrm{DME}+4 \mathrm{HCs}$ exemplified on the $\mathrm{L2}$ configuration}

Exemplarily, the data evaluation of the L2 configuration was made with and without the additional background correction implied in the $\mathrm{CO}_{2} \leftarrow \mathrm{DME}+4 \mathrm{HCs}$ crosstalk (compare Fig. 12). Figure D.26 shows the impact on the $\mathrm{CO}_{2}$ mole fractions and $z^{*}$-profiles in mixture fraction space. A value of up to 0.012 smaller mole fractions is obtained using the background correction. Independent of this correction all other scalars are very close to the calculation. Therefore, it is assumed that this obvious mismatch in the $\mathrm{CO}_{2}$-profile must be caused by an uncorrected interference signal on $\mathrm{CO}_{2}$. The impact on any other of the profiles shown in Fig. D.26 is negligible. This is exemplified on the most sensitive $z^{*}$-profile, where still no significant difference is observable. The impact of the additional correction on $\mathrm{O}_{2} \leftarrow \mathrm{DME}+4 \mathrm{HCs}$ (compare Fig. 12) was much smaller and is therefore not shown explicitly.

\section{References}

[1] TNF, International Workshop on Measurement and Computation of Turbulent Nonpremixed Flames (TNF), <http://www.ca.sandia.gov/TNF>.

[2] D.G. Pfuderer, A.A. Neuber, G. Früchtel, E.P. Hassel, J. Janicka, Combust. Flame 106 (3) (1996) 301-317.

[3] M.M. Tacke, S. Linow, S. Geiss, E.P. Hassel, J. Janicka, Proc. Combust. Inst. 27 (1998) 1139-1148.

[4] C. Schneider, A. Dreizler, J. Janicka, E.P. Hassel, Combust. Flame 135 (1-2) (2003) 185-190.

[5] R.S. Barlow, J.H. Frank, Proc. Combust. Inst. 27 (1998) 1087-1095.

[6] A.N. Karpetis, R.S. Barlow, Proc. Combust. Inst. 29 (2002) 1929-1936.

[7] R.S. Barlow, A.N. Karpetis, Flow Turbul. Combust. 72 (2004) 427-448.

[8] R.S. Barlow, J.H. Frank, A.N. Karpetis, J.-Y. Chen, Combust. Flame 143 (4) (2005) 433-449.

[9] R.S. Barlow, H.C. Ozarovsky, A.N. Karpetis, R.P. Lindstedt, Combust. Flame 156 (11) (2009) 2117-2128.

[10] S.H. Stårner, R.W. Bilger, R.W. Dibble, R.S. Barlow, Symp. Int. Combust. Proc. 23 (1991) 645-651.

[11] A.R. Masri, R.W. Dibble, R.S. Barlow, Combust. Flame 89 (2) (1992) 167-185.

[12] C. Dreyer, T. Parker, M.A. Linne, Appl. Phys. B: Lasers Opt. 79 (2004) 121-130.

[13] W. Meier, O. Keck, Meas. Sci. Technol. 13 (2002) 741-749.

[14] F. Rabenstein, A. Leipertz, Appl. Opt. 37 (21) (1998) 4937-4943.

[15] J. Egermann, T. Seeger, A. Leipertz, Appl. Opt. 43 (29) (2004) 5564-5574.

[16] P.A. Nooren, M. Versluis, T.H. van der Meer, R.S. Barlow, J.H. Frank, Appl. Phys. B: Lasers Opt. 71 (2000) 95-111.

[17] R.W. Dibble, A.R. Masri, R.W. Bilger, Combust. Flame 67 (3) (1987) 189-206.

[18] A. Brockhinke, A.T. Hartlieb, K. Kohse-Höinghaus, D.R. Crosley, Appl. Phys. B: Lasers Opt. 67 (1998) 659-665.

[19] R.S. Barlow, A.N. Karpetis, J.H. Frank, J.-Y. Chen, Combust. Flame 127 (3) (2001) 2102-2118.

[20] P.C. Miles, Appl. Opt. 38 (9) (1999) 1714-1732.

[21] F. Fuest, R.S. Barlow, D. Geyer, F. Seffrin, A. Dreizler, Proc. Combust. Inst. 33 (1) (2011) 815-822.

[22] A.N. Karpetis, R.S. Barlow, Proc. Combust. Inst. 30 (2005) 665-672.

[23] R.S. Barlow, G.H. Wang, P. Anselmo-Filho, M.S. Sweeney, S. Hochgreb, Proc. Combust. Inst. 32 (1) (2009) 945-953.

[24] C.-P. Chou, J.-Y. Chen, C.G. Yam, K.D. Marx, Combust. Flame 114 (3-4) (1998) 420-435.

[25] J.A. Miller, R.J. Kee, M.D. Smooke, J.F. Grcar, The computation of the structure and extinction limit of a methane-air stagnation point diffusion flame, Spring Meeting of the Western State Section of the Combustion Institute WSS/CI84$10,1984$.

[26] K. Seshadri, F.A. Williams, Int. J. Heat Mass Transfer 21 (1978) 251-253.

[27] A.E. Lutz, R.J. Kee, J.F. Grcar, F.M. Rupley, OPPDIF: a Fortran program for computing opposed-flow diffusion flames, Tech. Rep., Sandia National Laboratories Report SAND96-8243, 1997.

[28] Z. Zhao, M. Chaos, A. Kazakov, F.L. Dryer, Int. J. Chem. Kinet. 40 (2008) 1-18.

[29] E.W. Kaiser, T.J. Wallington, M.D. Hurley, J. Platz, J. Curran, W.J. Pitz, C.K. Westbrook, J. Phys. Chem. A 104 (35) (2000) 8194-8206.

[30] R.J. Kee, J.F. Grcar, M.D. Smooke, J.A. Miller, A Fortran program for modeling steady laminar one-dimensional premixed flames, Tech. Rep., Sandia National Laboratories Report SAND85-8240, 1992.

[31] G. Sutton, A. Levick, G. Edwards, D. Greenhalgh, Combust. Flame 147 (1-2) (2006) 39-48.

[32] W.C. Gardiner Jr., Y. Hidaka, T. Tanzawa, Combust. Flame 40 (1981) 213-219.

[33] G.B. Bacskay, S. Saebø, P.R. Taylor, Chem. Phys. 90 (3-4) (1984) 215-224.

[34] R.W. Bilger, S.H. Stsrner, R.J. Kee, Combust. Flame 80 (2) (1990) 135-149.

[35] A.E. Lutz, R.J. Kee, J.A. Miller, SENKIN: A Fortran program for predicting homogeneous gas phase chemical kinetics with sensitivity analysis, Sandia National Laboratories Tech. Rep. SAND87-8248, 1988. 
[36] S. Hädrich, S. Hefter, B. Pfelzer, T. Doerk, P. Jauernik, J. Uhlenbusch, Chem. Phys. Lett. 256 (1-2) (1996) 83-86.

[37] R.B. Miles, W.R. Lempert, J.N. Forkey, Meas. Sci. Technol. 12 (2001) R33-R51.

[38] D.A. Long, The Raman Effect: A Unified Treatment of the Theory of Raman Scattering by Molecules, Wiley, 2002.

[39] C.D. Carter, Laser-based Rayleigh and Mie Scattering Methods, Handbook of Fluid Dynamics and Fluid Machinery, Wiley, New York, 1996.

[40] N.J. Bridge, A.D. Buckingham, Proc. R. Soc. Lond. A 295 (1966) 334-349.

[41] R.L. Rowell, G.M. Aval, J.J. Barrett, J. Chem. Phys. 54 (5) (1971) 1960-1964

[42] M.P. Bogaard, A.D. Buckingham, R.K. Pierens, A.H. White, J. Chem. Soc., Faraday Trans. 174 (1978) 3008-3015.

[43] W.F. Murphy, J. Chem. Phys. 67 (12) (1977) 5877-5882.

[44] M. Pecul, A. Rizzo, J. Chem. Phys. 116 (4) (2002) 1259-1268.

[45] M. Sneep, W. Ubachs, J. Quant. Spectrosc. Radiat. Transfer 92 (3) (2005) 293310.

[46] Y.P. Raizer, Gas Discharge Physics, Springer, Berlin, 1997.

[47] A. Allan, D.C. McKean, J.P. Perchard, M.L. Josien, Spectrochim. Acta, Part A 27 (8) (1971) $1409-1437$.

[48] C.E. Blom, C. Altona, A. Oskam, Mol. Phys. 34 (2) (1977) 557-571
[49] H.F. Hameka, J. Mol. Struct.: THEOCHEM 226 (3-4) (1991) 241-249.

[50] V. Boudon, M. Rey, M. Lodte, J. Quant. Spectrosc. Radiat. Transfer 98 (3) (2006) 394-404.

[51] G. Herzberg, Molecular Spectra and Molecular Structure, Infrared and Raman Spectra of Polyatomic Molecules, vol. II, Krieger Publishing Company, Malabar, Florida, 1991.

[52] E. Jourdanneau, F. Chaussard, R. Saint-Loup, T. Gabard, H. Berger, J. Mol. Spectrosc. 233 (2) (2005) 219-230.

[53] P.B. Kelly, S.G. Westre, Chem. Phys. Lett. 151 (3) (1988) 253-257.

[54] W. Wiegeler, P. Bleckmann, J. Mol. Struct. 66 (1980) 273-280.

[55] P.J. Bruna, M.R.J. Hachey, F. Grein, J. Mol. Struct.: THEOCHEM 400 (1997) 177221.

[56] D.A. Stephenson, J. Quant. Spectrosc. Radiat. Transfer 14 (12) (1974) 12911301.

[57] A.V. Mokhov, S. Gersen, H.B. Levinsky, Chem. Phys. Lett. 403 (4-6) (2005) $233-$ 237.

[58] S. Linow, A. Dreizler, J. Janicka, E.P. Hassel, Meas. Sci. Technol. 13 (2002) $1952-$ 1961. 